Claremont Colleges

Scholarship@ Claremont

CGU Theses \& Dissertations

CGU Student Scholarship

2013

\title{
Appreciative Inquiry summits and organizational knowledge creation: A social systems perspective
}

Emi Makino

Claremont Graduate University

\section{Recommended Citation}

Makino, Emi, "Appreciative Inquiry summits and organizational knowledge creation: A social systems perspective" (2013). CGU

Theses \& Dissertations. Paper 80.

http://scholarship.claremont.edu/cgu_etd/80

DOI: $10.5642 / \operatorname{cguetd} / 80$

This Open Access Dissertation is brought to you for free and open access by the CGU Student Scholarship at Scholarship @ Claremont. It has been accepted for inclusion in CGU Theses \& Dissertations by an authorized administrator of Scholarship @ Claremont. For more information, please contact scholarship@cuc.claremont.edu. 
Appreciative Inquiry summits and organizational knowledge creation:

A social systems perspective

by

Emi Makino

Claremont Graduate University

2013

(C) Copyright Emi Makino, 2013

All rights reserved. 



\section{APPROVAL OF THE REVIEW COMMITTEE}

This dissertation has been duly read, reviewed, and critiqued by the Committee listed below, which hereby approves the manuscript of Emi Makino as fulfilling the scope and quality requirements for meriting the degree of Doctor of Philosophy (Management).

Joseph Maciariello, Ph.D., Chair

Peter F. Drucker and Masatoshi Ito Graduate School of Management Claremont Graduate University

Marie Rankin Clarke Professor of Social Science and Management

Mihaly Csikszentmihalyi, Ph.D.

School of Behavioral and Organizational Sciences

Claremont Graduate University

Distinguished Professor of Psychology and Management

Michelle C. Bligh, Ph.D.

Peter F. Drucker and Masatoshi Ito Graduate School of Management

School of Behavioral and Organizational Sciences

Claremont Graduate University

Associate Professor

David L. Cooperrider, Ph.D.

Weatherhead School of Management

Case Western Reserve University

Fairmount Minerals Professor of Social Entrepreneurship 


\begin{abstract}
Appreciative Inquiry summits and organizational knowledge creation:
\end{abstract}

A social systems perspective

by

\title{
Emi Makino
}

Claremont Graduate University: 2013

The purpose of this exploratory study is to develop alternative models for analyzing the systems dynamics of a large group conference format called appreciative inquiry (AI) summits. I apply Luhmann's social systems theory to the strategizing activities of AI summits to examine how this particular format is capable of generating organizational knowledge. An AI summit is a strategic planning conference in which hundreds of internal and external stakeholders collectively design the future of the organization through structured activities. It applies the principles of AI, a consulting method used in organizational development that attends to the positive aspects of an organization as opposed to its problems. Critics challenge this unconditional focus on the positive, questioning the validity of its methods and techniques. Indeed, very few rigorous evaluations of AI methods including AI summits exist.

I propose a new approach for assessing the effectiveness of AI summits. I focus on knowledge creation as the dependent variable. Previous studies have shown that successful AI interventions generate new knowledge, not just transformational change. I conceptualize an AI summit as a strategic episode that allows an organization to temporarily suspend its routines and structures for strategic reflection. 
According to social systems theory, organizations are autopoietic (self-reproducing) systems that maintain their identity through an ongoing production of decision communications. An AI summit consists of three different types of systems that co-evolve and are structurally coupled: an organization system, interaction system and the individual participants' psychological systems. I propose a typology for analyzing episodes during an AI summit as a starting point for determining the structural dynamics inherent in an AI summit system.

Using illustrative examples from a case study, I identify five structural features of an AI summit that facilitate organizational knowledge creation, including reduced communication barriers and the production of decisions during the conference. The study contributes to the existing literature by identifying the important but understudied role of self-organizing project teams in the knowledge creation process at an AI summit. Limitations and implications are discussed. 
Dedication

For Yo 


\section{Acknowledgements}

This intellectual journey would not have been possible without the support and encouragement of so many amazing people. I am indebted to my dissertation chair, Joseph Maciariello for his guidance, wisdom, and patience. His willingness to explore uncharted territories was instrumental. Joe was always available to discuss my half-baked ideas. He diligently read through some notoriously difficult and disorganized drafts. My gratitude extends to Judy Maciariello for having to endure the consequences of the additional work Joe had to take on as a result of advising my thesis.

This journey began thanks to the work of David Cooperrider. I stumbled upon appreciative inquiry while researching books on community organizing and grassroots leadership at my alma mater in Tokyo. David continues to inspire me each time we talk. I hope that this thesis will help extend appreciative inquiry to new domains. Mihaly Csikszentmihalyi gave me crucial advice at important junctures of this journey. Mike’s intellectual rigor and kind words of encouragement have helped keep me on track. I could not have finished this dissertation without Michelle Bligh. Michelle gently nudged me towards the road less travelled when I was ready to give up. Michelle continues to be my role model for her dedication to her students and research. Many thanks to TireCo and its Chief Sales and Marketing Officer for embracing my research.

Dennis Schoeneborn was kind enough to read an early draft of this dissertation. I cherish our lively conversation in at the bakery adjacent to the Boston convention center. I felt the skies clear up when David Seidl answered my questions about Luhmann and knowledge. The articles he sent me were foundational for this research. Thanks also to Ikujiro Nonaka who sat down with me to explain the philosophical foundations of his knowledge creation theory. 
I deeply appreciate the support of Doris Drucker who has cheered me along throughout my studies. I am honored to be the recipient of a fellowship endowed in her name and made possible through the financial support of Masatoshi Ito. Without Mr. Ito’s generosity and his conviction in Peter Drucker’s work, I would not have made it to Claremont. A special thank you to Bernadette Lambeth at the Drucker School, who has always been there for me when the going was rough.

Countless friends have made this journey worthwhile, especially Cindy Sherman and Bob Ono. The writing center at Claremont Graduate University and their dissertation boot camps gave me the space and discipline to continue writing. Financial support from the university's office of transdisciplinary studies in the form of the Kozmetsky transdisciplinary dissertation award helped offset the financial burden of pursuing a doctoral degree. Funding for travel from the Graduate School Council and the Drucker School enabled me to attend TireCo's summit and the Academy of Management conference.

Most of all, I have my family to thank. The inevitable delay in getting the thesis done was a source of stress for all of us. Yo, thank you for holding the fort together in my prolonged absence. I hope that our children may one day have the opportunity to experience the excitement and exhilaration that accompanied the intellectual journey I have had the privilege to enjoy. 


\section{Table of Contents}

Chapter 1 Introduction to the Study ......................................................................................... 1

Chapter 2 Appreciative Inquiry .................................................................................... 13

Introduction ........................................................................................................ 13

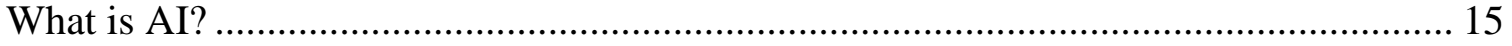

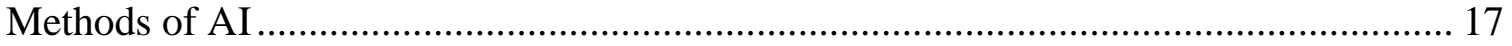

Theoretical background ........................................................................................... 19

AI criticism ...................................................................................................... 23

Limitations of meta-analysis of case studies ................................................................... 29

Reframing the purpose of AI ..................................................................................... 30

Chapter 3 The AI Summit: A Large Group Method of Strategizing ............................................ 37

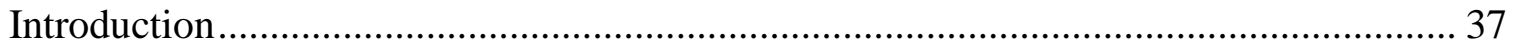

Large group methods: Theory and practice .................................................................... 39

Group dynamics meets systems theory...................................................................39

Future perfect thinking..................................................................................42

Breakthrough in practice...................................................................................43

Large group methods in practice.......................................................................45

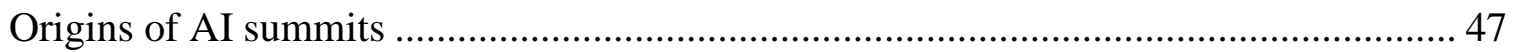

Key success factors of AI summits ............................................................................. 49

Towards AI as a strategizing practice ........................................................................... 53

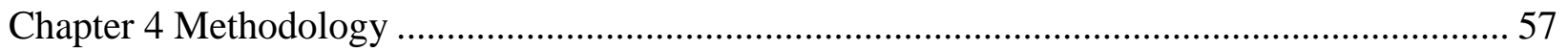

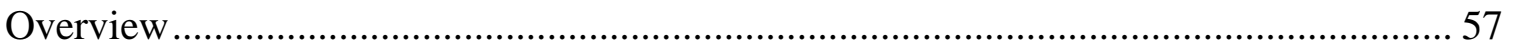

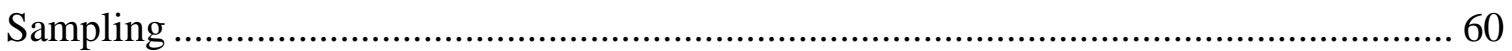

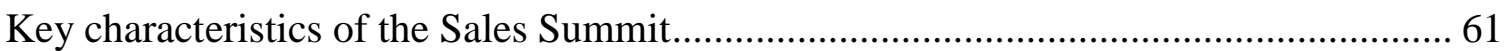

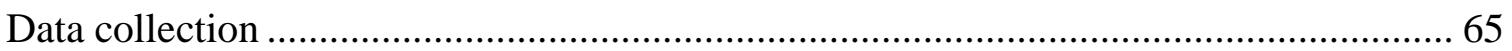

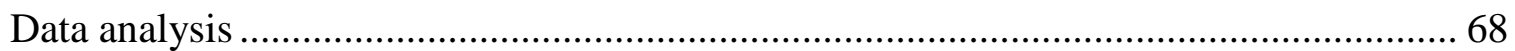

Chapter 5 Theoretical Lens: Autopoiesis.............................................................................. 70

Empirical origins of autopoiesis ........................................................................... 70

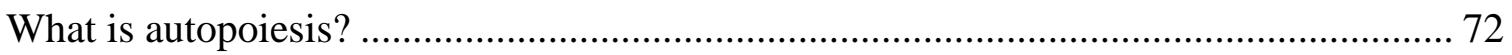

Adaptation through structural coupling ...................................................................... 75

Autopoiesis and human cognition............................................................................ 78 
Artificial intelligence, autopoiesis and the birth of Google............................................ 79

Autopoiesis in organization studies ........................................................................... 82

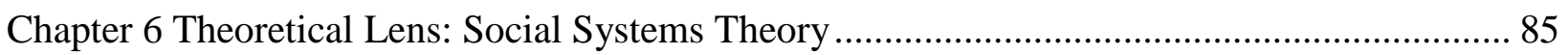

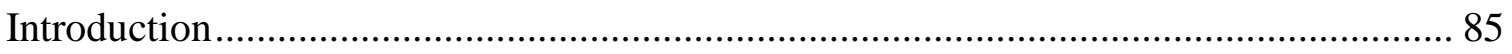

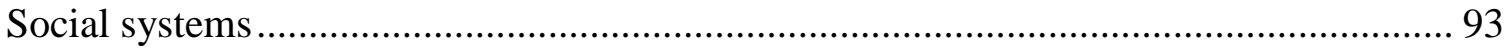

Communication as elemental unit.......................................................................93

Structural coupling and interpenetration..............................................................95

Concept of communications ...................................................................................... 97

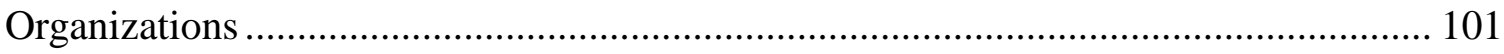

Decision communications constitute organizations.............................................101

The paradox of decision making.......................................................................103

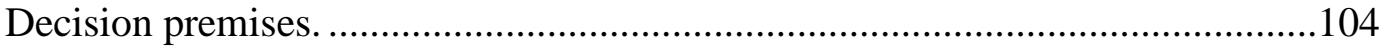

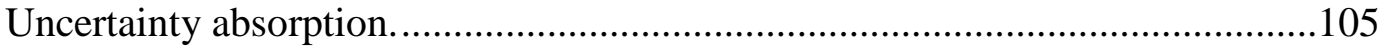

Relationship between organization and environment .................................................... 106

Organizational knowledge and nonknowledge ............................................................. 107

Organizational interactions .................................................................................... 110

Towards a social systems perspective of AI summits .................................................... 112

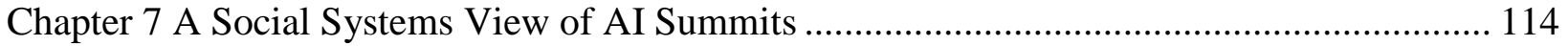

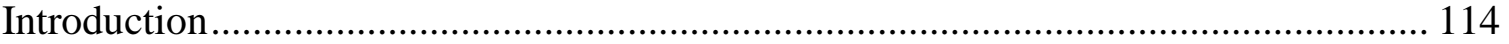

AI as management consulting ................................................................................. 116

A social systems model of an AI summit ..................................................................... 120

Generic strategy meeting model. ......................................................................121

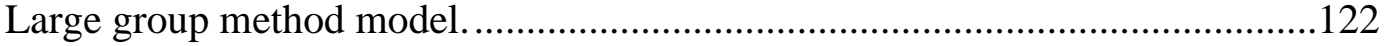

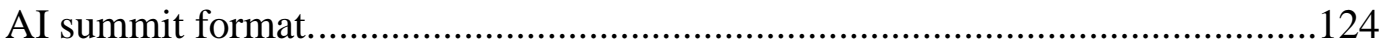

Strategic episodes................................................................................................ 129

Typology of strategic episodes ............................................................................. 134

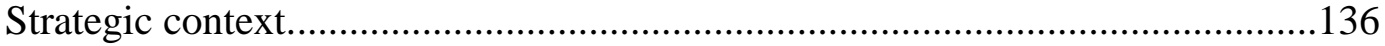

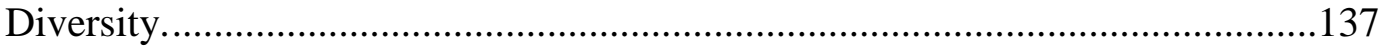

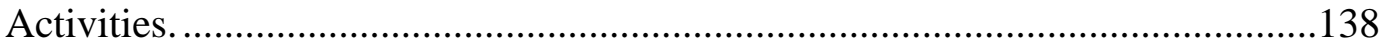

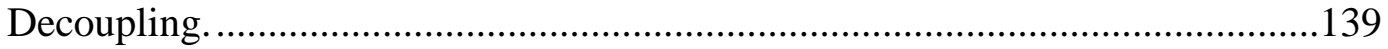

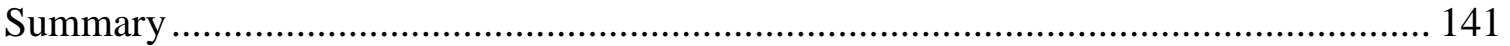

Chapter 8 The AI Summit as a Knowledge Creation System: An Illustrative Case.................... 143

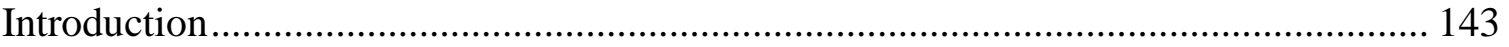

Knowledge creation at an AI summit ................................................................... 145 
The TireCo AI sales summit—an illustrative case …………...................................... 152

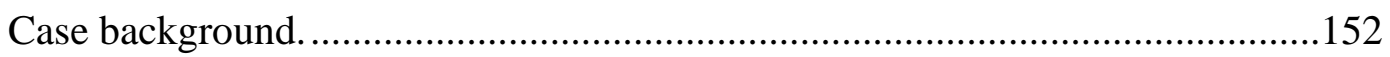

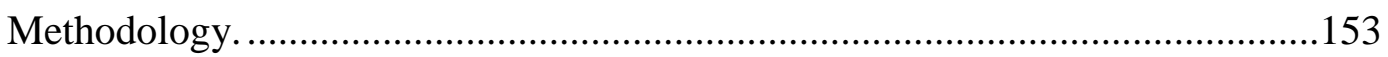

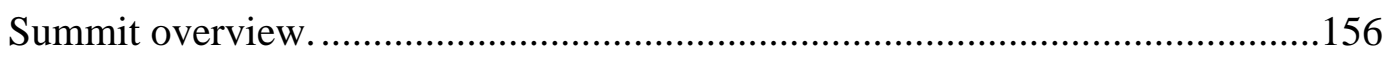

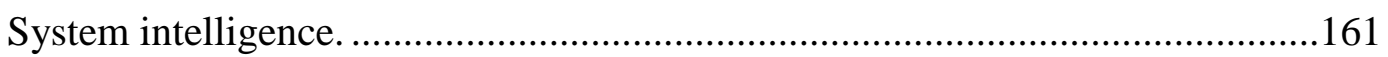

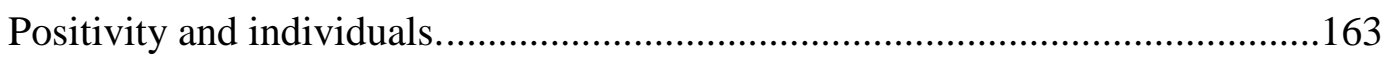

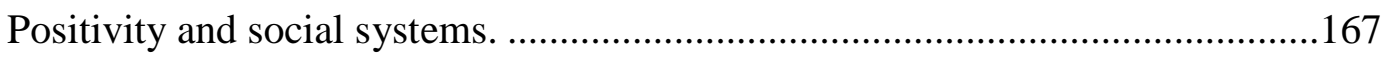

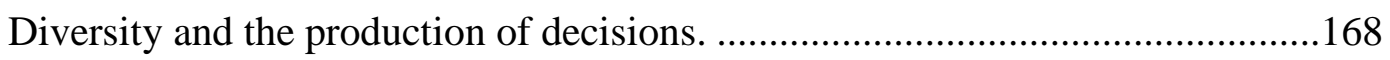

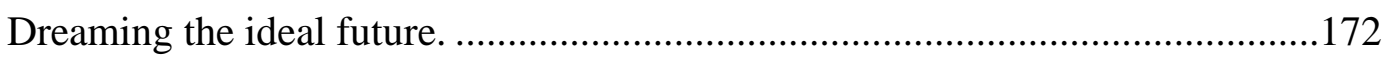

Conceiving new programs and initiatives........................................................177

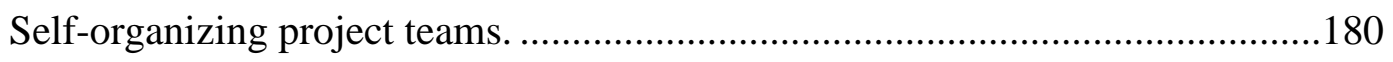

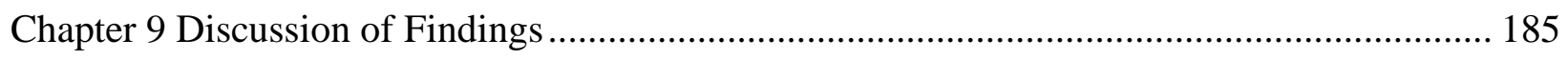

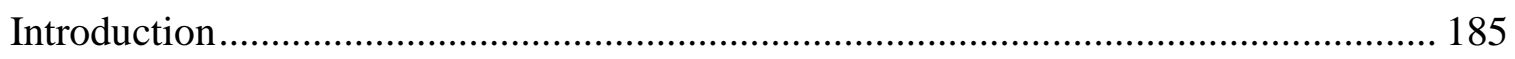

Social systems model of an AI summit................................................................... 186

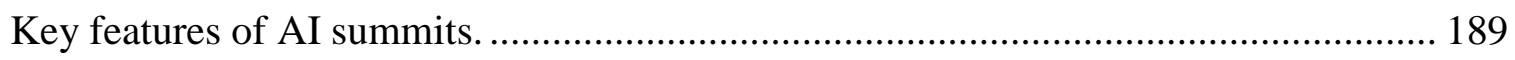

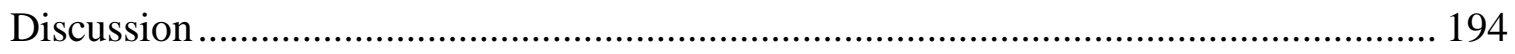

AI principle 1: Constructionist...........................................................................197

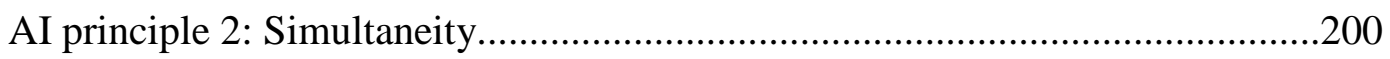

AI principle 3 \& 4: Poetic and anticipatory......................................................202

AI principle 5: Positivity...............................................................................204

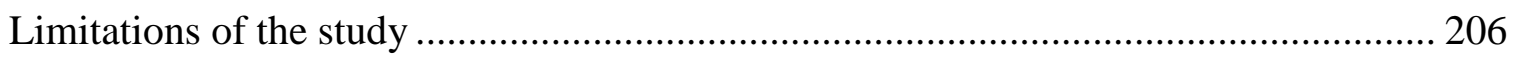

Relevance and implications for research .................................................................. 209

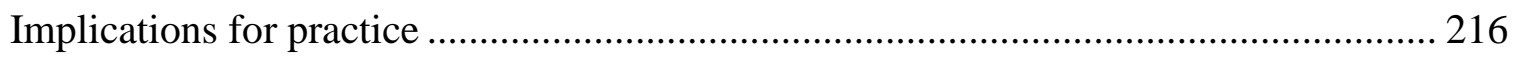

Experimenting with "experience meetings” ..................................................................... 220 


\section{Chapter 1 Introduction to the Study}

"Essentially, and perhaps arguably, there has been no innovation in the social technology of organization development (OD) since appreciative inquiry originated in 1987” (Burke, 2011, p. 143). Appreciative inquiry—commonly referred to by its acronym AI—is a popular method used by OD consultants to drive strategic change. For over 25 years, organizations around the world have been using AI to promote change, growth and innovation. There is no shortage of cases documenting successful interventions at companies and institutions ranging from GTE (now Verizon), British Airways North America, Green Mountain Coffee Roasters, BBC, to the United States Navy, World Vision, the United Nations, and the City of Cleveland (Bunker \& Alban, 2006; Cooperrider, Whitney, \& Stavros, 2008). Most recently, Walmart, the world's largest retailer, has been experimenting with AI to develop and execute a business case based on sustainability (Cooperrider, 2012). Yet for all its popularity, the validity of AI's methods remains open to question.

The AI approach emphasizes positivity, inclusiveness, and social constructionessentially, the notion that words creates worlds (Cooperrider \& Srivastva, 2008). In a sense, it represents an antithesis to traditional strategic management consulting practices. Strategists pride themselves on their ability to analyze a company's competitive environment and business trends to arrive at "seemingly hard truths based on models" (Wooldridge, 2010). Such models are mostly grounded in microeconomics (Besanko, Dranove, \& Shanley, 2000). Management decides on a strategy based on these "hard truths" which is then rolled out to the rest of the organization for execution. This approach to strategy development can be characterized as "big think in the boardroom" (Wooldridge, 2010). Consulting companies market themselves as 
delivering solutions, underscoring a world view that perceives organizations as problems to be solved.

AI takes a fundamentally different approach. It seeks innovation, not solutions. AI was founded on the assumption that organizational life is constructed through the social interactions of the people who constitute the organization, both inside and out (Cooperrider \& Srivastva, 2008), in other words, a social constructionist view of the world (Gergen, 2009). Corporate strategy is usually developed by an elite group of people, often consisting exclusively of top management and the board (Andrews, 1980). Sometimes, strategy consultants from the likes of McKinsey and The Boston Consulting Group are brought in. In contrast, AI is a democratic and participative approach to developing and executing strategy in which the AI process, not the consultant, takes center stage. AI differs from conventional strategizing practices in other ways as well. One of its core principles is positivity. The AI method directs an organization to exclusively study areas of strengths and opportunities. Root causes of success, not failures, are analyzed. This singular emphasis on the positive has been both a source of inspiration and contention. Traditional strategy development depends on historical data analysis, both quantitative and qualitative. AI is future-oriented. A guiding, positive image of the future is deemed a more powerful vehicle for driving an organization's success than a strategic plan developed by the "lords of strategy" as Kiechel (2010) called strategy consultants in his book chronicling the management consulting industry.

As Burke (2011) noted in his critique of OD practice, the AI method is indeed creative. It also suffers from a credibility issue. Critics point to an "amazing lack of rigorous assessment of AI methodology or techniques” (Messerschmidt, 2008). Hundreds of articles have been written about AI globally, but very few have made it through the peer-reviewed process and rigor of 
academic publishing. A review of the current literature suggests that AI has eluded evaluation partly because it has been framed as an OD intervention. OD deals mostly with organizational change. AI in particular is often described as an intervention for transformational change. One of the few studies evaluating the effectiveness of AI interventions across different organizations (Bushe \& Kassam, 2005), for example, examines the degree to which transformational change occurred as the key success factor. But a more recent evaluation study by Bushe pointed to a dilemma. One of the sites that did not undergo transformational change would not have benefited much from such change because it already had a high-performing culture. In a more general sense, causally linking change to firm outcomes such as financial performance can be problematic. This is especially true for a typical AI intervention, which engages hundreds of stakeholders across the entire organization in many different types of activities over a prolonged period of time. With so many moving parts-the changing external environment notwithstanding - trying to build a working model of AI that reliably predicts firm outcomes can be a difficult exercise. Some organizations have claimed millions of dollars in benefits from adopting AI and its methods. For example, plants at John Deere achieved three million dollars in immediate cost savings and "millions more in new market share" as a direct result from an AI summit (Ludema, Whitney, Mohr, \& Griffin, 2003, p. xii). But one could also make the case that these companies were able to execute the ideas generated through AI because they had good management and leadership practices in place to begin with. Failed interventions rarely make it into case studies, suggesting the existence of a selection bias.

For AI to endure as a valid and effective management technique, we need a better understanding of how and why AI functions as it does. I therefore propose a different lens with which to examine AI and its methods. In the literature review on AI (Chapter 2), I conclude that 
there are two aspects of AI that have been relatively underexplored: its capacity to create new organizational knowledge, and its function as a strategizing practice. AI does not seek a solution to a pre-existing or emerging problem; it seeks innovation. The creation of new knowledge is an aspect of innovation. Scholars have only just begun to recognize the knowledge-creating capacity of AI (Richer, Ritchie, \& Marchionni, 2009). While knowledge is also a slippery outcome to observe and measure, it is recognized as a source of sustained competitive advantage (Dierkes, Berthoin Antal, Child, \& Nonaka, 2001; Easterby-Smith \& Lyles, 2003b). Empirical studies in strategic management link knowledge to competitive advantage (e.g. Bierly \& Chakrabarti, 1996; Narver, Slater, \& MacLachlan, 2004; R. Sabherwal \& Sabherwal, 2005; Zander \& Kogut, 1995). If AI functions as method for creating organizational knowledge, then companies engaged in the practice may be building a dynamic capability (Teece, Pisano, \& Shuen, 1997) or core competencies (Prahalad \& Hamel, 1990) for generating innovation, thereby endowing them with a sustained competitive advantage that is hard for others to imitate.

The heightened interest in the study of organizational knowledge reflects a larger societal trend that Toffler (1981) called the third wave, the movement from an industrial society to the information society. Such a shift occurs in Western history only once every few hundred years (Drucker, 1993c). "The basic economic resource...is no longer capital, nor natural resources...nor 'labor'. It is and will be knowledge” (emphasis in original, p.8). Knowledge as an economic resource poses many difficulties for traditional economic analysis and strategy development. In the industrial age, strategists relied heavily on the tools of microeconomics to aid decision-making in an organization. For example, Porter's (1996) five forces model, one of the most famous conceptual frameworks for developing corporate strategy, used microeconomic principles to analyze a company's competitive position in its industry. "An advantage of 
economics, and one reason for its widespread use for analyzing individual and institutional decision making, is that it requires the analyst to be explicit about the key elements of the process under consideration” (Besanko, Dranove, \& Shanley, 2000, p.2). But knowledge cannot always be made explicit (Polanyi, 2009) let alone be quantified. As Drucker (1993c) noted, "there is no economic theory unless there is a model that expresses economic events in quantitative relationships. Without it there is no way to make a rational choice-and rational choices are what economics is all about” (p.185). Wooldridge, an economic journalist and commentator, wryly pointed out in a book review for the Wall Street Journal:

Today the status of strategic thinking in the business world is somewhat confused.... The lords of strategy are now given to happy talk about "people"-on the grounds that people are the key to innovation and innovation is the key to long-term success. (2010, March 12)

It is not surprising that a new research program has emerged in strategic management that is shifting the focus of study to strategizing activities and practice (Golsorkhi, Rouleau, Seidl, \& Vaara, 2010). Recent studies in this emerging area have great relevance for AI. Originally known in the literature as "strategy as practice” or SAP, this research program seeks to understand the doing of strategy as opposed to developing frameworks for formulating the right strategy (Jarzabkowski \& Spee, 2009; Johnson \& Melin, 2003). The latter is a description of traditional strategy research. It focused on the what of strategy and assumed that strategy is something that organizations have as opposed to something people do (Golsorkhi, Rouleau, Seidl, \& Vaara, 2010, p.7). Individuals were relegated to data points that are statistically correlated to quantifiable variables, resulting in a "curious absence of human actors” (Jarzabkowski \& Spee, 2009, p. 70). I suspect that the traditional approach to studying strategy is no longer sustainable because the key economic variable, namely knowledge, defies easy quantification. 
In the introduction to the Cambridge Handbook on Strategy as Practice, Golsorskhi et al. (2010) made some interesting observations that echo some of the fundamental assumptions upon which the AI approach is grounded:

First, the world of strategy is no longer taken to be something stable that can be observed, but constitutes a reality in flux. Second, strategy is no longer regarded as "located" on the organizational level; instead, it is spread across many levels from the level of individual actions to the institutional level. Third, the world of strategy constitutes a genuinely social reality created and recreated in the interactions between various actors inside and outside the organization. (p.7)

In this study, I turn away from the conventional view of AI as a change intervention, and

situate AI as first and foremost a strategizing practice. An intervention implies that an outsider, usually a consultant with expert knowledge, steps in to intervene in order to cause some desirable outcome. Looking back to the origins of AI, however, Cooperrider (1986) and his colleagues initially developed the approach as a research method for building grounded theory (Glaser \& Strauss, 1967). The whole point of AI was to provide an organization a way to inquire into its life-giving properties. After all, AI stands for appreciative inquiry. So much of the fanfare (and criticism) surrounding AI has been directed to its unconditional focus on positivity (Bushe, 2012) that the aspect of inquiry tends to be overlooked.

I posit that $\mathrm{AI}$ is a participative mode of strategizing that can accelerate the creation of organizational knowledge. The knowledge generated by AI endows an organization with a competitive advantage in a knowledge-based economy. Corporations are increasingly tapping collective strategizing methods like the AI summit format to propel growth and boost profitability. The purpose of this study therefore is to explore the effectiveness of AI compared to other forms of strategizing in the context of organizational knowledge creation. Adopting a systems perspective, the general research question I pose is: how and why AI as a whole, accelerates organizational knowledge creation? I adopt a systems perspective for two reasons: 
the complexity of AI summits, and its emphasis on working with whole systems. A systems perspective assumes that the system as a whole may be different from its parts. This should not be confused with the popular cliché "the whole is greater than the sum of its parts" which assumes that the system becomes whole by adding up all its parts. Systems are not that simple. A system is characterized as a system when there is "order in the gross with freedom in the small" (Weiss 1971, p. v in Weiss, 1978, p. 18). The hierarchical order and group interdependencies of subsystems reduce the range of varied behavior capable by its individual components.

To limit the scope of the research, I narrow the phenomena of interest to a specific format in the AI toolbox called the AI summit. It applies the principles of AI to a large group method (Bunker \& Alban, 2006) of strategizing. The AI summit method has become the format of choice among many practitioners of AI. For example, in September 2012, Walmart conducted a major conference using the AI summit method. It invited hundreds of suppliers to flesh out a sustainability index to which Walmart's supply chain would be held accountable (Personal communication, Cooperrider, 2012). The name summit is somewhat of a misnomer. Global summits such as the G8 are conferences where heads of states and ministers negotiate issues of contention. An AI summit is essentially the equivalent of an offsite strategy workshop, with two notable exceptions. Participation is not limited to the top management team, and the strategizing activities selectively focus on positive experiences and topics. Hundreds of people from every level of the organization are assembled in one room over multiple days to engage in structured, strategizing activities. Positive, democratic conversations are the order of the day. AI summits can be a powerful tool for developing strategy because internal stakeholders from all levels of the organization strategize in collaboration with external stakeholders such as customers and suppliers. This is achieved by structuring activities in many different group configurations in 
terms of size and diversity. I review the literature on AI summits and large group methods in Chapter 3. The methodology used for this study is provided in Chapter 4.

In the current analysis, I complement existing theories of AI and large group methods by viewing AI summits through an alternative theoretical lens: Luhmann's social systems theory. Luhmann's social systems theory is a good starting point for several reasons. First, social system theory is highly consistent with the social constructionist heritage common to both AI and large group methods. In fact, Luhmann has been labeled as being part of the "radical constructivism" movement (Luhmann, 1995), as his theories are based on a radical systems view of biology called autopoiesis (Maturana \& Varela, 1980). In Luhmann's formulation of the world, social systems are comprised of communications, not people. People fall into a separate category of systems - cognitive systems - and can only interact with social systems; they can never be a component of one. Organizations are a special type of social system that reproduces itself based on an ongoing production of decision communications. Luhmann's lens allows for a decoupling of the effects of positive psychology from the dynamics inherent in organizations and interaction systems, because social systems cannot think or feel—only people can.

Luhmann's social systems theory fits well also because it is based on a relatively new approach to thinking about systems called autopoiesis. The theory of autopoiesis was developed by the Chilean biologists Maturana and Varela (1980) in the 1970s. It has since had a tremendous impact on systems thinking, affecting the work of Senge (2006) among others. Winograd (1987) applied autopoiesis to computer systems design. Under his guidance, his students, Page and Brin invented a highly effective database retrieval system that now dominates search on the Internet—Google. 
I provide an overview of autopoietic theory in Chapter 5. Autopoiesis means selfreproduction (Maturana \& Varela, 1980). An autopoietic system reproduces itself and its components, using only its components. A social system cannot be autopoietic if it is comprised of people, because society cannot produce people. An autopoietic system is simultaneously a closed and open system. Its operations are completely closed from the environment, but it is open to its environment through interactions. A key insight of this so-called new systems theory is that an autopoietic system can refer only to itself. It is self-referential. It operates according to its internal structures and logic. This means that the environment can never directly affect a system. An external event in the environment is a trigger that perturbs the system. The system is not immune to the environment, because it is interactionally open. External events can trigger a perturbation so great that the system disintegrates. It is in this respect that autopoietic theory is different from open systems theory, which relies on a logic based on inputs and outputs between system and environment. Luhmann (1995) wrote: "The distinction between 'closed' and 'open systems' is replaced by questions of how self-referential closure can create openness” (p. 9). A theory of cognition and knowledge based on autopoiesis, leads to the conclusion that there is no pre-given world from which we select and process information to make ever more accurate representations of the world. Rather, "we have only the world that we bring forth with others" (Maturana \& Varela, 1987, p. 248).

Luhmann (1995) looked at the mechanism of autopoiesis, and concluded that autopoiesis can be used to describe social systems, not just living and cognitive systems. He recognized autopoiesis as a major paradigm shift in systems theory. Maturana and Varela (1987) were hesitant in applying autopoiesis to social systems. Some have deemed that Luhmann's application to sociology is inappropriate (e.g. Mingers, 1995). That said, his theory has had great 
utility in highlighting the communication issues inherent in law (Luhmann, 1988), the mass media (Luhmann, 2000b), art (Luhmann, 2000a), and sustainability (Luhmann, 1986). I introduce the key concepts of social systems theory relevant to this study in Chapter 6. In particular, I look at the implications of Luhmann's conceptualization of organizations as social systems that reproduce themselves based on their ongoing production of decision communications. This radical view of organizing forces one to seriously consider the role of the observer-the researcher-in the study of organizations. Although Luhmann's theory is notoriously complex, it has the benefit of developing models that disambiguate social dynamics from psychological and cognitive effects. Luhmann's lens allows one to scrutinize the structural couplings between various systems to sort out phenomena occurring at different units of analysis.

I look at recent studies that apply Luhmann's theory to management to develop a new conceptual model of AI summits. A leading scholar in the emerging strategizing activities and practice research program, Seidl (2005b), has drawn on Luhmann to develop new ways of thinking about organizational identity, management consulting (Mohe \& Seidl, 2011), strategy workshops (Jarzabkowski \& Seidl, 2008) and organizational knowledge (Seidl, 2007). These studies serve as a foundation in building alternative ways of viewing AI summits through a social systems lens. This line of theorizing defines knowledge as structures that determine how a system deals with information (Seidl, 2007). The premises a company uses for its decision making, for example, qualify as organizational knowledge because they specify what matters to the organization-“the difference that makes a difference” (Bateson, 1979) and determines the meaning of that information (Seidl, 2007).

Guided by the work of Seidl and his colleagues, in Chapter 7, I begin modeling AI summits through a social systems lens. First, I situate AI in the context of management 
consulting. This allows me to contrast AI with other forms of management consulting. Luhmann (2005b) has written about the communication barriers inherent in management consulting. Mohe and Seidl (2011) expanded upon Luhmann's ideas in theorizing the client-consultant relationship in consulting. I apply their methodology in my analysis of AI summits.

I conceptualize an AI summit as a strategic episode (Hendry \& Seidl, 2003) in which an organization suspends its operational routines to reflect upon itself in a strategic context. I develop a conceptual model of AI summits based on Luhmann's theoretical concepts. The model describes the components, and the structural coupling mechanisms of a generic workshop, a large group method, and finally an AI summit. It begins to surface how an AI summit is differentiated from other types of strategic workshops and large group methods. The model shows that hundreds of individual psychological systems are structurally coupled to the organization system through their positions within their company. These couplings form an intimate type of structural coupling called interpenetration. Not only can systems co-evolve through interpenetration, they can leverage the structural complexities of the other system to facilitate their autopoiesis. Such extremely tight couplings between individual participants, the organization and the summit's interaction system create a social dynamic that enable the production of organizational decisions during the strategic episode.

In contrast, strategy meetings at many organizations typically limit participation to a handful of executives and at times, external consultants. Although their positions may be at the apex of an organizational hierarchy, not all decisions can be produced during the strategy meeting. Many, if not most decisions must be produced closer to the fringes of the organization—at the level of managers and front-line employees, the people who implement the chosen strategy. A social systems lens allows us to see that such decisions are produced in vivo 
so to speak, at a summit. This is possible because the communications barriers between the consultant and the client company, as well as between executives and the rest of the company, are significantly reduced.

In the next step, I focus on the characteristics of an AI summit as a strategic episode. An AI summit is comprised of dozens of episodes that unfold in linear sequence over several days. Each episode varies in the degree to which existing structures are suspended. This creates a dynamic oscillation between strategic and routine contexts throughout the duration of the summit conference. I develop a typology of episodes based on four dimensions: overall context, group composition, activity and level of decoupling from the organizational system. I posit that this constant oscillation between different contexts play a significant role in generating new knowledge structures.

In Chapter 8, I expand the social systems theoretical lens to explore the dynamics involved in the generation of organizational knowledge at an AI summit. I propose that the AI summit method structurally couples its systems components, such that communication barriers are reduced, and access to "nonknowledge” (Seidl, 2007) increases. The summit system creates, modifies and reinforces organizational knowledge through the production of decisions. These decisions are not only produced, but also can reconnect back to the organization's operations while the strategic episode is still ongoing. This accelerates knowledge creation while making more robust, emerging but fragile decision premises that are produced at the summit. I identify self-organizing project teams as one of the most important outcomes of an AI summit in the context of organizational knowledge creation. I then introduce a case study to illustrate some of the dynamics identified in this chapter and the previous chapter. A discussion and implications for future research follows in Chapter 9. 


\section{Chapter 2 Appreciative Inquiry}

\section{Introduction}

In this chapter, I review the literature on appreciative inquiry (AI). As the name implies, AI was originally conceived as a method of inquiry (Cooperrider, 1986; Cooperrider \& Srivastva, 2008). One of AI's co-founders, Cooperrider (1990), emphasized that AI is first and foremost, a joint process of knowing. AI seeks to discover new knowledge about an organization by understanding what gives it life. Organizations are treated as though they are living systems. Once the life-affirming properties of the organization are identified, they become the basis for articulating possibilities for a better organizational future. Dialogue is the primary means by which knowledge is generated and strategic plans are developed. New knowledge and new images of possibility can disrupt and interrupt the status quo, but are nevertheless valued because the process unfolds through shared experiences. AI's methods aspire to include every person who has a stake in the organization's future, whether they are employees, executives or external customers and suppliers. Knowledge is jointly created, and corresponds to the visions of human and social possibility, which are jointly imagined (Cooperrider, 1990).

In the 25 years since the seminal paper on AI was published in 1987, AI and its application in practice have evolved considerably, sometimes in ways the founders did not intend or anticipate. AI’s emphasis on positivity, inclusiveness and holism has generated a large and devoted practitioner following in the field of organization development (OD). AI has been hailed by some as the most innovative social technology to emerge in OD in recent years. There has been no shortage of case studies documenting success stories, often written by the very consultants who designed and executed the intervention. In contrast, scholarly research on AI's methods has been limited. Despite the method's popular appeal, few scholarly articles on AI 
have been published in the mainstream literature in business and management studies. This implies that theories of AI have not developed as quickly or robustly as the practices of AI. Therefore, as part of this review, I retrace AI's history and examine in particular, its theoretical heritage and foundations, some of which have been pushed into relative obscurity in the rush to apply AI in practice.

Criticism of AI in the literature for the most part has been concentrated in one area: positivity. From its very beginning, AI's selective focus on the positive aspects of organizing has been a source of considerable concern. Advances in positive psychology offer some remedy. Others have proposed that generativity as a more useful concept than positivity. Scholars are also paying more attention to the dark side of AI, linking it to concepts like the shadow organization. Practitioners have also begun to reflect more carefully about why some interventions fail.

That said, the lack of rigorous evaluations of its methods continues to undermine the validity of the approach and its techniques. I argue that one of the reasons AI has eluded evaluation is the perception that $\mathrm{AI}$ is a change intervention. Change is often difficult to link to firm performance, the generally accepted standard by which methods are tested. I propose turning to a different outcome to measure AI's effectiveness: the creation of organizational knowledge. AI is first and foremost a strategizing practice. Its goal is innovation. Positioning AI as a strategizing practice is consistent with existing theories of AI. However, the knowledge creating aspect of AI has not been fully explored. Organizational knowledge is a known source of competitive advantage in the post-industrial economy. Alternative theories and conceptual models are necessary to understand how and why AI can generate knowledge in organizations. Such frameworks can generate testable propositions upon which AI's effectiveness can be critiqued and evaluated. 


\section{What is AI?}

AI has been described simultaneously as a philosophy (Cooperrider et al., 2008), social technology (Burke, 2011), constructive inquiry process (Cooperrider \& Avital, 2004), and most often as a change intervention (Bunker \& Alban, 2006). A practitioner-oriented definition is given in the leading handbook and textbook on AI (Cooperrider et al., 2008):

Appreciative Inquiry is the cooperative co-evolutionary search for the best in people, their organizations, and the world around them. It involves the discovery of what gives "life" to a living system when it is most effective, alive, and constructively capable in economic, ecological and human terms. (p. 3)

The handbook lists 20 application areas in which AI has been used successfully including “innovations leading toward the ideal organization,” strategic planning, leadership development, work process redesign, culture change, diversity initiatives, evaluation, and new product development (p. xxix).

The method originated at Case Western Reserve University in the 1980s. Cooperrider was a doctoral student at the time, working with faculty and students on a consulting project for the Cleveland Clinic, one the world's largest medical centers. Cooperrider had been interviewing physician leaders there. His advisor, Srivastva "was impressed by the excitement in his young student" and "encouraged him to put the problems aside and focus on what gave life and vitality to the organization” (Bushe, 2012, p. 8). The study led to an article theorizing conditions for egalitarian ways of organizing (Srivastva \& Cooperrider, 1986), which was published in Human Relations. The AI model was mentioned as a footnote. Citing Cooperrider's dissertation and a chapter in press, it described AI in the following way:

[AI] is based on an assumption that organizing is a miracle to be understood rather than a problem to be solved. It seeks to uncover the forces which give organizational life its vitality and self-generative capacity. It seeks to contribute knowledge about organizations-in-action which is: (1) appreciative,(2) applicable, (3) provocative, and (4) collaborative. (p. 686) 
The initial reception to Cooperrider's idea of focusing on the positive was apparently quite cool. During a presentation Cooperrider gave 1984 at the Academy of Management, "he was laughed at” (Bushe, 2012, p. 9) when he suggested organizations should be appreciated as mysteries. When he gave his first presentation on AI to practitioners at the OD Network conference in San Francisco, 1985, he was met with similar skepticism. Bushe, who subsequently became a leading scholar in AI, attended the conference. It was his first exposure to AI.

I remember how the majority of those in attendance were incredulous at the suggestion that they should stop focusing on problems. It seemed too one sided. Many thought the argument that diagnosis should be abandoned, as it simply recreated the mental models of those doing the diagnosis, was fanciful at best. (Bushe, 2012, p. 9)

AI would have to wait over a decade for the emergence of a similar turn in psychology that became the positive psychology movement (Seligman \& Csikszentmihalyi, 2000).

Nevertheless, AI resonated with many. AI represented a genuine breakthrough in OD (Bunker, Alban, \& Lewicki, 2004), a sub-field of management consulting that evolved out of social psychology. Burke (2011) described it as an innovative social technology. AI's popularity grew exponentially in the 90s among consultants and practitioners involved in strategic planning and organizational change efforts. Applications of AI spread rapidly in part due to the publication of high profile success stories (Bunker, 2004). Forbes ran a feature story on Roadway Express which had conducted an AI conference in which teamsters and managers wrote business plans together. By the early $21^{\text {st }}$ century, its status had risen to "the current hot intervention” (Bunker et al., 2004) in organization development. Even McKinsey has been sending their consultants to AI training sessions (Personal communication, 2009). AI also extended beyond OD into areas such as community development (Messerschmidt, 2008), nursing 
and social work (eg. Richer, Ritchie, \& Marchionni, 2009), IT (Gonzales \& Leroy, 2011), and education (Bushe, 2010; Conklin, 2009).

\section{Methods of AI}

Whitney and Trosten-Bloom (2003) have identified at least eight different methods of AI. Common to them all is a process known as the 4D model (Cooperrider et al., 2008). An intervention cycles through the four phases of Discover, Dream, Design, and Destiny (alternatively Deploy or Deliver). In the first D, stakeholders discover the organization's positive core, what makes it tick. This is usually done by sharing stories and conducting interviews about the high point moments of organizational life. The second D encourages stakeholders to dream and construct images of its preferred future. Facilitators push participants to dwell on "what might be" rather than "what is." This is a major aspect of AI that differentiates it from other strategizing approaches. It is also why AI tends to be associated with change interventions than strategizing. In the context of strategy development, AI's future- oriented framework is a significant break from convention. Traditional strategy development is grounded in analysis of data collected from its past. Historical data analysis, both quantitative and qualitative, is crucial for understanding the organization's competitive advantages in order to develop strategy. A guiding, positive image of the future is a deemed a powerful vehicle for driving positive actions

in an organization (Cooperrider, 1990). The images of the future become the equivalent of a strategic focus or vision of the organization (Cooperrider \& Whitney, 2005).

The second half of the 4D cycle represents the planning side of strategizing. In the third $\mathrm{D}$, stakeholders begin to design the elements necessary to realize the images of the future they created in the dream phase. What the participants design depends on the topic and purpose of the inquiry. "Good news-stories are used to craft provocative propositions that bridge the best of 
'what gives life' with a collective aspiration of 'what might be'” (Cooperrider et al., 2008, p. 162). Provocative propositions are also called design statements and possibility statements, depending on the organization. They can be called the equivalent of a corporate vision statement. More recently, AI practitioners have been incorporating the industrial design company, IDEO's (T. Brown, 2009) product design approaches. Instead of design statements, participants are involved in a brainstorming activity followed by a rapid prototyping exercise (Cooperrider et al., 2008). At Fairmount Minerals, participants of a 3-day AI summit made a cardboard mock-up of a new sand filter that purified water. They presented it "with a skit demonstrating its use in a part of the world where many children suffer from lack of clean water” (p. 173). Rapid prototyping is far more effective than "a five-page report" because "they persuade and they help move the ball forward for real-life experimentation” (p. 173).

The final D is called Destiny but is also known as Deploy or Deliver. In some AI formats, participants develop specific plans for executing the visions and prototypes developed in the previous three phases. This includes two aspects: 1) "aligning the actual organization with the provocative propositions created in the Design phase" and 2) "building AI learning competencies into the culture” (p. 200). The focus is on generating action. Cooperrider and the co-authors of the AI Handbook for Leaders of Change have insisted that the ultimate goal of the Destiny process “is to create highly improvisational organizations” (p. 205). Following Barrett (1998) these are organizations that are "affirmative, expansive, generative, and collaborative" (p.205). These competence areas are expanded by an ongoing application of the skills used during the 4D process.

Practitioners have noted that the 4D model overlooks an important step: defining the topic of inquiry. According to Bushe (2012), the Clergy Leadership Institute in the U.S. 
advocates a 5D model, the first step being Define. In the 4D model, the affirmative topic choice is at the core and centers the entire intervention (Cooperrider \& Whitney, 2005). A successful intervention will cycle through all four or five phases. If we step back for a bit, and situate AI not as an intervention but as a strategizing activity, the $4 \mathrm{D}$ process resembles a qualitative approach to strategy development. Data is collected, coded and analyzed for patterns and themes during Discover. In the Dream and Design phase, hypotheses are generated from the data in the form of vision statements and prototypes. They are then tested against reality once again in the Destiny phase when participants begin to develop executable plans and deploy them.

The specific activities and levels of participation vary depending on the actual method deployed (Whitney \& Trosten-Bloom, 2003). The form of engagement ranges from involving a small, core group of people to conduct the activities, all the way to involving all stakeholders from the entire organizational system, often including external stakeholders. The scope of the intervention can be limited to a specific project, as in an "AI learning team" method. GTE adopted a "positive change network" in which the company trained hundreds of its employees in AI to share resources and best practices. In a "mass mobilized inquiry" thousands of interviews are conducted across communities and organizations. One of the most popular methods in the corporate sector is the AI summit (Ludema et al., 2003), which is a conference involving large groups of stakeholders who go through the entire 4D cycle in two to four days. A "whole system 4D dialogue” was conducted at Nutrimental in Brazil, which temporally shut down its operations to enable literally all its employees to participate in an AI summit (Barros \& Cooperrider, 2000).

\section{Theoretical background}

The theoretical framework used to justify AI has changed over the years from the one originally proposed by Srivastva and Cooperrider in the footnotes of their 1986 article. It is 
useful to trace AI's theoretical roots, as some of its history has been lost in translation, so to say, as the practice of AI took off and evolved. Two of the most important influences on AI theory have been the work of Lewin (1946) and Gergen (1978). Lewin is considered by some, the founding father of OD. He pioneered research in group dynamics (1947a, 1947b). He also developed the concept of action research. Lewin (1946) envisioned research as being inseparable from action. The scientist (or consultant) is not a detached observer but part of the action. Diagnosis is necessary yet insufficient to help the practitioner. Furthermore, Lewin emphasized: "Socially, it does not suffice that university organizations produce new scientific insight. It will be necessary to install fact- finding procedures, social eyes and ears, right into social action bodies” (Lewin, 1946, p. 38). Lewin was neither denying the role of logical positivist modes of research nor underplaying the importance of theory. Rather, he called for research methods that incorporated both action and theory.

Cooperrider and his colleagues at Case Western Reserve University conceived of AI as an action research method that would enhance an organization's capacity for social innovation (Cooperrider, 1986; Srivastva \& Cooperrider, 1986). Cooperrider contended that action research had diverged from Lewin's ideal, and as a result, had become pre-occupied with action and problem solving. AI’s original agenda was to bring creative theorizing back into the picture. According to Cooperrider, the inability to "dream” constrained organizations from reaching their full potential to innovate. He cited Kierkegaard in his dissertation: "If I were to wish for anything, I should not wish for wealth and power, but for the passionate sense of the potential” (Cooperrider, 1986, p. 1). Cooperrider and Srivastva wrote in their 1987 article "Appreciative Inquiry in organizational life” that they were attempting a "conceptual re[con]figuration of action research”(Cooperrider \& Srivastva, 2008, p. 353) based on a social constructionist view of 
science. They claimed that "good theory may be one of the best means human beings have for affecting change in the postindustrial world” (p. 353). What they were proposing was a method for generating such theories.

Cooperrider was drawn to the work of Gergen (1978) who championed social constructionist thought in psychology. In social constructionism, the world is constructed according to how we approach the world. How we approach the world "depends on the social relationships of which we are a part" (Gergen, 2009, p. 2). Therefore, "the realities we live in are outcomes of the conversations in which we are engaged" (p. 4). In 1978, Gergen wrote an influential article titled "Toward generative theory" in the prestigious psychology journal, Journal of Personality and Social Psychology. He rejected the logical-positivist assumptions that dominated at the time, writing:

Much contemporary theory appears to lack generative potency, that is, the capacity to challenge prevailing assumptions regarding the nature of social life to offer fresh alternatives to contemporary patterns of conduct. (Gergen, 1978, p. 1344)

Gergen urged for a "sociorationalist" perspective which "places the locus of knowledge not in the minds of single individuals, but in the collectivity” (Gergen, 1982, p. 207). Knowledge and rationality is generated through "a social process of communication" instead of in the minds of individuals. This notion of sociorationalism lies at the heart of AI.

In 1990, Cooperrider wrote a chapter on the impact of positive images on actions in a book he co-edited on appreciative management. He reviewed the literature in neuroscience and psychology to build a case that positive images lead to positive action in organizations. Synthesizing this material with his earlier work, Cooperider and his colleagues formulated a new set of five principles which represent "the most widely accepted" (Bushe, 2011) theoretical framework of AI: constructionist, simultaneity, poetic, anticipatory and positivity (Cooperrider et al., 2008). 
Constructionist reflects AI’s social constructionist roots inspired by Gergen. Simultaneity refers to the dynamic feedback loop of inquiry and change. It is analogous to the "circulatory response” (Follett, 1924) and the double interact (Weick, 1979) in which stimulus and response can simultaneously be a cause and an effect, a cornerstone of systems thinking (Senge, 2006). It also builds from the famous studies by Rosenthal and his colleagues in which the expectations of the experimenter can be transmitted to participants of an experiment (Rosenthal, 1966), drawing the conclusion that inquiry is in and of itself an intervention.

The poetic principle assumes that an organization's inner talk or narrative has a profound effect on organizational outcomes. This is consistent with Weick's views on historicizing (Weick, 1979), Boje’s storytelling organizations (Boje, 2008) and the power of metaphors (Lakoff \& Johnson, 2003; Morgan, 1997). The anticipatory principle takes the view that the image of the future guides current behavior. Weick's theory of future perfect thinking, which will be described in detail in the next chapter, supports this notion. Finally, the principle of positivity "grows out of years of experience with AI" (Cooperrider et al., 2008, p. 9) based on the claim that change requires energy and momentum which can be created through positive affect.

Bushe (2011) has claimed there are ten theoretical levers he identified in the literature that explain the underlying change mechanisms of AI. His critique includes theories of discourse and narrative (Barrett, Thomas, \& Hocevar, 1995), stakeholder engagement (Gergen \& Thatchenkery, 1996), and self-organizing processes (Jantsch, 1980). Bushe singled out the theory of "inquiry as intervention" as the most important contribution AI has made to theories of organizational change. According to Bushe, Cooperrider and his colleagues theorize "that organizational inquiry is simultaneously the production of self-and-world. What researchers choose to study and how they study it creates as much as it discovers the world” (Bushe, 2011). 


\section{AI criticism}

\section{Positivity.}

The claim that has been the greatest allure and has drawn the greatest criticism toward AI is the principle of positivity. Critics of AI worry that an unconditional focus on the positive may do more harm than good. One major concern is the possibility that AI dodges conflict and important structural problems under the rug. Pagés (1990), a psychoanalyst and researcher from Europe, shared his reservations and discomfort towards a focus on the positive dimensions of organizational life in a book edited by Srivastva and Cooperrider in 1990.

I fear it may be used to create solutions so distinct from reality that one could view it as a defense mechanism rather than a visioning process grounded in reality. Such a coping mechanism may overlay profound conflict; it may prove ephemeral and damaging in the long run. (Pagés, 1990, p. 354)

In a critical review of AI interventions in health care published in 2011, some participants who were interviewed by the reviewers echoed these concerns. One project developer was quoted as saying: "Some people may look at AI as yet another concept that will be a 'band aid' to the symptoms that really block our change” (Dematteo \& Reeves, 2011, p. 206). The authors of the review noted that a lack of critical analysis can undermine examinations of existing structural tensions in the workplace-interprofessional tensions between nurses and doctors, for example. As a result, AI "may have also helped to legitimate existing unequal power relations" (Dematteo \& Reeves, 2011, p. 206), despite the appearance of a democratic change process, and restoration of hope and meaning towards the future among the participants. Although the participants clearly desired more interprofessional collaboration, Dematteo and Reeves concluded that in the absence of critical analyses of structural issues, AI will be limited in its effectiveness in securing lasting change in health care. Aldred (2009) criticized AI's use in community development for similar reasons, especially in situations in which "institutional 
legitimacy and trust are low" (p. 66). She questioned whether participants in an AI intervention were really in control of their destiny as opposed to a temporary feeling of control arouse through provision of "a bounded space for flouting convention” (p. 66).

Reflective practitioners have noted that in some situations, facilitators may have inadvertently stifled opportunities for liberal discourse by steering a group away from talking about the negative issues and constraints of the larger system. Grant and Humphries (2006) critiqued four case studies from their own AI practice involving school boards, and noted that in one instance, the researcher-facilitator's positive bias "could have exacerbated participant perceptions of the relative power imbalance within the research group and the de-valuing of local knowledge within the action research process” (p. 413). Grant and Humphries raised the possibility that deflecting attention from negativity may have led to a diminished sense of trust within the group, resulting in members being less open and granting less disclosure in the inquiry. None of the four cases were able to complete the full 4D cycle of AI.

A comparative study by Bushe (2010) of AI interventions within the same organization provides a partial response to the issues raised above. Bushe examined interventions at eight sites belonging to a large, urban school district. AI summits were an integral part of the intervention methodology in all eight sites. Half the sites achieved transformational change where changes could be attributed to the AI process, and where the normative routines of teachers at the site clearly differed after the process. Change was incremental at two sites where the observed changes were consistent with change efforts prior to the AI process and were not changes to normative routines. Two sites were classified as having no change (Bushe, 2010). 
What is noteworthy in his study was "that the inquiry needed to address some problem, issue or concern that was widely shared for transformational change to occur” (Bushe, 2010, p. 22).

Sites where there were no identified "problems" that the AI was attempting to solve either had no change or incremental change. When there were obvious, unresolved conflicts in the system not addressed by the AI there was no change. It is probably significant that the two sites with the highest levels of morale and pride prior to the AI was it to that experienced only incremental changes.... Sites that experienced transformational changes, however, were those where the AI was connected to real, shared concerns within the schools and helped to 'solve problems' that were meaningful to participants. (Bushe, 2010, p. 19)

Sites with no change were significantly worse at getting the right people to participate in the process given the topic of inquiry. "AI does not magically overcome poor leadership, communication failures, and unresolved conflicts” and requires normal OD processes necessary for successful change (Bushe, 2010, p. 22). Bushe also found that levels of positive affect generated by the inquiry did not predict levels of change.

This line of reasoning is similar to the objections to the positive psychology movement raised by some psychologists. Depending on the context, negative emotions such as anger can be generative and lead to positive change (Hunter, 2009). Bushe has argued that, "the generation of new, compelling ideas was central to the change process” (Bushe, 2010, p. 21). Generativity, not positivity, was core to the AI change process (Bushe, 2007). Elliott has pointed out that AI is an “appreciative” approach, deliberately differentiated from a positive or affirmative approach (Elliott, 1999). The positive lens is a way of compensating for "the tendency in our culture to highlight deficiencies” (Elliott, 1999, p. 10) and ignore the positive and the pleasing. At the same time, it is important for AI not to undervalue the "shadow" (Fitzgerald, Oliver, \& Hoxsey, 2010). Grant and Humphries cite an analogy by Rogers and Fraser who question an unconditional focus on the positive as risking distortion similar to a lopsided plant reaching out to the sunlight 
(Rogers and Fraser, 2003, cited in Grant \& Humphries, 2006). That said, Bushe raised the possibility that positive affect may be a necessary but not sufficient condition for successful AI interventions because all eight sites reviewed showed high levels of positive affect after the completion of the AI summits (Bushe, 2010, p. 21).

Advances in positive and cognitive psychology suggest that the positive affect generated during an AI intervention may have effects that influence their outcome. Research on the benefits of positivity on individuals, groups and organizations has expanded significantly (Donaldson \& Ko, 2010). One of the foundational theories on positivity was posited by Fredrickson who hypothesized that positive emotions play an evolutionary role in that they broaden the scope of attention and thought-action repertoire of an individual, allowing them to build resources for physical, intellectual and social resiliency (Fredrickson, 2001). Lab experiments not only support this hypothesis (Fredrickson \& Branigan, 2005; K. J. Johnson, Waugh, \& Fredrickson, 2010) but also show that positive emotions can reduce own-race bias and increase the likelihood of recognizing faces of a race other than our own (K. J. Johnson \& Fredrickson, 2005). In the organizational behavior literature, Losada and Heaphy (Losada \& Heaphy, 2004) used non-linear modeling to demonstrate that high performance teams in business have a higher "positivity ratio" than their lower performing counterparts. The ratio was calculated by dividing the number of positive comments by negative comments in meeting settings. High performance teams showed an orientation towards others and inquiry as opposed to self and advocacy. These findings lend support to the effectiveness of an approach that stresses appreciation and inquiry. That said, it is not clear from the current literature how individual level outcomes translate into organizational ones. 


\section{The validity of AI methods.}

Lewin (1946) noted that action must be evaluated by some criteria that determines the relation between effort and achievement or else there is no way of judging whether "an action has led forward or backward” (Lewin, 1946). One significant concern continues to weigh down AI: a lack of evaluation of results and methods. There continues to be a dearth of literature evaluating the effectiveness of AI. In 2008, Messerschmidt estimated that there were over 500 articles on AI in the international literature. Yet there was "an amazing lack of rigorous assessment of AI methodology or techniques” (Messerschmidt, 2008, p. 455). Messerschmidt observed, "many AI practitioners appear almost evangelical in their belief in the 'positive affirmation' theory” (Messerschmidt, 2008, p. 455). The studies that Messerschmidt identified were illustrations of "only tentative attempts at evaluating AI" (Messerschmidt, 2008, p. 463).

Relatively few articles on AI have been published in peer-reviewed research journals in management. Many of the scholarly articles on AI have appeared in the Journal of Applied Behavioral Science. Founded by the NTL Institute, the journal is devoted to OD and "the effects of evolutionary and planned change" according to the publication's web page (http://jab.sagepub.com/). Six articles have been published in JABS with the keywords "appreciative inquiry" in the abstract. Burke's critique is one of the six. A keyword search in all fields in the journal retrieved 61 citations. A similar search of publications of the Academy of Management—-the world's largest scholarly society in the discipline-yielded nine citations containing the words in the abstracts. Of these, only one was a published, academic journal article (Powell et al, 2004). Six were conference papers and symposia presented at AOM's annual conference, and two were book review related. A full-text search of the AOM archives retrieved 85 citations. This is a drop in the bucket, considering that these results were culled from 
the full-text of all journals and conference proceedings for the past 25 years. These results suggest that mainstream academics in the management field may not be taking AI seriously. Burke was careful to include the words "and perhaps arguably" in describing AI as one of the greatest technical developments in OD; the legitimacy of AI is still in question. Is AI an enduring innovation? Or is it a fad that will fade once OD clients who "are eager for the new and different, for any magic that will make change easier” (Bunker et al, 2004, p. 404) inevitably move on to the next big thing?

One of the first published quantitative analyses of an AI intervention was a laboratory experiment by Bushe and Coetzer (1995). They compared three conditions: team-development using AI, task-oriented team development (TOTD) and a lecture (placebo). Significant differences were found between both treatment groups and the placebo in task performance, group processes and outcomes. However, in comparing AI with TOTD, significant differences in variance were limited to task performance, with TOTD scoring higher (Bushe \& Coetzer, 1995). Jones (1998) studied the effect of AI interventions on employee turnover at 94 fast-food restaurants and found that a test group using the AI methodology resulted in 30-32\% higher retention rates compared to two control groups (Jones, 1998).

Van de Haar and Hosking (2004) have argued that quantitative evaluations comparing pre and post intervention outcomes, which they call the "product evaluation" approach, are inconsistent with the social constructionist assumptions of AI. “A ‘product evaluation’ approach does not aim to be responsive to multiple local ontologies, imposes one reality construction (in the name of science and rationality) on others and so reproduces relations of 'power over'” (p. 1028). 
After ten years of experience using the AI method, Whitney and her colleagues conducted a qualitative study to evaluate why it works (Whitney \& Trosten-Bloom, 2003). They used the AI approach for the study. Many of the participants were from Hunter Douglas, which had experienced great financial success from the AI interventions. Their data suggested that the liberation of power contributed to the success of AI. There were at least six conditions for power to be liberated: the freedom to be known in relationship, to be heard, to dream in community, to choose to contribute, to act with support, and to be positive (pp. 238-239).

To date, there has only been one published study that systematically compared different interventions from different organizations to ascertain the conditions necessary for a successful intervention. Bushe and Kassam (2005) conducted a meta-analysis of 20 published case studies AI interventions prior to 2003. The interventions were evaluated for transformational outcomes. Seven showed transformational change that went beyond "what we might expect from any competently managed change process” (p. 171). The authors identified conditions that were common to the transformational cases. Before discussing those conditions, I will briefly point out some issues on the methodology of comparing case studies.

\section{Limitations of meta-analysis of case studies}

Case studies are generally accepted as a valid research method (Bluhm, Harman, Lee, \& Mitchell, 2011). However, a perception persists in academia that they are not scientifically rigorous (Yin, 2011). There are valid concerns regarding comparisons of AI case studies, because they are vulnerable to selection bias. Most are written by scholar-practitioners who were hired by the clients as consultants. This has consequences: many more cases are written about successes than failures. People are reluctant to talk about failed interventions. The facilitators of the intervention have no interest in talking about and neither is the organization. 
Failed interventions, therefore, are likely being systematically excluded from being documented and published as case studies. Bushe and Kassam (2005) sampled published case studies that may have been susceptible to such biases. A more fundamental issue has to do with the validity of a meta-analysis of AI case studies. A meta-analysis analyzes the results of previously published research according to certain criteria. They are often used to compare and contrast quantitative findings from experimental studies. Meta-analyses of qualitative methods like case studies are far less common and are relatively undeveloped (Rudel, 2008). The application to AI cases begs another question: are AI interventions even comparable to one another? AI comes in many shapes and forms. There are at least eight different methods. Depending on the method, data might be collected by the consultant, a select group of employees, or by hundreds of internal and external stakeholders. The degree to which management and employees buy into the approach may also differ. Such factors make it problematic to pool data in the first place.

\section{Reframing the purpose of AI}

\section{AI and knowledge creation}

Despite the methodological issues, Bushe and Kassam's (2005) meta-analysis provide some crucial insights into the conditions for successful AI interventions. They compared 20 published cases of AI prior to 2003 and evaluated them for transformational outcomes. Seven showed transformational change that went beyond "what we might expect from any competently managed change process” (p. 171). All cases reporting transformational outcomes 1) created new knowledge, 2) created a generative metaphor, and 3) changed or created new background assumptions underlying the organization's actions. In contrast, none of the non-transformational cases created knowledge, and only one case each showed 2) or 3). Transformational cases tended 
to take a more improvisational approach in the final AI phase. Bushe and Kassam concluded that in the transformational cases, the organization was able to:

(a) generate new, internally validated knowledge that is meaningful to system members and provokes new actions and

(b) plan for, and guide, the action phase in a way that supports local innovations without requiring a consensual or centralized approval. (p. 178)

In the more recent comparative study of AI summits at four different sites of the same organization, Bushe (2010) was unable to find any significant correlation between positivity and transformational outcomes. Bushe (2007) stressed in an earlier article that the generative aspects should be emphasized, not just the positive.

It is the quest for new ideas, images, theories and models that liberate our collective aspirations, alter the social construction of reality, and in the process, make available decisions that were not available or did not occur to us before. When successful, AI generates spontaneous, unsupervised, individual, group and organizational action toward a better future. (p. 30)

In the language of strategic management, AI can be conceptualized as a systematic strategizing process for practicing innovation and entrepreneurship. It is not surprising that AI echoes many of the management principles advocated by Drucker (2009): “An organization will have a high spirit of performance if it is consistently directed toward opportunity rather than toward problems. It will have the thrill of excitement, the sense of challenge, and the satisfaction of achievement if its energies are put where the results are, and that means on the opportunities,” (p. 460). An organization is destined to die if it loses its spirit of performance. According to Drucker (2008), "the purpose of organization is to enable ordinary human beings to do extraordinary things. It is a means to make strengths productive and weaknesses irrelevant” (p. 280). To do so, the focus must be on performance and opportunities. AI not only orients an organization's attention to areas of strengths and opportunities, but it does so in a way that engages the entire organizational system. Opportunities are identified collectively as a whole instead of in 
organizational silos or by management consultants, raising the likelihood that resources are allocated to areas with growth potential.

The AI method can be viewed as a way for an organization to adjust what Drucker calls its theory of business. An organization can stall if its theory of the business becomes incongruent with its operating environment. Cooperrider intended AI to enable organizations to creatively theorize about itself. AI often engages external stakeholders such as suppliers and customers in its strategizing activities. Their presence serves both as a reality check and a source of insight. The theories that emerge form the basis for generating images of the future. This is in line with Drucker's famous words: "the best way to predict the future is to create it." Strategic planning is an entrepreneurial skill. "Forecasting attempts to find the most probable course of events or, at best, a range of probabilities. But the entrepreneurial problem is the unique event that will change the possibilities" (Drucker, 2009, p.124). The key question is "What should our business be?" as opposed to "What is our business?"

According to Drucker (1993), innovation is one of two basic functions of a business (the other being marketing). "Innovation is the specific tool of entrepreneurs, the means by which they exploit change as an opportunity for a different business or a different service” (p. 19). Drucker identified three managerial practices required for entrepreneurship in existing businesses. First, managerial vision must be focused on opportunity. Second, an entrepreneurial spirit must be generated throughout the entire management group. This includes constantly asking the people and units who do things better and differently, "What are you doing to that explains your success?” (p. 157). Third, scheduled sessions should be systematically carried out in which a member of top management sits down with junior people from various divisions of the company to listen to their aspirations, their views of where the opportunities and threats are, their ideas for 
new things. All three practices are highly congruent with the AI approach. Indeed, the AI summit format appears to incorporate the three practices in a large group setting.

Additional insights can be culled from a recent study of an AI intervention in nursing. Richer, Ritchie and Marchionni (2009) examined the use of AI to promote innovative ideas for improving work environments of nurses and health care workers. They sought to answer the question "How does an AI change process lead to the development of innovative ideas regarding the organization of health care services?” (p. 949). The authors developed a theoretical framework relying on the notion that" knowledge is a source of innovation and change that requires synergy between individuals within a group" and situated AI as process in which tacit and explicit knowledge is exchanged to build a shared future. Using a multiple embedded casestudy methodology, they looked at an AI change process at two cancer care clinics consisting of 11 one-hour sessions with each health care team simultaneously over nine months. In addition to participant-observation of the sessions, the researchers observed management meetings and conducted interviews with team members. Participants classified ideas that were generated from the sessions as innovative or not.

Their results suggested that in addition to change processes, AI creates opportunities and some of the conditions promoting the emergence and implementation of innovative ideas.

Throughout the AI process, discussions between different members of the team permitted the refinement and the evolution of the generated ideas. This process of knowledge exchange and development is in line with Nonaka's (1991) proposition that the emergence of innovative ideas or new knowledge always begins with individuals, is embedded in values and beliefs and is created when tacit knowledge is made explicit and transformed into something new. (p. 952)

The authors elaborated how the AI process served as a "space" where knowledge is developed and shared. 
This shared space, called "ba” (Nonaka \& Konno 1998, Nonaka et al. 2000), encompasses any virtual or physical area designed for the creation of collective knowledge and the development of relationships. Thus, the common context in which knowledge was shared, created and utilized during the AI process united physical and mental spaces, "ba", that promoted the sharing of common goals and provided a platform for innovation. (Richer et al., 2009, p. 953)

Nonaka's (1994) theory of knowledge creation is one of the best known theories in the organizational knowledge literature (Easterby-Smith \& Lyles, 2003b). In Nonaka’s framework, knowledge is dynamic, and at a fundamental level, created by individuals. Referencing the work of Varela and his colleagues (Varela, Thompson, \& Rosch, 1991), “cognitive experience is ‘embodied action' rather than a mere representation of a world that exists independent of our cognitive system” (Nonaka, 1994, p. 24). He explained:

An organization cannot create knowledge without individuals. The organization supports creative individuals or provides a context for such individuals to create knowledge. Organizational knowledge creation, therefore, should be understood in terms of the process that "organizationally" amplifies the knowledge created by individuals, and crystallizes it as a part of the knowledge network of organization. (Nonaka, 1994, p. 17)

Nonaka describes innovation as a key form of organizational knowledge creation. Innovation cannot be adequately explained in terms of information processing or problemsolving, he argued. "Innovation can be better understood as a process in which the organization creates and defines problems and then actively develops new knowledge to solve them” (Nonaka, 1994, p. 14). In Nonaka's theory of knowledge creation, knowledge is dynamically converted from tacit to explicit forms, from the individual to the organizational level, in four phases known as the SECI model. Knowledge goes through a conversion between tacit and explicit modes in four phases: Socialization, Externalization, Combination and Integration, hence the acronym SECI (pronounced “seki”). Knowledge is created in shared contexts (ba) which are perpetually in motion and transcend physical space and time. The various AI methods including an AI summit could constitute the shared context necessary for knowledge to emerge. 
Nonaka’s model is very intuitive. Polanyi’s (2009) famous insight that "we know more than we can tell,” is something most people can relate to. Thus, it naturally follows that companies that are better able to convert the tacit knowledge of its employees into an explicit mode in which it can be leveraged and exploited, have more knowledge resources and are more competitive. Ambrosini and Bowman (2001) have suggested cognitive mapping as one way of operationalizing tacit knowledge. Knowledge comes in various degrees of tacitness. Not all knowledge can be made explicit. Some of it is embodied deep in our adaptive unconscious (Wilson, 2002) and is out of reach. Cognitive mapping methods such as causal mapping, the authors claimed, can make explicit, at least some of the tacit knowledge that is closer to the surface. AI's appreciative interviews can be considered a form of causal mapping; stakeholders probe deeper and deeper into the root causes of success to make explicit the organization's positive core.

Nonaka’s work had a great “popularizing influence”(Emphasis in the original, EasterbySmith \& Lyles, 2003a, p. 11) in the burgeoning field of organizational knowledge studies. The Knowledge Creating Company co-authored by Takeuchi (1995) expounded on important ideas including "the importance of national culture and philosophy to understanding the construction and communication of knowledge” (Easterby-Smith \& Lyles, 2003a, p. 11). There are some issues, however. Critics have contended that the very nature of tacit knowing prohibits it from ever being converted into explicit knowledge (Tsoukas, 2003). Nonaka takes the view of knowledge as a resource-a resource based view (Barney, 1996), whereas Tsoukas and others take more of a social practice view of organizing. The two approaches have yet to be reconciled (Nonaka \& von Krogh, 2009). There are some issues in the empirical application of the SECI model as well. Demonstrating the acquisition and transfer of tacit knowledge in the socialization 
and externalization phases is especially problematic, and any description can be open to interpretation. For example, a second-order observer-an individual reflecting upon themselves — may have a very different perspective from a third-order observer who is observing the individual from the outside in. One interpretation can be just as valid as another.

The study by Richer and her colleagues is nevertheless informative in that there appears to be something embedded in the AI process that contributes to the creation of organizational knowledge. It is worth pointing out here that, despite the social constructionist roots of AI, its methods implicitly acknowledge a representational view of knowledge. AI is referred to as "a search for knowledge" (Cooperrider et al., 2008, p. 3) in the AI handbook for practitioners, a choice of words more consistent with the notion that knowledge is out there to be grasped. The first phase of AI sets out to discover an organization's positive core, implying that some positive core already exists and is begging to be found. The purpose of the current study therefore is to pursue the line of vision opened up by Richer et al. that situates AI as a shared context for generating new knowledge leading to innovation.

\section{Summary}

In this chapter, I reviewed the literature on AI and identified the following points pertinent to this study. First, AI originated as a research method, not an intervention. Second, the role of positivity in AI remains controversial. Third, past studies of AI suggest that the purpose of AI can be reframed as a shared context for organizational knowledge creation. This suggests that there may be alternative ways of evaluating AI's effectiveness by situating AI as a strategizing practice for organizational knowledge creation, rather than a change intervention. 


\section{Chapter 3 The AI Summit: A Large Group Method of Strategizing}

\section{Introduction}

Although there are a variety of methods available to appreciative inquiry (AI) practitioners, the AI summit has recently become the format of choice at many companies. The AI summit integrates AI with another recent innovation in OD: large group methods. Formerly known as large group interventions (Bunker \& Alban, 1997), these methods seek to involve a wide range of stakeholders in the decision-making process for systemic change (Bunker \& Alban, 2006). The four characteristics common to these methods are the inclusion of stakeholders, engagement of multiple perspectives through interactive activities, opportunity to influence outcomes, and a search for common ground as opposed to conflict resolution (pp. 19-21).

Bunker and Alban categorized large group methods into four types based on their purpose. The first are methods geared towards “creating the future together” (pp. 10-13), including AI. They all revolve around a conference with participants ranging from about 40 people to as many as several thousand. Creating a future is equivalent to developing strategy. Therefore, these methods are analogous to strategy workshops in large group configurations. The two others are methods for "work design” (pp. 13-15) and for "whole-scale participative work" (pp. 15-19). These methods, redesigning the flow of work and engaging people in participation, are similar to business process reengineering projects except they utilize large group meetings. The last category is methods for “discussion and decision making” (pp. 28-31) such as World Café.

Large group methods emerged partly in response to the increased levels of complexity that confront organizations today. Advances in information technologies promoted globalization and greater levels of interdependencies between what used to be independent, self-contained 
systems. In practice, OD consultants were frustrated by the unintended consequences and unexpected changes in the environment that accompanied conventional interventions. "The idea that change must involve the whole system has been growing in currency over the last forty years” (2006, p. 4) wrote Bunker and Alban.

The idea of a system-wide approach may sound appealing to an OD consultant. But proposals that seek the participation of lower-level employees in strategic decisions in organizational level strategic planning and change development "meets definite resistance and skepticism” (Powley, Fry, Barrett, \& Bright, 2011, p. 69) from management. There is a strong perception that large groups take too long to reach consensus, are "unruly" and "seldom result in action” (p.69). Yet there has been a considerable amount of experimentation by practitioners since the mid-1980s, based on developments in research in social psychology. The AI summit is a beneficiary of such trial and error. That AI's popularity has not waned for over 25 years may have as much to do with the innovations in large group methods as the AI approach itself.

In this chapter, I trace the theoretical origins of large group methods and how those theories were integrated into practice. I then turn to the AI summit format, and review the findings of a case study of AI summits conducted by the US Navy (Powley et al., 2011). The authors suggested that the AI summit format can be used as a participative management tool in a command-control environment like the Navy. Of particular interest is their observation that the AI summit "represents a communal atmosphere where the temporary suspension of normal organization structure allows for the accomplishment of significant, empowered strategic work” (p. 78). The mechanism of suspension allows the members of a strictly hierarchical organization like the Navy to engage in democratic dialogue without permanently altering the formal 
command-control structure. I pick up this thread and connect it to recent studies on the concept of strategic episodes (Hendry \& Seidl, 2003) in the strategic management literature.

Hendry and Seidl developed the concept of strategic episodes by applying Luhmann's social systems theory to strategy meetings. "Episodes, in Luhmann's theory, provide a mechanism by which a system can suspend its routine structures and so initiate a reflection on and change of these structures” (Hendry \& Seidl, 2003, p. 175). I introduce the findings from Jarzabkowski and Seidl who conducted a study of 51 strategy meetings of a university. Despite the ubiquity of strategy meetings and workshops in organizational life, strategic management scholars have largely overlooked their role in strategy development. Jarzabkowski and Seidl analyzed the meetings through the concept of strategic episodes. I conclude the review with some thoughts on how Luhmann's theory is a useful lens through which to evaluate the conditions that make AI summits effective as a space for creating organizational knowledge.

\section{Large group methods: Theory and practice}

\section{Group dynamics meets systems theory.}

Large group methods evolved through a combination of theory and practice. In 2006, Bunker and Alban published the most comprehensive book on large group methods to date, The Handbook of Large Group Methods. They identified three strands that became the precursors to large group methods of organizing. The first strand can be traced back to the research of Lewin and Bion. Independently of each other, they developed the foundational ideas and theories of "group dynamics," the former in the US, the latter in the UK. Lewin is credited for having coined the word group dynamics in a 1939 article (Weisbord, 1987). He emigrated to the US from Germany in 1933 after working with two of the founders of Gestalt psychology, a stream of psychology that focused on understanding the whole rather than the elements of cognitive 
processes. He made significant contributions to social psychology in general, and large group methods in particular. In reflecting upon those contributions, Weisbord wrote:

Lewin wed scientific thinking to democratic values and gave birth to participative management.... He taught that to understand a system you must seek to change it.... Diagnosis does not mean just finding the problem, but doing it in such a way as to build commitment for action.... Not only could you solve the problem, you could simultaneously study your own process and thereby refine the theory and practice of change. (p. 72)

Lewin posited that group experiences based on mutual tasks, changed the attitudes and actions of everyone in that social system more quickly than through individual exercises. According to Weisbord, Lewin discovered a core principle during his experiments with anthropologist Margaret Mead in the midst of World War II, in which they were tasked with getting housewives in Iowa to reduce their consumption of rationed foods. The principle was: "we are likely to modify our own behavior when we participate in problem analysis and solution and likely to carry out decisions we have helped make" (Emphasis in the original, Weisbord, 1987, p. 89). Lewin saw a downside in conventional methods of consulting. When an expert comes in to do everything from defining the problem to generating the solutions, ironically, the more the expert does, the less inclined are the people affected by the proposed solution to cooperate. Instead, Lewin called for an action-oriented mode of consulting and research in which the expert collaborates with those experiencing the problem at hand, enabling "those with a stake in the problem to define and solve it” (Weisbord, 1987, p. 190). Lewin's conceptualization of action research was crucial not only to the development of large group methods in the context of whole-system change, but also to the emergence of the appreciative inquiry approach to consulting. This latter point will be explored in a later section.

Meanwhile, Bion, an army psychologist in the UK trained in psychoanalysis, paved the way for advancing theories in group dynamics at the Tavistock Institute. Guided by his 
observations in group psychotherapy, Bion theorized that when groups are confronted with highanxiety change, there is a tendency for people to behave based on one of three emotional states: fight-flight (battle or withdraw), dependency (rely on leader or expert), and pairing (find a partner within the group) (Weisbord, 1987). Different leadership behaviors were needed to be matched with the different emotional states of the group. Researchers at the Tavistock Institute went on to further develop Bion’s work through “a form of laboratory” (Weisbord, 1987, p. 147) that conducted training sessions using learning groups called "Tavi” groups. "When people fight, run away from the task, pair up defensively, or depend on a leader to solve their problems, they become childish, immature, and unable to grow” (Weisbord, 1987, p. 149) impeding creativity and joint action. These insights were later applied to developing methods for work design and studies of leaderless groups—-self-organizing work teams.

Systems theory was brought to the Tavistock Institute by Emery, an "assertive young activist” (Weisbord, 1987, p. 157) who had been studying the open systems theory of von Bertalanffy (1969). In the 1940s, the Austrian biologist von Bertalanffy (1969) proposed a "theory of the organism as open system" (p. viii), which described living organisms as open systems that continuously interact with their environment. Emery was one of the first social scientists to fully appreciate the significance of the open systems ideas for psychology and the social sciences (Weisbord, 1987). He collaborated with Trist, one of the founders of the institute and a colleague of Bion's. Trist had been studying the impact of new technology in the coal mining industry. The two developed their ideas into a theory of sociotechnical systems (STS) which recognized the importance of understanding how both technology and people relate to "the larger whole they serve" (p. 159). STS showed "how changes in technology can disrupt system functioning, even when what is being introduced is a more efficient technology” (Bunker 
\& Alban, 2006, p. 5). A change in one part of the system can lead to unintended consequences in another. This insight meant that in order to institute sustainable change, the whole system must be taken into account (Bunker \& Alban, 2006), and provides the theoretical rationale for bringing the whole system into the room.

\section{Future perfect thinking.}

Lewin's colleague Lippitt is one of the researchers credited for bringing in the final dimension, futuring. Lippitt played back tape recordings of 30 planning groups in action. He was struck by "how voices grew more depressed" as they went down their list of problems, especially those that were beyond their control. Lippitt noted that the motivation "was to escape the pain induced in part by the method itself: the piecemeal listing of problems, the solution of any one of which might create still more problems” (Weisbord, 1987, p. 283). Lippitt shifted gears. He teamed up with Lindaman, a planning director for the Apollo mission to the moon. Weisbord wrote:

Lindaman believed that the future was created by our present ways of confronting "events, trends and developments" in the environment. The "preferred future"-an image of aspiration-could be a powerful guidance mechanism for making far-reaching course corrections. (Weisbord, 1987, p. 283)

The two found that when they asked people to work back from the future they desired to plan the present, "they develop energy, enthusiasm, optimism, and high commitment” (Weisbord, 1987, p. 283).

People also give more detailed and understandable accounts of hypothetical situations that are temporally in the past than in the future (Bavelas, 1973 as referenced by Weick, 1979). In an experiment, accounts of an imagined trip that "will occur" were less detailed, shorter and less sensible than if the trip was presented as if it had already occurred. Weick cites Schutz (1967) who explained: "because it is pictured as completed, the planned act bears the temporal 
character of pastness...as if it were simultaneously past and future” (Weick, 1979, p. 198).

Weick has described this as thinking in the future perfect tense.

The future event is more sensible because you can visualize at least one prior set of means that will produce it. The meaning of that end is those means that bring it about. Furthermore, when one imagines the steps in a history that will realize an outcome, then there is more likelihood that one or more of those steps will have been performed before and will evoke past experiences that are similar to the experience that is imagined in the future perfect tense. (Weick, 1979, p. 198)

In contrast, the simple future tense has a greater cognitive load because without a cognitive anchor, any number of outcomes is possible. Weick linked these ideas to organizational sensemaking.

When an event yet to happen is treated as if it's over, this aids sense-making because that imagined completion can be related more easily to similar cause maps that have already been enacted. When something is thought about as ongoing and changing, it's harder to match it with something known in the past than if the event is thought of as completed and fixed. (Weick, 1979, p. 201)

\section{Breakthrough in practice.}

As Powley and his colleagues pointed out, large groups are perceived to be unruly. In the late $19^{\text {th }}$ century, the French physician and writer, Le Bon (1930) wrote a bestselling book titled The Crowd: A Study of the Popular Mind.

The fact that [individuals] have been transformed into a crowd puts them in possession of a sort of collective mind which makes them feel, think, and act in a manner quite different from that in which each individual of them would feel, think, and act were he in a state of isolation. (pp. 29-30)

Le Bon described the characteristics of crowd psychology such as impulsiveness, irritability, an exaggeration of sentiments, among others (p. 39). These are certainly not the characteristics one would hope for in a strategizing meeting that will determine the future direction of an organization. According to Bunker and Alban (1997), issues of large group dynamics fall under four categories: dilemma of voice, dilemma of structure, a systems problem, and the contagion of 
affect. The dilemma of voice arises from the limited amount of airtime available for all participants to speak, resulting in some speaking a lot and others staying silent. This can lead to the tyranny of the few, causing those who are silent to feel marginalized and even less inclined to contribute. Latane and Darley’s (1968) “diffusion of responsibility” suggests that as the number of people in the group increases, the sense of personal responsibility for the outcome decreases. The second issue is the dilemma of structure. Having too much or too little structure can cause anxiety in people. There is fear of losing control and the potential for chaos and total disorganization. "The right amount of structure is reassuring and allows people to function in a healthy way” (Bunker \& Alban, 1997, p. 204). The problem is we neither know how much anxiety exists nor how much structure is needed.

The third issue is a systems problem. Analogous to the blind man's elephant, employees have a limited range of vision of their organization. This is the egocentric dilemma. At the beginning of a large group event, "hundreds of people with differing pictures of organizational reality all act as if theirs is the only true reality” (Bunker \& Alban, 1997, p. 207). Some of these issues are exacerbated due to the contagious nature of affect in larger groups, the fourth issue. Bunker and Alban (1997) have suggested that "people begin to experience feelings because they feel them vicariously in others, not because they are all having the same experience” (p. 208). The affective center of a group is easily manipulated. In extreme cases, strangers can quickly act in concert and turn cruel and violent, even in a simulated role play, as the Stanford prison experiments by Zimbardo (1973) demonstrated.

Breakthroughs in large group methods came with the realization that many small groups can be the equivalent of one large system (Bunker \& Alban, 2006). Large group conferences became effective by adopting "small group technologies and processes that allow people to 
participate fully and feel engaged” (Bunker \& Alban, 1997, p. 204). Large groups can be divided into many small groups of 12 or less, and assigned specific tasks. Groups interacting within the larger framework of the whole system in the room reduced the probability of contagion.

Clear task and group structures lower the potential for chaos while encouraging active and individually determined behavior. Functional group roles such as recorder and reporter can be rotated, promoting individuation and leadership (Bunker \& Alban, 1997). As the methods matured, professional facilitators were no longer needed at every discussion table, paving the way for organizations with smaller budgets to adopt the methods (Bunker \& Alban, 2006). By bringing the whole system in the room, participants gain a holistic view of the organization and a better sense of what it is like to be in the shoes of someone in a different functional position.

\section{Large group methods in practice.}

Strategy development consists of making sense of the future. In the 1980s, Emery. Weisbord, and others sought to integrate and apply these theories to strategic planning through large group conferences designed to search for the future. Weisbord's seminal book, Productive Workplaces (1987) examined the contributions of Taylor, McGregor and the theories outlined above "in a new light" (Bunker \& Alban, 1997, p. 22) that made clear the implications for large group methods. Weisbord also referenced some theories of practice culled from his own conference model called Future Search. Weisbord took the "back to the future" concept and combined it with conference management processes consistent with democratic values. The conference is based on three assumptions:

1. Change is so rapid that we need more not less, face to face discussion to make intelligent strategic decisions. Teleconferencing won't do....

2. Successful strategies - for quality goods and services, lower costs, more satisfying ways of working-come from envisioning preferred futures. Problem solving old dilemmas doesn't work under fast-changing conditions.... 
3. People will commit to plans they have helped to develop. (Emphasis in the original, Weisbord, 1987, p. 285)

There are four steps in the Future Search conference. Participants build a database, look at it together, interpret what they find and draw conclusions for action (Weisbord, 1987, p. 289). It is worth noting here that these processes closely resemble qualitative research methods (Yin, 2011): data collection and compilation, coding, analysis and discussion. Participants are tasked with looking at the past and present from various perspectives (self, company, society, outside and inside), then generating images of the future (Weisbord, 1987, pp. 288-290). Participation is limited to people who have a stake in the organization's future. Groups of 50 to 60 people are chosen for diversity with consideration to their linkages to the outside. Planning for the conference involves external consultants and a voluntary committee of four to six potential participants. The committee sets the agenda and decides the selection method for participants.

Some methods emerged independent of developments in OD. One of the better known methods is GE's Work-Out (D. Ulrich, 2002). According to Bunker and Alban (1997), WorkOut was the brainchild of GE's former CEO, Jack Welch and Jim Bowman, the head of the Crotonville learning center at the time. The method emerged in the late 1980s. Welch was dismayed at supervisors and employees who were telling him at training sessions that they liked Welch’s ideas but didn’t have the power to make things happen (Bunker \& Alban, 1997, p.170). The Work-Outs were designed to overcome the stiff joints of bureaucracy. They were led by teams of internal and external consultants, conducted off-site, and typically involved 100 to 200 employees crossing functions and positions. Part of the success, Bunker and Alban (1997) have suggested, appeared to be Welch's presence at these meetings:

Rumor has it that if the workers' recommendations were reasonable and the upper-level manager procrastinated or balked, Welch would bang his fist on the table and say, "Sounds good to me. Let's do it!" Whether this story is true or not, what is true is that 
Welch's presence brought strong support for the process and sent a clear message to the decision makers. (p. 171)

The Work-Out eventually became an internalized process within GE. A book (D. Ulrich, 2002) is currently available that details the process.

Another method emerged in the 1980s out of a training engagement for Ford (Bunker \& Alban, 2006). Ford had asked Dannemiller, a student and colleague of Lippitt, to "train Ford middle managers to be more proactive” (p. 7). She refused. Dannemiller thought the training was destined to fail because "the Ford system did not encourage that kind of behavior" (p.7). Dannemiller said she would take on the engagement if Ford would let her take 500 managers from all three levels of management to an off-site meeting for a week. By assembling such a large number of people at one time, Dannemiller's method demonstrated that an entire organization or division "could work on the same issue together and make decisions that would stick and could be immediately implemented” (p. 7). The method was initially called Real Time Strategic Change, is currently known as Whole-Scale Change (Dannemiller Tyson Associates, n.d.). World Café created by Brown (2005) and Open Space Technology by Owen (1997) are also well known large group methods. The $21^{\text {st }}$ Century Town Meeting was developed by AmericaSpeaks as a method developed specifically for town hall meetings on public policy issues.

\section{Origins of AI summits}

The AI summit is modeled after Weisbord and Janoff's (2010) Future Search conference format. But it "breaks new ground by stressing the relational nature of innovation and by highlighting the power of the positive to unleash extraordinary organizational performance" (Ludema et al., 2003, p. 20). AI summits differ from Future Search in three ways. First, summits

tend to be larger in scale. A typical Future Search involves 60 to 100 people, whereas an AI 
summit usually engages hundreds, sometimes thousands of people (Ludema, Whitney, Mohr, \& Griffin, 2003; Weisbord \& Janoff, 2010). Second, activities are structured differently. Future Search goes through five "sessions"-focus on the past, focus on the present, focus on the future, discover common ground and action planning. Activities include mind-mapping around timelines and trends, future scenario development, and planning around common ground statements. AI summits begin with a one-on-one peak experience interview, then move through the 4Ds through activities such as group discussion, skits, possibility statement design, brainstorming, rapid prototyping, and business plan development. Both methods take advantage of small group activities, large group report-outs and voting schemes to select themes to focus on (Ludema et al., 2003; Weisbord \& Janoff, 2010). The most important distinction is that AI summits selectively focus on positive experiences while Future Search “accepts all experiences as relevant” (Weisbord \& Janoff, 2010, p. 12).

The origins of AI summits date back to the mid-1980s when Cooperrider and two fellow graduate students at Case Western Reserve University experimented with large group methods in strategic planning. They brought together 350 partners of Touche-Ross Canada to take part in a “fully participatory, open, dialogical” roundtable to develop strategic plans. Through this experience they learned the power of full participation in crossing the "generational divide” (p. 14) among organizational members. Storytelling and creating images of the future were two other aspects of the roundtable that left an impression (Ludema et al., 2003). This was followed by a leadership development program funded by the US Agency for International Development, which brought together 30 to 100 executives at a time to engage in the AI process. In 1994, a group of AI practitioners tested an idea to bring entire organizations to the table. Working with the international development organization, Christian Reformed World Relief Committee 
(CRWRC), they designed AI meetings that blended Future Search with AI. They were called “Appreciative Future Search Conferences” (p. 16).

According to Ludema et al., the word "summit" replaced the name of the conference format when Cooperrider and Whitney were involved in the United Religions Initiative (URI) from 1995 to 2000. URI was an initiative to promote interfaith cooperation. The summit format was used for regional and global summits of between 100 to 250 people in order to develop a charter. This culminated in a global summit in June 2000, for the signing of the charter. Ludema and his colleagues wrote that they learned through this process, three lessons. First, that appreciation can dislodge certainty. Second, a good AI interview guide can allow "people to anticipate the entire summit within the first hour or so of the four-day meeting” (p. 18). They called this a "holographic beginning” (p.18). Third, “leadership levels the playing field” (p. 19). By this they mean that leaders join in as peers, as fellow inquirers.

\section{Key success factors of AI summits}

Ludema et al. (2003) have written that there are six factors that contribute to the AI summit approach's effectiveness. Summits were quicker at enabling change, better at building organizational confidence, provided broad and immediate access to information, promoted a “total organization mindset," inspired action, and gave a means to sustain positive change (p. xiii). These are generally consistent with the findings of Powley et al. (2011), who analyzed AI summits held at the US Navy. They are benefits derived from the structure of an AI summit which puts the whole system into one room for multiple, consecutive days, concentrated on a common purpose and tasks. Powley et al. were focused on how the AI summits structure conversations, a dialogical perspective. 
The authors proposed three design principles for successful democratic organizing: normative consciousness, holistic collegiality and communal conviction. Normative consciousness "is a practical awareness of oneself in relation to others" (p. 74). The physical presence of so many organizational members in one place at one time heightens an awareness of relatedness. Holistic collegiality refers to a cooperative environment where people are aware of the connectedness of their micro-level interactions to the macro-level issues of the organization, "giving each person an opportunity to experience a sense of efficacy in relation to others and the organization" (p. 76). Communal conviction is "a sense of commitment to the organization and its future well-being” (p. 76). Individuals willingly engage in conversations about substantive issues, thereby enhancing intrinsic motivation and a willingness to commit.

In the minds of the authors, the key differentiating factor of an AI summit as a forum for strategizing is the democratic nature of its activities. Powley et al. noted a general trend in organizations of a more participative form of management. Employee stock options, open-book management, and an emphasis on teamwork are some of the examples they gave as evidence of this trend. "There is no question that we are in the participative era of management and leadership. Yet at the strategic level, we seem equally rooted in the hierarchical mode of decision-making and action taking” (p. 67). The AI summit is a democratic and participatory method which makes it "possible and worthwhile to bring everyone into the inner circle of strategy” (p. 69). Although some dialogic practices for involving multiple stakeholder groups exist, "these interventions, when attempted, generally encourage and support the voices of all participations up to the point of recommending action" (Emphasis in original, p. 69). Ultimately, "a senior sponsor or other organizational leader decides which proposals to legitimize and which to set aside” (p. 69). Indeed, the authors warned that AI summits can at times backfire. They 
wrote, "a short-lived Summit experience may in fact discourage organization members from truly participating in post-Summit work groups” (p. 79).

Powley et al. cited research in small groups that linked dialogic participation to team outcomes (eg. Losada \& Heaphy, 2004). This research generally demonstrated that the issue of voice mattered in groups such that employees felt more ownership towards outcomes they had a hand in designing and monitoring. This is consistent with Lewin's wartime experience in trying to change food habits (Weisbord, 1987). Procedural justice also mattered. Kim and Mauborgne (1998) have argued that "when people feel their strategic decision-making processes are fair, they display a high level of voluntary cooperation” (p. 323). Powley et al. were blunt: "Leaders should not hold a Summit if they fundamentally do not wish to expand the involvement, participation, and discretion of employees” (2011, p. 78).

Democratic organizing can be a challenge for organizations like the military that depend on a command-control structure. Powley et al. proposed the AI summit format as a method for achieving this goal without compromising the necessary structure. A longitudinal study observing the process and outcomes of two AI summits at the navy showed that the summits were useful for creating and strengthening informal ties that cut across organizational silos.

In the comparative study by Bushe (2010) of eight sites in a Canadian school district, all conducted an AI summit. Two affirmative questions were chosen for the intervention: "What do educators do that create exceptional learning experiences?" and "What choices and options offered in educational settings most enhance learning?” (p. 10). The purpose of Bushe’s study was to determine what contributed to differences in the levels of change in the following year. Four sites had transformational outcomes (as defined by clear and compelling changes in normative routines), two had incremental outcomes and two experienced no change. The factors 
identified in the study were "how generative the inquiries were, how well the Discovery phase was managed and the quality of Design statements that came out of the summits” (p. 7). Each summit lasted two days with participants ranging from 50 to 100 . The Discovery phase was conducted prior to the summit. Technically, the summits only went through the Dream and Design phases during the summit, as the bulk of the processes for Destiny happened after the summit ended. Therefore, of the three factors that contributed to the difference in change outcomes, at least one was not part of the summit activities. The Destiny phase commenced at the summit but the communication of the results differed by different sites. Bushe noted that "many of the design statements and commitments to action faded with time" (p. 22). Whether the Design statement would have mattered as much had the summit had more time to devote to the Destiny phase remains an open question.

Bushe’s study also raised another important point. "It is probably significant that the two sites with the highest levels of morale and pride prior to the AI were the two that experienced only incremental changes” (p. 19). Bushe discussed this in the context that sites needed to have some level of shared pain for there to be transformational change. The incremental sites did not transform "because stakeholders were pretty happy with their leaders and with their school" (p. 22). Bushe raised these points to highlight "that it is inaccurate to say that AI is not concerned with solving problems” (p. 22). The term transformation implies a dramatic change, in this case, normative changes in organizational routines. As the cliché goes: “Don’t fix what isn’t broken.” More insights into the AI process might be gained if sites that were already thriving prior to the intervention were evaluated by measures other than the transformation of existing norms. 


\section{Towards AI as a strategizing practice}

The 2011 article by Powley et al. is the only one on AI that has been published in the journals of the Academy of Management (AOM). It appeared in the Academy of Management Executive, a peer-reviewed journal more oriented towards practitioners. It is interesting to note that while the content of article is mostly about the benefits of admitting a wider set of stakeholders into the inner circle of strategy, the title acknowledges AI's OD roots: "Dialogic democracy meets command and control: Transformation through the appreciative inquiry summit” (p. 67). During the proceedings of a symposium on the future of OD at the annual AOM conference in 2012, Burke reiterated the views he expressed in his article in 2010 that OD has become too preoccupied with the concept of change. This is the article in which he set off to say that "perhaps arguably" there had been no innovation in OD since AI. He wrote that "the failure rate for organization change efforts is around 70\%," with rates even higher for mergers and acquisitions (p. 144).

Burke was one of the invited panelists of a symposium including OD heavyweights like Schein, a pioneer in the study of organizational culture. Burke pointed out that OD has become very knowledgeable and adept at loosening the tightly coupled structures of bureaucratic organizations. Conversely, the field knew very little about how to deal with "loosely coupled" structures. Burke suggested that OD needs to go beyond the idea of "managing change" if it is to be relevant in a world in which new forms of organizing such as virtual organizations and teams are emerging.

The US Navy is a prime example of a tightly coupled organization. Powley et al. demonstrated the utility of AI summits for enabling democratic organizing in a command-control organizational structure. One of the key characteristics identified by the authors was the AI 
summit's ability to temporarily suspend its organizational routines and realities. This aspect of AI summits should hold regardless of how tight or loose the underlying structures may be. As part of the strategizing activities and practice (SAP) literature, Hendry and Seidl (2003) have developed a concept called "strategic episodes" that encapsulates the mechanism necessary for organizational processes of strategic change. The switching of contexts from the operational to the strategic, the temporal features of the episode, the choice of participants, and the reconnection back to the organization's ordinary routines are some of the key elements of a strategic episode. The authors posited that "strategy presents two distinct faces" when seen from a sociological perspective.

On the one hand, strategies serve to structure, organize and give meaning to the complex operations of business organizations.... On the other hand, the discourses of strategy and the role-definitions of strategists are very largely concerned with change. Strategy, for practitioners as well as academics, is explicitly concerned with the future, and with how this might differ from the present: with what "should be" rather than what is. (pp. 176177)

This description of strategy is a very good fit for the practice of AI. AI aims to give new meaning to organizations by using a positive lens, and develops an image of a preferred future. Because so many of the organizational members are personally involved in the development of the strategy, more people are likely to buy in and commit to action. Jarzabkowski and Seidl (2008) applied the concept to an analysis of strategy meetings at a university. Their findings suggested that a strategy meeting can stabilize the strategic direction of an organization, especially if the organization is "loosely coupled" like a university. In other words, strategic “change” may, in some organizational contexts, denote a change from flux to stability.

In the context of strategic management, scholars in the SAP research stream take a more constructivist approach to strategy making (Grand, Rüegg-Stürm, \& von Arx, 2010). Strategy is defined "as a situated, socially accomplished activity" (p. 70). Practice is considered a both "the 
situated doings of the individual human beings (micro) and to the different socially defined practices (macro) that the individuals are drawing upon in these doings” (Jarzabkowski, Balogun, \& Seidl, 2007, p. 7). The actions and interactions of people as they accomplish that activity is the primary focus of inquiry. The research stream is relatively new, consisting mostly of European scholars. At AOM, SAP remains an "interest group" that complements the work of other divisions like organizational behavior and organization management theory.

There are some notable gaps in the SAP literature that a study of AI summits will likely fill. Jarzabkowski and Spee (2009) identified that there has only been one study that looked at the impact of external practitioners on strategy making. External practitioners such as consultants, regulators and special interest groups certainly impact strategy, but "these interactions have been widely neglected in empirical strategy research so far” (p. 79). In addition, conferences have also been understudied. The most detailed and comprehensive study of the impact of conferences has been by Garud (2008), who examined how academic conferences affected innovation in the hearing device industry. These academic conferences were attended by scientists from device manufacturers with vested interests in trying to persuade the scientific community to adopt particular scientific models over others. Jarzabkowski and Seidl (2008) looked at the role of strategy meetings at a university with regard to their effect on strategic orientations. Gustavsen and Engelstad (1986) reviewed how work-life reform can be affected by democratic dialogue in conferences. To date, no large group methods of collective strategizing have been studied from a social practices perspective.

In this study, I extend the concept of strategic episodes to AI summits. An AI summit can be described as a strategic episode that extends over several days with the participation and engagements of large numbers of stakeholders from both within and without the organization. 
One of the purposes of AI is to generate organizational knowledge that can stimulate innovation. In the corporate world, AI has primarily been used in hierarchical organizations with tightly coupled structures. This study, in contrast, was inspired by my participation in a summit conducted by a relatively young, fast growing, entrepreneurial automotive company. What I experienced felt different from the descriptions of AI summits as a change intervention. I situate AI summits as a strategizing practice and ask: How and why does an AI summit, as a whole, generate and possibly accelerate organizational knowledge creation?

To answer this question, I propose an analysis of AI summits using Luhmann's social systems theory, upon which the notion of strategic episodes is based. Following an overview of the methodology used for this study (Chapter 4), I devote two chapters to explain the two theoretical lens I will be using. These chapters introduce readers to the radical systems theory that underlies the analysis. In Chapter 5, I explain the concept of autopoiesis (self-reproduction), a theory that has had an enormous impact on systems theory in general, and on Luhmann's social systems theory in particular. Autopoiesis was developed by the Chilean biologists Maturana and Varela in the 1970s as a biological theory for explaining cognition and living systems. It radicalizes and extends general systems theory by positing that living systems are operationally closed but interactionally open. The core ideas are complex and counterintuitive for those of us who take open systems theory for granted, but it is crucial to understanding Luhmann's social systems theory. I will also briefly review how Luhmann's theories are being applied to the study of organizations. 


\section{Chapter 4 Methodology}

\section{Overview}

The purpose of this study is to develop an alternative conceptual framework for understanding how and why appreciative inquiry summits function as a system for organizational knowledge creation. The goal is to build theory rather than to test the validity of an existing theory. I use a case-study research design to facilitate theory-building and to identify illustrative examples of the propositions that have been developed.

In the discipline of management, case studies have become a widely accepted research method for building theory, especially for studies of organizational processes. A case study is a type of qualitative research design. Qualitative methods generally seek to describe and explain rather than provide empirical evidence supporting specific theory-based hypotheses and claims. Qualitative methods are appropriate for studying phenomena that are not easily quantifiable (Yin, 2011). Processes by their very nature are difficult to quantify. In an article on strategies for conducting process research, Langley (1999) cautioned: “Process data is messy” (p. 691). Process data often deals with the intangible assets of an organization, the so-called soft side of the business like people’s thoughts, interpretations, and relationships.

Process models are driven by stories of what happened (Langley, 1999). They typically consist of "events, activities and choices ordered over time” (p. 692). Such characteristics render process data from organizational settings “difficult to analyze and manipulate” (p. 692). Consequently, process research does not try to explain organizational behavior through models of variance, in which a difference in an independent variable X (e.g. strong leadership) might account for the variance in the dependent variable Y (e.g. profits). Rather, a process model seeks 
an explanation based on how and why events, activities and choices lead to an outcome. The conceptualization of events and pattern detection are important in analyzing data.

Case studies are a good fit for research in which how and why questions are being asked of a contemporary event over which the researcher has little control (Yin, 1984, p. 20). In other words, they are useful for studying processes in the context within which they unfold. This applies to the current study which seeks to understand the organizational knowledge creation processes in the case of one specific AI summit; the researcher essentially has no control over the summit itself. Case studies are often used for exploratory research such as this one, when there is little or no existing theory. The preceding chapters demonstrated how conventional theories do not adequately address how AI creates organizational knowledge. Strategy workshops and conferences have been underexplored by scholars both theoretically and empirically, and the few existing studies also relied on a case study design.

In this study, I probed the activities of a single AI summit. Although a comparison of multiple cases can lead to more robust, generalizable findings, the exploratory nature of this study justifies the use of a single-case design. The research question asks the question of how and why an AI summit generates organizational knowledge from a systems perspective. A systems perspective requires one to look at the phenomenon of interest as a whole that is different from its parts. "The performance of a system is not the sum of the independent effect of its parts; it is the product of their interactions" (Gharajedaghi \& Ackoff, 1985, cited in Patton, 2002, p. 121). The foundational question revolves around the "how" and the "why" a system as a whole functions the way it does (Patton, 2002). This assumption is consistent with Luhmann's social systems theory, which is grounded in a systems perspective. 
The study takes an inductive and iterative approach to theorizing. At the early stages of this research during the pilot phase, I was planning to study the impact of the psychological state called "flow" (Csikszentmihalyi, 1990) on the outcomes of an AI summit. Flow is a state in which one is fully absorbed in the task at hand. It has been linked to optimal performance in individuals. However, when I actually participated in a summit conference as part of the pilot study, I was struck by the extent to which knowledge was made explicit, shared and combined into new knowledge, which then formed the basis for further action.

The presence of external stakeholders was also extremely important. My participantobservations from the summit shifted my focus to organizational knowledge creation. I began theorizing by drawing upon the organizational knowledge creation theory proposed by Nonaka and his colleagues (Nonaka, 1994; Nonaka, Toyama, \& Konno, 2000). These findings were presented to the sales leadership team who sponsored the summit. Nonaka's theory seemed to be in congruence with the overall dynamics that appeared to be driving the summit in terms of tacit to explicit knowledge conversion. However, on closer scrutiny, the theory was insufficient in explaining the specific social practices and activities at a summit. I then looked at the literature on organizational knowledge creation that was more grounded in Maturana and Varela's theories of cognition. In the next iteration, I shifted to Luhmann's social systems theory to develop a conceptual model and propositions.

After familiarizing myself with Luhmann's social systems, I went back to the data I had collected, analyzing the data for illustrative examples of the conceptual model I had developed. The study is inductive and iterative in its theorizing. It is important to note that it does not take a grounded theory approach to theorizing (Glaser \& Strauss, 1967). Grounded theory consists of a specific, research method, which involves systematic procedures of coding and categorizing 
(Patton, 2002, p. 127). In its purest form, grounded theorists begin with no presupposed theory. The empirical data grounds the theory. In contrast, this study tries to build theory not only by extrapolating from the empirical data, but also guided by pre-existing theories from neighboring domains.

\section{Sampling}

The sampling strategy for this study was opportunistic. I had taken a course on appreciative inquiry by Cooperrider in the spring of 2010 at the Drucker School of Management as part of my requirements for an MBA degree. I approached Cooperrider about my research interests in the AI summit methodology, and in January, 2011, he offered to introduce me to a mid-west company that regularly conducted these summits for visioning and strategic planning purposes. Cooperrider was a consultant to this company, and was planning to be facilitate an AIbased sales summit in February for this company. The company, TireCo—a pseudonym— distributed tires to car dealers in the US and Canada. The AI approach to organizational development was an integral part of their growth strategy, and it had been conducting AI summits on a regular basis for approximately five years.

The Chief Sales and Marketing Officer (CSMO) of TireCo was the sponsor of the February Sales Summit. She had been working with Cooperrider for more than 10 years, and is considered one of the experienced practitioners of AI. In her previous job at a major trucking company, she had organized and executed dozens of summits. She immediately approved my request to participate in the 4-day summit in the mid-west as an external stakeholder. I was required to be a full-participant in the conference and not an observer. I paid for travel and accommodation, but all conference expenses for materials and meals were paid for by TireCo. In 
return, I committed to writing a post-summit report (about 5,000 words) about the conference, which was submitted to TireCo’s sales organization in April, 2011.

I observed and participated in the February AI summit as an external stakeholder in the capacity of a graduate student conducting a pilot study for her dissertation research. One of the goals of the pilot study was to determine how flow might be measured, especially in the group setting of an AI summit. Prior to my participation, I had not realized how often the group configurations changed during a summit. In addition, the aspect of knowledge creation appeared far more significant than the literature had suggested. Subsequently, the research question was changed to reflect these observations. The revised research question focused on how and why the activities of an AI summit create organizational knowledge. Institutional Review Board approvals were sought and provided based on the revised research question.

\section{Key characteristics of the Sales Summit}

A closer analysis of the TireCo summit revealed five major characteristics that benefit the study. First, the summit falls within the parameters of a "regular" summit. AI summits come in a variety of shapes and sizes. They can be as short as one or two days by selectively focusing on a particular part of the 4D cycle. They can involve a dozen people on site at the organization, or tens of thousands of people by utilizing virtual conferencing technologies. TireCo's summit was organized very much in line with the practices outlined in Ludema et al.’s (2003) handbook for practitioners on running AI summits. The summit involved about 400 stakeholders of which about one in ten were from outside the organization. A steering committee conducted the planning for the summit, including the choice of a topic statement and the selection of participants. The summit went through the entire 4D cycle over four days. The activities for each phase were also standard, starting from high point moment paired interviews in the Discovery, 
and ending with the presentation of business or action plans in the Deployment. A 43-page workbook was printed and distributed to the participants. The summit relied on self-managed group activities in which the participants themselves, appointed facilitator roles such as timekeeper, recorder and presenter. The overall summit was facilitated by one external consultant.

Second, the summit method is a routine business practice for strategy development at TireCo, not a novel, one-time intervention for transformational change. Appreciative inquiry is a standard business practice that is embedded into their business planning cycle. TireCo is an entrepreneurial company founded in 1999. Despite the challenging market environment of the US auto industry, the company has experienced sales growth of nearly $40 \%$ a year on the heels of an innovative new business model. About five years prior to the Sales Summit, TireCo put together a new management team and recruited executives who had been working at a Fortune 500 trucking company based in the mid-west. The trucking company was one of the early adopters of the AI method. The management team incorporated the AI method for strategizing purposes. TireCo had implemented AI summits in previous years to create a set of guiding principles and values for the company, and to generate a strategic roadmap for the future. Although TireCo executives talk about the need for constant, transformational change, the explicit purpose of this particular Sales Summit is strategic planning. The summit was held in the larger context of positive business results. It is therefore is different in nature from some of the early, documented cases of AI summits which often involved larger, more established companies that were using $\mathrm{AI}$ as a means for breaking out of stagnation or conflict through transformational change.

Third, the summit method had buy-in from multiple levels of the organization because it is an ongoing practice with demonstrated results. The company's leadership, including its two 
founders, fully supports the AI method. Buy-in for the method exists among line level management and employees as well, since many of those who have been at the company longest have experienced an AI summit and seen the results from those summits. The AI summit methodology is well aligned with TireCo's organizational culture. For example, one of the guiding principles of the company is fairness. This is highly consistent with the democratic principles of organizing that are foundational to AI summits. At the same time, the summit has not become so rigid that it has become merely a ritual. A board meeting for developing corporate strategy, for example, at some corporations can lose its practical value when the business practice has more meaning as a ceremony or ritual. TireCo has had to hire at a rapid pace to keep up with accelerating sales. As a result, a significant proportion of the Sales Summit attendees were relatively new to the company, and for them, the AI method is novel. For those newcomers, the summit format itself serves to reinforce the open-book culture that TireCo leaders are promoting.

Fourth, TireCo's summit is run and facilitated by the most experienced practitioners of AI, and can be considered a best practice in AI summit execution. The main internal "owner" and sponsor of the Sales Summit process - the chief sales and marketing officer-is an expert in AI. She has been working with Cooperrider for many years, and has directly supervised dozens of summits, making her one of the most seasoned practitioners of AI summits in the world. Cooperrider himself, is the external consultant facilitating the Sales Summit. Cooperrider is a cofounder of the AI approach, and continues to be considered the foremost expert in AI. Since TireCo has conducted several summits before, the company has procedures, positions, and tools in place to facilitate the smooth execution of the summit. Nearly $80 \%$ of the employees at the time attended the summit in the previous year and have first-hand experience of the process. 
Significant financial resources were committed for implementing the summit as well. The conference was held at a luxury hotel in the downtown area near TireCo's corporate office, using the main ballroom for the plenary session, and many of the adjacent meeting rooms for breakout sessions. Hundreds of participants were flown in from across the country. The conference was conducted from Tuesday to Friday, requiring accommodation from out-of-town participants for at least four nights. The entire proceedings for the plenary session were recorded by a professional video production crew. A graphic artist was hired to graphically record the key point of the conference in real time.

Finally, the summit also includes events that are not purely strategizing activities, allowing for better observation of the oscillation between strategic and operating routines.

The Sales Summit also included sessions that were not part of the AI summit. For example, the morning of the second day was devoted to education and training sessions. Recognition dinners were held in the evening to honor the best performers of the sales organization. Other social events encouraged networking among the sales organization. Breakfasts and lunches often doubled as an unofficial space for conducting business meetings. Breaks between the summit activities were often used to conduct day-to-day operations. This meant that a given individual would go back and forth between strategizing, networking and operational activities, offering an opportunity to study how such oscillations affect knowledge creation.

The sampled case also has weaknesses. The summit focused specifically on the sales organization rather than the business as a whole. Roughly half of the company's employees participated in the conference, with representation from all departments but skewed heavily towards sales and marketing. External stakeholders mainly consisted of TireCo's customers such as dealers and auto manufacturers. Suppliers such as tire manufacturers, software vendors and 
transportation companies were not represented, possibly because a separate summit had been organized the week after to address the supply chain. As a result, the Sales Summit did not represent the whole organizational ecosystem. In addition, since this study developed out of a pilot study involving a single researcher-myself, I could only observe and participate in the activities of one group configuration at a time. These issues will be addressed more fully in the next section on data collection. Despite these shortcomings, the paucity of existing empirical and theoretical research on the strategizing activities of an AI summit means that this study will likely make a contribution to the literature.

\section{Data collection}

Data was collected in two stages. In the pilot study phase, I collected data from three sources: participant-observation, informal conversations, and documents. I was a full participant of all of TireCo's activities during the four days of the Sales Summit, including all of the summit activities and most of the corporate events (training, socials and recognition dinner). Detailed notes were taken of my observations, including my comments related to reflexivity. I did not keep a separate research journal on my reflections. Instead, I recorded observations of reflexivity and possible bias directly into my observation notes. I also had many informal conversations during the summit activities, breaks and at social events. I kept notes of the conversations that I thought might have implications for my research. I also exchanged emails with some of the participants after the conference. Prior to attending the summit, I conducted a document search on the Internet. I collected data from the company's website, as well as news databases to gather published news articles about the company. TireCo also sent me emails after the summit regarding post-summit activities. Some of the data collected was used to write a 5,000 word post-summit report which was submitted and distributed to the key sales executives at TireCo 
including the chief sales and marketing officer. The report was a subjective account of the summit proceedings written in a journalistic format.

During the pilot study, I had been reading Polanyi’s (2009) seminal book on tacit knowing, The Tacit Dimension as well as Bohm's (1996) book On Dialogue. These two books had a profound influence on how I approached and thought about the summit, and precipitated a shift in the topic of interest towards knowledge creation. A more thorough literature review on both appreciative inquiry and organizational knowledge creation was conducted, and the research question was revised to reflect the shift in focus. Permission to collect data was obtained from the Internal Review Board in September, 2011, on the basis of the revised research question.

The second stage of data collection began shortly after IRB approval. The additional data collected consisted of video footage from the Sales Summit, interviews, and additional documents from the Sales Summit. This data was collected during a visit to TireCo's Cleveland headquarters for 3 days in October, 2011. TireCo provided me with approximately 15 hours of unedited video footage from all four days of the plenary session of the Sales Summit. The footage came from one of the three cameras, Camera C, which recorded the speakers on stage. Audio from speakers on the floor was also captured. All the video was time-coded. The High Definition digital video files were saved on a hard disk drive. This video was then converted into WMV file formats with time codes embedded in the footage, using Adobe Premiere. These WMV files were imported into nVivo, a qualitative analysis software package, and then manually transcribed.

During the November visit to TireCo, I conducted interviews with several TireCo employees and executives. All interviewees signed a consent form. The purpose of the interviews was to begin gathering data about the impact of the Sales Summit on the interviewees 
and the operations of TireCo. Notes were taken and in some cases, the interviews were recorded. I also delivered a presentation to TireCo's sales executives on the topic of the current study, including an overview of Nonaka's organizational knowledge creation theory. Although participant feedback was not officially recorded, the participants were supportive of the study, and genuinely interested in my take of $\mathrm{AI}$ as a system of knowledge creation. In addition, TireCo provided additional documents and artifacts from the Sales Summit. Digital files of planning materials including floorplans, master planning document, meeting notes, agenda, workbook, group configurations and presentation PowerPoint slides were obtained. I was given a photocopied set of the handwritten table notes from the group tasks.

Multiple sources of data will not only enhance the depth and breadth of the data, but also increase validity through triangulation (Yin, 2011). The video footage in particular, allows a robust way to validate observations made during my participant-observation. Since the video only recorded presentations and comments delivered at the plenary session, planning documents and table notes from the summit provide additional levels of detail about the composition of the groups, and discussions at the breakout session. However, the strategizing activities in table groups were not fully recorded. Observations from these sessions are limited to the notes I took during my participant-observation in the pilot phase. No data was collected to reconstruct what happened in the breakout sessions I did not participate in, except for the table notes recorded by the recorder, and the remarks made by the presenters in the plenary session. The breakout sessions are important from a group dynamics perspective. An ethnographic study of the microlevel strategizing activities at a summit would be incomplete without a comprehensive record of the breakout session. The temporal ordering of events is important in process research, and the breakout sessions represent gaps in the data set if the entire AI summit. In this study, I focus on 
the plenary session as the interaction system of interest, as it is only the plenary session in which all the participants of the summit are physically present. Although it is desirable for future studies to collect more data on the breakout sessions, for the scope of this current study, supplementing these gaps with my observations from the pilot study should suffice.

\section{Data analysis}

This study is theoretical in nature and does not aim to test an existing theory. Data was reviewed and analyzed in multiple phases to facilitate theorizing. In the first phase, I developed a descriptive, 5,000 word summary of the conference, based on the notes I had taken during my participant-observation. This exercise familiarized me with the data. These reflections, coupled with a literature review on AI, large group methods and organizational knowledge creation, enabled me to begin conceptualizing AI summits as a forum for creating new organizational knowledge. In the next phase, I focused on Nonaka's organizational knowledge creation theory as an alternative framework for explaining AI summits. I reviewed my notes to find illustrative examples of the theory. While it was relatively easy to find examples of Externalization and Combination, I found it difficult to operationalize tacit knowledge. I consequently went back to the literature on social systems theory to develop a conceptual model of AI summits from Luhmann’s social systems perspective.

Data was entered into a database created with the software package nVivo. The primary data source was the transcriptions from the 15 hours of video footage from the plenary session, supplemented with other data described in the previous section. I then looked for illustrative examples that demonstrate the insights gained by analyzing the structure of an AI summit seen through a social systems lens. As most readers will be unfamiliar with the theories of autopoiesis 
and Luhmann's social systems, the next two chapters will provide an overview of their core concepts and how they are being applied to organizational studies. 


\section{Chapter 5 Theoretical Lens: Autopoiesis}

\section{Empirical origins of autopoiesis}

The empirical roots of autopoiesis can be traced to experiments Maturana conducted on vision in the 1960s. Maturana taught biology at the medical school of the University of Chile in Santiago while pursuing research in the neurophysiology and neuroanatomy of vision. Varela had been his student. For a while, Maturana experimented on frogs and pigeons without ever questioning the conventional view that there existed "an objective reality independent of the

observer”(Maturana \& Varela, 1980, p. xv). But when he and his fellow researchers began to examine color vision, they quickly found this approach "leads to deep trouble” (p. xiv). They could not seem to map the visible world of color in the external world onto the activity of the nervous system. They tried a new approach. Instead of correlating physical stimuli to the nervous system, they attempted "to correlate the activity in the retina with the color experience of the subject” (p. xv). Explains Maturana:

The new approach required us to treat seriously the activity of the nervous system as determined by the nervous system itself, and not by the external world; thus the external world would only have a triggering role in the release of the internally-determined activity of the nervous system. (p. xv)

This approach required them to "close off” the nervous system from its environment and treat it as if it were the whole system. Perception would be viewed not "as a grasping of an external reality, but as the specification of one” (p. xv). What this means is that it is impossible to distinguish perception from hallucination in a closed system. The color spectrum experienced by the nervous system would be essentially the same for visions of reality or hallucination. This approach is a radical departure from the tradition in biology of assuming there is "an objective reality independent of the observer”(p. xiv). Perception had to be studied from the inside out, 
"looking at the properties of the nervous system as the generator of phenomena, rather than as a filter on the mapping of reality” (Winograd \& Flores, 1987, p. 42). The goal was to understand how the retina and the nervous system participate in generating the color space. This radical approach enabled Maturana and his colleagues to map out the entire color space of the observer.

Previous experiments in vision by other researchers lent credibility to treating the nervous system as closed, autonomous, and self-referential. Maturana and Varela (1987) cited research by Sperry in the mid-1940s as an example. In this experiment, the eye of a tadpole is surgically rotated 180 degrees and left to develop into its mature adult state. The experimenters then cover the rotated eye so that the frog can only see with its normal one. The frog is shown a worm. Its tongue shoots out to capture its prey. When the frog can only see with its rotated eye, however, it consistently misses by a deviation of exactly 180 degrees. "The frog shoots out its tongue as if the retinal zone where the image of the prey is formed were in its normal position” (p. 125) noted Maturana and Varela. This could "be direct evidence that the operation of the nervous system is an expression of its connectivity or structure of connections and that behavior arises because of the nervous system's internal relations of activity” (p. 126).

Maturana felt he had made significant findings in his research on vision and perception, and began studying cognition as a biological phenomenon. In March of 1969, Maturana accepted an invitation from von Foerster-a physicist and a prominent figure in cybernetic theory— to speak at a conference in Chicago on the anthropology of cognition (Maturana \& Varela, 1980). The interdisciplinary nature of the symposium inspired him to reflect upon the broader implications of his research and to deliver a speech on the neurophysiology of cognition without talking about neuronal circuits. The following year, he published an essay based on his findings. 


\section{What is autopoiesis?}

What Maturana would propose represented a paradigm shift in the way we think of systems today. In traditional biology, living systems were viewed as purposeful, open systems that have inputs and outputs. Change came from the environment. Living systems respond to those changes based on its purpose. Open systems thinking was first proposed by the biologist von Bertalanffy (1969) in 1940. "The organism is not a closed, but an open system. We term a system 'closed' if no material enters or leaves it; it is called 'open' if there is import and export of material” (p. 121). The theory’s scope was expanded from physics and biology into a general systems theory (von Bertalanffy, 1969). The idea that systems are open and that the environment can change a system has become so pervasive that we take it for granted. Porter's five forces framework for industrial analysis is more or less exclusively about how the environment influences a company’s competitiveness. “Traditional approaches to organization theory have been dominated by the idea that change originates in the environment” (Morgan, 1997, p. 253).

Maturana's experiments on vision led him to the conclusion that living systems are closed, not open, in their organization. In the early 1970s, Maturana expanded those ideas with his student Varela into a theory of cognition that rigorously explained what attributes make living systems living. "Our proposition is that living beings are characterized in that, literally, they are continually self-producing” (Maturana \& Varela, 1987, p. 43). Living systems are systems of interactions, they argued. These interactions are not organized in the linear mode of inputs and outputs, where a certain input leads to a certain output. Instead, the units of interactions are "all organized in a closed causal circular process” (Maturana \& Varela, 1980, p. 9). These systems of interactions maintain their circularity, independent of the environment; they are closed systems. The closed system's autonomous, circular, self-referential structure, enables 
it to reproduce itself on the basis of an ongoing production of its own components using the very components that itself produced. This process is called autopoiesis.

Autopoiesis is a word invented by Maturana and Varela. Maturana stumbled upon the Greek word poiesis while conversing with a friend who had written an essay on Don Quixote. His friend was analyzing Don Quixote’s “dilemma of whether to follow the path of arms (praxis, action) or the path of letters (poiesis, creation, production)"(Maturana \& Varela, 1980, p. xvii). The prefix auto was added. "We could not escape being immersed in a tradition, but with an adequate language we could orient ourselves differently and, perhaps, from the new perspective generate a new tradition” (p. xvii).

The formal definition of autopoiesis is rather intimidating. Maturana and Varela described autopoiesis in the context of living machines. An autopoietic machine (or system) is:

...a machine organized (defined as a unity) as a network of processes of production (transformation and destruction) of components that produces the components which:

(i) through their interactions and transformations continuously regenerate the network of processes (relations) that produced them; and

(ii) constitute it (the machine) as a concrete unity in the space in which they (the components) exist by specifying the topological domain of its realization as such a network. (Maturana \& Varela, 1980, pp. 78-79)

Maturana and Varela described this at the cellular level in The Tree of Knowledge, a book intended as an advanced introduction to their theory. A cell's molecular components are dynamically related to each other through a dynamic network of ongoing interactions, what biochemists call "cell metabolism” (Maturana \& Varela, 1987, pp. 43-44). What makes cells distinctive from other natural collections of molecular transformations (and hence, make them living) is their autopoiesis.

...this cell metabolism produces components which make up the network of transformations that produced them. Some of these components form a boundary, a limit to this network of transformations. (p. 44) 
This boundary is the cell's membrane; it is a product of the cell's metabolism. The membrane limits the cell's network of transformation (the cell's metabolism) from extending beyond the membrane. In this sense, the membrane is not only produced by the transformation network but also actively participates in the network by playing a functional role, so to speak. It is this special spatial arrangement (i.e. the membrane separating the cell from its medium) that prevents the cell's metabolism from disintegrating into "a molecular mess that would spread out all over and would not constitute a discrete unity such as a cell” (p. 46).

Open systems theory has conditioned us to hardly question the distinctions we draw between a system and its environment (Morgan, 1997). Maturana and Varela challenged the validity of system boundaries in open systems, because those boundaries are drawn by an external observer, not by the system itself. "The most striking feature of an autopoietic system is that it pulls itself up by its own bootstraps and becomes distinct from its environment through its own dynamics" such that the system and its environment become "inseparable" (p. 47). The system's dynamics produces a system's boundary which in turn produces the system's dynamics and so forth in a circular, self-referential manner. Unlike an input-output model, there is not beginning or end.

When self-referential systems couple to other self-referential systems, "a change in any one element can transform all the others” (Morgan, 1997, p. 254). This is reminiscent of chaos theory and the butterfly effect, in which a flutter of a butterfly's wing can generate a string of interactions that produce a hurricane weeks later (Gleick, 1987). Morgan used the honeybee to demonstrate the implications of autopoietic theory in analyzing complex systems. A honeybee is part of a chain of circular, self-referential relations. Its physiological system is coupled to a society of bees which is coupled to a wider ecology. Eliminating the bees changes the whole 
ecology because the bees are linked to the botanical system which links to other systems such as insects, animals, and people. I quote at length, as Morgan eloquently explains a crucial point:

We could attempt to understand such systems by drawing an artificial boundary between system and environment-for example, around the individual bee, or the society of bees, or the bee-flora-fauna system-but in doing se we breake the circular chain of interaction. An understanding of the autopoietic nature of systems requires that we understand how each element simultaneously combines the maintenance of itself with the maintenance of the others. It is simply not good enough to dismiss a large part of the circular chain of interaction as "the environment." The environment is part of the bee system, and the different levels are in effect coproduced. (Morgan, 1997, p. 254)

The implication of autopoiesis for thinking about change is not insignificant. Changes do not come from the environment. They come from "variations within the overall system that modify the basic mode of organization” (p. 254).

\section{Adaptation through structural coupling}

The ultimate aim of autopoietic systems is self-reproduction. "Their own organization and identity is their most important product” (Morgan, 1997, p. 253). When it loses its identity as a unified whole, the system disintegrates. Maturana and Varela had proposed the simple but powerful idea that "the essential characteristic of a living system is that it is a collection of components constituting a unity that can live or die” (Winograd \& Flores, 1987, p. 45) and therefore, "that exactly this simple property leads to the complex phenomena of life" (p. 45).

Maturana and Varela's (1980) theorizing culminated in the essay "Autopoiesis and Cognition” first published in 1973. "This small book is very large: it contains the living universe," proclaimed Beer (1980, p. 66), a prominent cybernetician who wrote the introduction to the essay when it was republished in book format seven years later. He explained:

The authors first of all say that an autopoietic system is a homeostat. We already know what that is: a device for holding a critcial systemic variable within physiological limits. They go on to the definitive point: in the case of autopoietic homeostasis, the critical variable is the system's own organization. It does not matter, it seems, whether every measurable property of that organizational structure changes utterly in the system's process of continuing adaptation. It survives (p. 66). 
There are two ways an organization can remain static and constant. Either the components themselves are held constant or the relationships between components are maintained. Autopoietic systems fall in the latter category. Autopoietic systems can be integrated into larger systems as parts without losing their autopoietic nature. Physical, autopoietic systems can be divided and analyzed as parts, but this "does not reveal the nature of the domain of interactions that they define” (p. 82).

The theory of autopoiesis invites the observer to see the system in its unity, not by its components. The way a system maintains its circularity (i.e. how the system organizes itself) can evolve over time. Maturana and Varela posited that living systems are closed, but they are by no means isolated. Nor do they claim that the structure of the system is fixed; a living system's structure is plastic and can change so long as those changes allow it to maintain its overall organization and identity. Autopoiesis assumes that living systems are inherently purposeless; there are no innate programs or projects being realized in and through them (p. 85). Nor do systems have any inherent role or function per se. These notions "are established by the observer and belong exclusively to his domain of description” (p. 86). Therefore, "the notions of purpose and function have no explanatory value in the phenomenological domain in which they pretend to illuminate” (p. 86).

An autopoietic system simultaneously tries to maintain itself while it maintains other unities that are structurally coupled to it. A particular living being exists "in a medium that constitutes the ambience in which it emerges and in which it interacts”(Maturana \& Varela, 1987, p. 95). The ambience has its own structure "operationally distinct from the living being” (p. 95). These two structures - the living being and the environment-interact with each other in congruence with their respective structures. They may trigger perturbations in each other's 
structure but importantly, neither the living being nor the environment can specify or instruct the structural changes in the other resulting from the interaction. A history of recurring interactions results in the structurally coupled systems to adapt their structures accordingly.

Autopoietic systems interact with other systems through its environment, just like systems in open systems theory. However, operationally, they are closed. Systems can structurally couple to one another in a circular manner, just like the dynamic feedback loops in open systems theory. The difference though, is that systems can only refer to itself. It is selfreferencing. Unlike open systems theory, the system produces the distinction between itself and the environment, not an external observer. The system produces its boundaries and distinguishes itself from the environment. It is this distinction that the system makes, that makes a system a system. Without that distinction, the system is no longer a unity and would collapse into the environment. The system can refer to the environment, but only on its own terms. Its references to the environment can never be accurate one-to-one representations. The environment might be described through language. Those descriptions are produced by the system and are therefore, self-referential.

A nervous system is autopoietic. "For the operation of the nervous system, there is no inside or outside, but only maintenance of correlations that continuously change”(Maturana \& Varela, 1987, p. 169). Furthermore, “in each interaction it is the nervous system’s structural state that specifies what perturbations are possible and what changes trigger them” (p. 169). The nervous system is recognized as a unified whole by virtue of its operational closure. Maturana and Varela objected to the popular metaphor of referring to the brain as "an information processing device” saying that not only is it ambiguous, "but patently wrong” (p. 169): 
...the nervous system does not "pick up information" from the environment as we often hear. On the contrary, it brings forth a world by specifying what patterns of the environment are perturbations and what changes trigger them in the organism. (p.169)

\section{Autopoiesis and human cognition}

Living systems are characterized by autopoiesis. Couplings on the second-order create unities such as metacellular systems and organisms. Organisms can further couple on the third order and generate new domains from which social phenomena can emerge. Maturana and Varela go on to describe communication, language, and cognition based on the theory of autopoiesis. When we observe organisms coordinating their behavior with one other, as observers, we define this as communication. "Biologically, there is no 'transmitted information' in communication" (p. 196). The notion of transmitting information is false because "each person says what he says or hears what he hears according to his own structural determination; saying does not ensure listening” (p. 196). Animals can communicate. Only humans though, have evolved enough to produce the phenomena called language. "The so-called 'language' of bees, for instance, is not a language. It is a mixed case of instinctive and linguistic behaviors” (p. 208). The stability of the linguistic behavior of bees "depends on the genetic stability of the species and not on the cultural stability of the social system in which they take place” (p. 208), and hence, do not constitute language.

Language is an ongoing process, perhaps better described as "languaging.” Language can radically modify domains of human behavior. For example, languaging "enables those who operate in it to describe themselves and their circumstances through the linguistic distinction of linguistic distinctions" (Emphasis in the original, p. 210). Self description, therefore, is a key feature of language. Distinctions made using language form webs of distinctions that give rise to meaning, observation, reflection, and consciousness. All these are social phenomena. The 
phenomenon of consciousness is one of the "unique features of human social life and its intense linguistic coupling” (p. 223). Maturana and Varela posited that phenomena such as selfconsciousness, awareness and mind take place in language, and therefore "take place only in the social domain" (p. 230) or in other words, "the realm of social coupling” (p. 234), and not something that is within our brains. They came to a radical conclusion, reminiscent of social constructionism.

Language was never invented by anyone only to take in an outside world. Therefore, it cannot be used as a tool to reveal that world. Rather, it is by languaging that the act of knowing, in the behavioral coordination which is language, brings forth a world. (p. 234)

Maturana and Varela's theory of cognition—knowing how we know—provided a biological case for social constructionism. "What biology shows us is that the uniqueness of being human lies exclusively in a social structural coupling that occurs through languaging” (p. 246). Language generated "the regularities proper to the human social dynamics, for example, individual identity and self-consciousness” (p. 246). It also generated recursive social dynamics that necessitated "a reflection enabling us to see that as human beings we have only the world which we create with others—-whether we like them or not” (p. 246).

\section{Artificial intelligence, autopoiesis and the birth of Google}

Maturana and Varela's theory of cognition has had less an impact in biology as it has in other disciplines. Winograd, a professor in computer science and artificial intelligence at Stanford University, wrote an influential book on the implications of autopoiesis for computer systems design in the 1980s. Winograd later mentored two students who went on to revolutionize

the world of information systems: Page and Brin, the founders of Google. Winograd was introduced to autopoiesis through his co-author, Flores. Flores was a former Chilean Minister of Economics and Finance, who "was instrumental in a large-scale project to apply cybernetic 
theory to practical management problems” (p. xii) in Chile. The project was implemented by Beers but never completed; Augusto Pinochet ousted Salvador Allende’s government in 1973 and the project was disbanded. Their book, Understanding computers and cognition, devotes a large portion towards explaining philosophical and biological theories including those of Heidegger and Maturana. In the preface to the book, the authors justify their approach as follows:

Readers with a background in science and technology may find it implausible that philosophical considerations have practical relevance for their work. Philosophy may be an amusing diversion, but it sees that the theories relevant to technological development are those of the hard sciences and engineering. We have found quite the opposite. Theories about the nature of biological existence, about language, and about the nature of human action have a profound influence on the shape of what we build and how we use it. (p. xii)

In their book, Winograd and Flores called for programmers to look at systems design in a new way. The authors criticized “descriptions of human thought as 'decision making' and language understanding as the manipulation of representations” (p. 178). They were deeply concerned "with the discourse and actions that are generated by a rationalistic interpretation of human action” (p. 178), especially since computers have a powerful impact "because they are machines acting in language” (p. 178). Referring to Maturana and his ideas that our cognitive systems have a plasticity which gives it the "power of structural coupling," the authors argued:

We cannot directly impose a new structure on any individual, but whenever we design changes to the space of interactions, we trigger changes in individual structure-changes to the horizon that is the precondition to understanding. (p. 178)

Winograd played a pivotal role in the development of the search engine that became Google. Page and Brin, developed the original search engine in his lab at Stanford. Page and Brin entered the doctoral program in computer science just as the World Wide Web was emerging. They began collaborating on a project to develop a search engine that could deliver 
high quality search results while keeping up with the exponential growth in web pages. Winograd was Page's dissertation adviser at the time. Although the developers of Google did not explicitly apply autopoiesis to its design, their PageRank system utilized the logic of the internal structure of the web, specifically its linking structure. This is a major break from previous search engines that were based on a content classification scheme that categorized web pages according to "high quality human maintained indices" (p. 1). Unfortunately, such systems are "subjective, expensive to build and maintain, slow to improve, and cannot cover all esoteric topics” (p. 1). They were also not that meaningful. "Anyone who has used a search engine recently, can readily testify that the completeness of the index is not the only factor in the quality of search results" (p. 3).

The PageRank system created massive maps containing hyperlinks. The authors explained:

These maps allow rapid calculation of a web page's "PageRank", an objective measure of its citation importance that corresponds well with people's subjective idea of importance. Because of this correspondence, PageRank is an excellent way to prioritize the results of web keyword searches. (pp. 3-4)

An inspiration for this design had been the citation mechanism used in academia. The more an article is cited, the more the author is considered important and relevant. Page noticed that the link structure of the web allowed Google's search engine to incorporate a similar logic. This is why their search results tend to deliver superior results compared to engines using categories or keywords in text to retrieve pages. Categorization imposes a structure onto the content and is limited in scalability. In autopoietic terms, the search engines at the time were essentially imposing an external logic —a search index created by people—onto a system that was closed, self-referential and reproducing itself based on the ongoing production of hyperlinks. In contrast, the PageRank algorithm looks at the context of the web page in relation to the whole 
system. The algorithms determine what interactions between pages are relevant and calculate a score that continually changes as more pages and interactions are added to the system. The resulting engine, later named Google, has become such a staple of our digital lives that “Googling” has become synonymous with searching for relevant information. Google’s artificial intelligence is transforming how humans acquire and interact with knowledge.

\section{Autopoiesis in organization studies}

The theory of autopoiesis is deep and complex. At first sight, it seems to complicate rather than simplify the already challenging task of dealing with a world of complex systems. Taking autopoiesis seriously requires us to acknowledge the closed nature of systems, and by extension, challenges the utility and validity of observations and analyses made by a detached, neutral, objective observer. This has real methodological and research implications for social scientists. Von Krogh and his colleagues (1994) pondered the consequences of adopting autopoiesis as the foundation for a new "corporate epistemology." Their essay appeared in The

Strategic Management Journal, one of the most influential journals in organization studies. It began:

Dear reader,

Please try to forget the reality you have previously constructed and let yourself be open to the signals this article carries. These signals are truly distinct from those in previous articles and books within the strategic management field. (p. 53)

In the essay, the authors proposed autopoiesis as an alternative lens to the cognitivist approach that had come to dominate strategic management theory. Citing Varela's work, the cognitivist notion of knowledge is one in which cognition is primarily characterized by “information processing and rule-based manipulation of symbols" (p. 57). In this view, "knowledge is abstract, task-specific and oriented towards problem solving” (p. 57). At the heart of cognitivism is a representationist view of the world; the goal is to create ever more accurate 
representations that correspond to a pre-given world. These representations are then stored in knowledge structures (p. 58). As I introduced earlier, autopoiesis rejects this representationist view of the world. "Knowledge is a component of the autopoietic (self-protective) process, it is history-dependent, context-sensitive and, rather than being oriented towards problem solutions, knowledge enables problem definition” (p. 58).

Von Krogh et al. assumed that knowledge is embodied in the individual, and therefore, "languaging is the nexus of organizational knowledge development" (Emphasis in the original, p. 63). They identified "knowledge connectivity"-how knowledge connects to other knowledges — as key to understanding organizational knowledge. They also emphasized the importance of the advancement activities of an organization. Conventional studies in strategy were oriented towards survival activities, such as market position, planning, and controlling. Advancement activities on the other hand, develop options for the organization. "Advancement emerges from knowledge development” (p. 64). Many companies do not have such practices in place. "There are few theories explaining the, limited knowledge on how to research them, and few outlets in which to publish” (p. 64).

According to the authors, strategic management simultaneously requires both survival and advancement activities. They go a step further and argued that "firms can be less different in terms of their survival activities and more different in terms of their advancement activities” (p. 65). Advancement activities include developing distinctions and norms, scaling knowledge, ensuring knowledge connectivity, and activities related to self-referencing and languaging. The research of such activities requires new methodology because the observer-independent paradigm is unacceptable in an epistemology based on autopoiesis. Von Krogh and his colleagues questioned the systems-distant observer paradigm, which ran "the risk of becoming 
less and less relevant to practice" because theorizing was becoming ever more self-referential within the closed domains of academia. They proposed methods such as ethnographies and action research as appropriate for studying the languaging aspect of advancement activities.

"Languaging in strategic management research means that researchers and practicing managers cospeculate, costudy, and cowrite” (p. 66) concluded the authors. Appreciative inquiry (AI) as a research method would fit this bill. But the AI summit method in particular, seems to go beyond the parameters set by von Krogh and his colleagues have laid out. There is no doubt an AI summit is an advancement activity. A question remains though, in one of the assumptions von Krogh et al. made about organizational knowledge. They assumed that individual knowledge scaled up to organizational knowledge. Nonaka's organizational knowledge creation model is certainly one way to explain the conversion from individual to organizational knowledge. But as I noted earlier, Nonaka's model is difficult to apply to AI summits because of the tacit dimension of personal knowledge. What I observe to be a tacit to explicit knowledge conversion is based on my self-referential interpretation of a particular summit. Another observer may interpret the same events differently. Furthremore, such an analysis would not be based on the system's internal logic.

A framework based on autopoiesis would require "that one must be able to give a precise description of the component production processes” (p. 56). Luhmann tried to do so for social systems and his theorizing culminated into a general theory of social systems. Application of autopoietic theory in organizational studies have mostly relied on a Luhmannian lens (See Bakken \& Hernes, 2003). In the next chapter, I will introduce the core ideas of Luhmann's social systems theory. 


\section{Chapter 6 Theoretical Lens: Social Systems Theory}

\section{Introduction}

In his book, Mind and Nature, Bateson (1979) chastised our choice of metaphors for describing and explaining mental phenomena. Words like power, tension, energy, and forces, all had a "strange physicalism” to them which in Bateson's view, reflected notions that were ancient and obsolete (p. 217). Cognition and behavior are phenomena that arise out of the biological domain. We unheedingly use words borrowed from physics to describe and explain social phenomena. Power, tension, energy and forces are staples in the linguistic domain of sociology and organization studies.

Maturana and Varela's (1987) concept of autopoietic systems gave us a theory for explaining the biology of mind and cognition. But they had serious reservations towards applying their theory to social systems. Autopoietic systems “are characterized by a circular organization of production processes that continually reproduce and replace the components necessary” (Mingers, 1995, p. 29) to maintain the system's unity and survival. To apply autopoiesis to social systems would require "a precise description of the component processes... and systems” (von Krogh et al., 1994 p. 56). The conventional view of social systems such as society and organizations is that they are made up of people. Clearly, society and organizations cannot reproduce people.

An early attempt to apply autopoiesis to organizations was by Morgan (1997), who chose autopoiesis as one of the metaphors to describe organizations in his book, Images of Organization. Morgan used autopoiesis in a metaphorical sense to give an alternative view of organizations as entities that are in "flux and transformation” (1997). Like Heraclitus' river, organizations and their processes never stand still; they are constantly changing. An autopoietic 
view of organizations looked very different when juxtaposed against other metaphors such as the organization as brain or prison.

Luhmann (1995) went much further. He spent much of his later career rigorously applying autopoiesis to sociology. He recognized autopoietic theory as "the current state of the art in general systems theory” (p. 11), and developed a theory of social systems around it. His innovation was to specify what a social system produced. Social systems produced communications. They were autopoietic systems that maintained their unity of organization through the ongoing production of communications. Organizations were conceptualized as a special type of social system, one that maintains itself through the ongoing production of decision communications.

Luhmann wrote over 50 books and several hundred articles during his lifetime (Seidl \& Becker, 2006). He died in 1998. Luhmann scholars like Seidl and Becker have written that he "is generally considered of equal rank and standard to the works by such prominent social theorists as Bourdieu, Giddens, Foucault and Habermas” (p. 10). The bulk of Luhmann's work has not been translated into English, however. One of his important works on organization theory Organisation und Entscheidung (“Organization and decision”) published posthumously in 2000 has yet to appear in English. He remains virtually unknown in the United States. Recently, scholars in Europe such as Baecker, Seidl, Becker, and Schoeneborn, have been actively publishing research applying Luhmann's theories to the study of organizations. For this study therefore, I will rely heavily on the work of these scholars that have appeared in English language books (Bakken \& Hernes, 2003; Seidl \& Becker, 2005b), and journals including Organization (e.g. Baecker, 2006; Mohe \& Seidl, 2011; Seidl \& Becker, 2006), Academy of 
Management Review (Kieser, 2007), and Organization Studies (Blaschke, Schoeneborn, \& Seidl, 2012; Jarzabkowski \& Seidl, 2008).

Similar to von Bertalanffy (1969), who generalized a biological theory into open systems theory, Luhmann abstracted the principles of autopoiesis and modified them into a general theory for explaining social systems. Luhmann was already a highly prolific and noted sociologist in his native Germany when he began contemplating the sociological implications of autopoiesis in the 1980s. Born in 1927, Luhmann began his academic career extending the work of Parsons, whom he met while studying at Harvard University in 1960 to 1961 (Seidl \& Becker, 2005a). In the early 1970s, he "quickly gained publicity as a relentless critic” (Knodt, 1995 p. xiv) of Habermas, a sociologist who represented the Frankfurt School of thought. Luhmann went on to develop his own "grand theory" by proposing a paradigm shift in sociology. He called for a "break with the structural-functionalism of Talcott Parson" (Knodt, 1995 p. xiv) and instead adopt "theoretical models developed in the biology of cognition and second order cybernetics” (p. xiv). This culminated in the publication of Soziale Systeme published in German in 1984, and translated into English in 1995 under the title Social Systems.

Luhmann (1995) claimed in his introduction to Social Systems that traditional sociology "adheres to the model of the classical authors" (p. 1) and has not linked to the developments in systems theory. He described what he saw as a "paradigm change" in systems theory that could greatly benefit the study of society. There were two moves that brought about this shift. The first was "to replace the traditional difference between whole and part with that between system and environment" (Emphasis in the original, p. 6). This move was led by von Bertalanffy who developed open systems theory. A closed system in this context was defined as a system "for which the environment has no significance or is significant only through specified channels” (p. 
7). Rather than looking at the difference between the whole and its parts, attention shifted to discerning different systems.

The second turn, argued Luhmann, came from “a surpassingly radical further step” (p. 8) in the form of theories of self-referential systems. He conceded there is no generally accepted theoretical foundation for such theories. "Enough is apparent, however, for us to assess the consequences for a theory of social systems” (p. 8). He was referring to the theory of autopoiesis. He explained:

The theory of self-referential systems maintains that systems can differentiate only by self-reference, which is to say, only insofar as systems refer to themselves (be this to elements of the same system, to operations of the same system, or to the unity of the same system) in constituting their elements and their elemental operations. (p. 9)

Given the constraints of only being able to refer to themselves, for systems to differentiate themselves they have to do the following:

Systems must create and employ a description of themselves; they must at least be able to use the difference between system and environment within themselves for orientation and as a principle for creating information. Therefore, self-referential closure is only possible in an environment, only under ecological conditions. (p. 9)

Everything that is attributed to the environment can only be introduced as a distinction between system and environment. "The (subsequently) classical distinction between "closed" and "open" is replaced by the question of how self-referential closure can create openness” (p. 9).

The resulting theory is more complex and nuanced. "One can now distinguish the system/environment difference as seen from the perspective of an observer (e.g., that of a scientist) from the system/environment difference as it is used within the system itself” (p. 9). Luhmann identified some of the "remarkable shifts" in general systems theory that this provoked, "from interest in design and control to an interest in autonomy and environmental sensitivity, from planning to evolution, from structural stability to dynamic stability” (p. 10). 
Luhmann tried to bring autopoietic theory into the realm of action systems. Some scholars like Mingers (2003), however, question the validity of applying autopoiesis to social systems. But Luhmann has emphasized that he was abstracting the principles of autopoiesis relevant to a general systems theory rather than adhering to them literally. One of the most important consequences was what Luhmann (1995) called "the radical temporalization of the element” (p. 11). An element is anything that comprises a system. An element is produced as a result of being used by the system (Luhmann 1997, pp. 65-66 in Seidl \& Becker, 2006, p. 16). Anything that is not used by the system for its self-reproduction is not an element. When appropriating the theory of autopoiesis to action systems such as organizations, the theory cannot hold unless it is taken as a fact that system elements have no duration. Elements of a system vanish as soon as the system produces them. This is not so in biological systems. Elements have a shelf life, no matter how short. Luhmann (1995) was saying that the constraint peculiar to a social system's autonomy is:

the fact that the system would simply cease to exist in any, even the most favorable, environment if it did not equip the momentary elements that compose it with the capacity for connection, that is, with meaning, and thus reproduce them. (p. 11)

Luhmann was conceptualizing social systems as meaning systems. Meaning dissolves no sooner than it appears. When meaning loses its ability to connect to meaning, a social system cannot maintain its identity and will cease to exist.

Luhmann's theorizing has been called radical not only for his application of a radical form of systems theory, autopoiesis. His work is sometimes characterized as radical constructivism, a form of social constructionism that "expresses the idea that all cognitions (ideas) are constructs of the respective cognitive system and do not in any way reflect any kind of external reality” (Seidl, 2005a, p. 23). Luhmann also assumed that systems exist. Though this 
may not sound radical, some theorists use systems exclusively as a construct or concept used for analysis. "The most narrow interpretation of systems theory as a mere method for analyzing reality is deliberately avoided” (1995, p. 120). Systems are real; they are part of our world. Without systems, "the social world disintegrates, as it is no longer possible to distinguish what is from what is not, from what is the system and what is the environment” (Bakken \& Hernes, 2003 p. 10). That does not imply that social systems are living systems. On the contrary, Luhmann drew a sharp distinction between meaning and life.

In Luhmann's hierarchy of systems (Figure 1), social systems and living systems are separate entities. They are distinguished according to their purpose: to give meaning or to give life. Since cognitive systems give meaning, they are not living systems either. Luhmann labeled the cognitive systems of people "psychic systems" and differentiated them from social systems based on "whether they use consciousness or communication as modes of meaning-based reproduction” (Luhmann, 2005a, p. 65). This scheme was intended for the observaton of systems, not as a scheme for the operations of systems. "This kind of approach is only usable only if we are prepared to accept its anti-Aristotelian premise that social systems, and even psychic systems, are not living systems” (Luhmann, 2005a, p. 65). In this study, I will substitute the expression “psychic” with "psychological” where possible to avoid any unintended, mystical connotations the word psychic might convey. 


\section{Self-referential autopoietic systems}

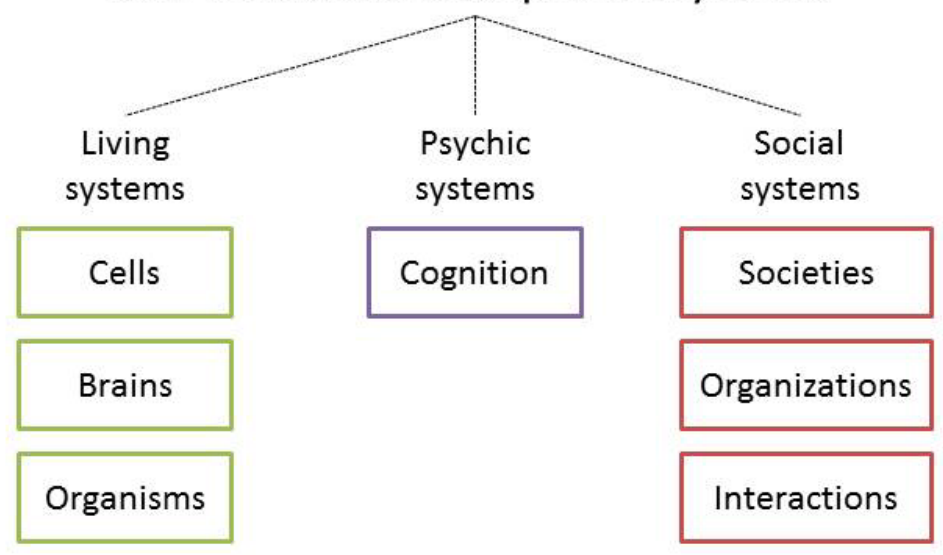

Figure 1. Typology of self-referential autopoietic systems. Adapted from Luhmann (1990, p. 2)

The clear distinction Luhmann makes between social and psychological systems, and as a consequence, social and pscyhological phenomena, is "the most striking" of his conceptual achievements, according to Seidl and Becker (2005a, p. 9). People do not make up an organization. People constitute the environment for organizations and vice versa. Constructs like intrinsic motivation, psychological safety, and the intent of an individual, cannot be employed to explain the system dynamics of an organization. These are constructs that apply to a specific individual's psychological system. The psychological system's operations are completely closed off from an organizaton's system, and cannot contribute any element in its operations. Perhaps even more counterintuitive but nevertheless important to note, is that the notion of a "person" or a "human being" does not exist as a systemic unity under Luhmann (Seidl, 2005a, p. 31). A person, in the world of Luhmann, is a "conglomerate" of psychological and organic systems. "In other words, 'persons' do not exist as such: they are not systems, but a construct of the social system” (pp. 31-32). 
The advantage of this conceptualization is that we can analyze the logic of social systems "in its own right, thereby shedding light on the genuine dynamics that social phenomena possess, independent of individual psychic processes” (Seidl \& Becker, 2005a, p. 9). This is especially useful in analyzing the dynamics of an AI summit because we can begin to unpack the impact of positivity. The effect of positive psychology is limited exclusively to individual participants of a summit, and cannot apply to the organization or interaction system. Seidl and Becker (2005a) have cautioned:

That does not mean, however—and this is where the controversy started — that the human being is irrelevant to the social system; on the contrary, as Luhmann stressed over and over again, it only underlines the relevance of the two systems for each other. (p. 9)

One of the reasons why Luhmann's work has "received comparatively little serious attention within the international field of organizational studies” (Seidl and Becker, p. 10) is the complexity of the theory itself. It is based on autopoietic theory, which is a radical departure from the open systems theory many organizational scholars are used to. The "distinctive terminology” (p. 10) Luhmann used for the concepts he used is another barrier. Common words like "communication" and "knowledge" are defined and used in unconventional ways. This is somewhat unavoidable when new theory that is based on a paradigmatic shift is introduced. Finally, Luhmann's social systems theory essentially "brackets out” individuals from the organizational picture; this has been a source of both contention and confusion. Despite such limitations, there has been a marked uptick in the application of Luhmann in the organizational literature. These studies are highly informative in viewing AI summit from a social systems perspective and will provide the launching ground for developing an alternative view of AI summits. These will be covered in Chapter 6. At this point, I will briefly go over some of the core concepts in Luhmann's social systems theory that are particularly relevant to this study. 


\section{Social systems}

\section{Communication as elemental unit.}

Luhmann's innovation in applying autopoietic theory to social systems was to specify what they reproduce. Luhmann posited that social systems maintain their unity through an ongoing production of communication. In doing so, Luhmann rejected the notion that social systems are constituted by action. "It is not action but rather communication that is an unavoidably social operation and at the same time an operation that necessarily comes into play whenever social situations arise” (Luhmann, 1992, p. 252). This has significant implications for organization theory. It implies that all organizational issues are fundamentally issues of communication.

Luhmann's conceptualization of communication is sophisticated and unconventional, which I will subsequently explain in more detail. At the current point in our discussion, I would like to point out a few key points in Luhmann's notion of communications. In his view, “only communication can communicate and that only within such a network of communication is what we understand as action created” (Emphasis in the original, p. 251). Luhmann was saying that only social systems have the ability to communicate. People do not and cannot communicate. This sounds like a wild proposition. It only makes sense in the context of Luhmann's definition of what a communication is, and what it is not. According to Luhmann, communication is an inherently social phenomenon requiring the social coupling of at least two people. A person's utterance becomes a communication only when it is perceived and understood (or misunderstood) by another. The concept of communication that we are used to, was developed by information theorists of the late $20^{\text {th }}$ century who essentially stripped out the meaning contained in communication to advance theorizing using mathematical models. Luhmann broke 
from tradition to include understanding as a key component that is part and parcel of communication. When meaning is brought back into the picture, communication can only be defined as a social event.

People make their thoughts known through language. A soliloquy becomes a communication only when there is someone else there to perceive it. At that point, the soliloquy becomes a social phenomenon produced by the social system. The production and reproduction of communication, is therefore confined exclusively to social systems. A distinction must be made between communicating and what Maturana and Varela called languaging. This fine distinction allows us to study the dynamics of communication in and of themselves.

All social systems maintain their unity by reproducing communication. There are three basic types of social systems in Luhmann's classification of systems (Figure 1): societies, organizations, and interactions. Luhmann described them as:

(1) interactions, the smallest and most elusive form of social gatherings on the microlevel; (2) organizations as more formalized and stable social systems on the mesolevel; and finally, (3) society as a whole, which encompasses all forms of social systems on the macrolevel and can be further differentiated into various functional subsystems such as the political system, economic system, legal system, and so on. (Luhmann, 1986, p. 173)

It is extremely important to remember that Luhmann classified social systems into these levels for observational purposes only. They do not describe their operations. Social systems are autopoietic. That means that individual systems are always operatively closed from another. We must put aside conventional notions of interactions as elements of an organization, and organizations as elements of society. Each type of social system is constituted by the ongoing production of communications specific to that type. Societies produce societal communications, organizations produce decision communications, and interaction systems produce interactional communications among people that are present (Luhmann, 1995). 
Both social systems and psychological systems (i.e. the cognitive systems of people) use meaning as part of their autopoiesis. "Meaning systems are completely closed to the extent that only meaning can refer to meaning and that only meaning can change meaning” (p. 37). People

and social systems are dependent on each other to emerge and to continue to exist (p. 59). They have co-evolved and are bound together. Meaning, in Luhmann's view, is the "evolutionary achievement” (p. 59) of this structural coupling. Meaning is a broader concept than behaviorism. Luhmann did not define meaning, but gave a complicated phenomenological description beyond the scope of this overview. In short, Luhmann described meaning as "processing according to differences” (p. 71). If information is the difference that a difference makes, then what difference that difference makes can be considered meaning. I will return to this in the discussion on communications.

\section{Structural coupling and interpenetration.}

Structural coupling is the mechanism by which two or more closed systems co-evolve and adapt their internal structures through mutual perturbations. Luhmann did not fully specify the relationship between organization, interaction and psychological systems. Guided by Luhmann's work on societal systems, Seidl (2005c) suggested that the organization is coupled to interactions and individuals by a special type of structural coupling called interpenetration. Luhmann developed the concept of interpenetration to define the relationship between human beings (the conglomerate of organic and psychological systems) and social systems (Luhmann, 1995, pp. 210-254). In social systems theory, human beings are part of the environment of society and vice versa. When a system's environment makes its complexity (such as the system's "indeterminacy, contingency and the pressure to select") available for building another system, this is called penetration (p. 213). The penetrating system's behavior is co-determined by the 
receiving system. Interpenetration happens when two systems make their complexity available for one another. The two systems become much more interdependent as a result of interpenetration. It also means that with increased levels of complexity comes a greater variation of possibilities that can be exploited (p. 239).

Interpenetration is undoubtedly a very abstract concept. A more accessible description is the notion of intimacy, which is what Luhmann called the relationship of interhuman interpenetration. "Intimacy comes into being when more and more domains of personal experience and bodily behavior become accessible and relevant to another human being and vice versa” (p. 224). Social systems must be formed for intimacy to happen, because interhuman interpenetration is "indisputably possible only by communication" (p. 228). Intimacy exceeds the possibilities of communication, both through language and bodily contact. It includes the experience of not being able to find the means to communicate. "Each one knows each other so well that they cannot conceal themselves because this would be another act that would have to be answered. The rest is silence" (p. 228). Interpenetration is not to be confused or exchanged for intersubjectivity or shared meaning. In closed, self-referential systems, meaning can never be shared. "What is social cannot be traced back to the conscious performances of a monadic subject” (p. 81) and thus, intersubjectivity raises issues that cannot be resolved (p. 146).

The coupling between an organization and its associated interaction systems can be considered one of interpenetration. Seidl (2005c) explained:

Interactional communications orient themselves not only according to their interactional structures but also according to organizational structures, that is to say, their environment.... The interaction observes its own communications with regard to their significance for the interaction and the organization.” (p. 150) 
An AI summit can be characterized as the particular interaction system of a particular organization attended by hundreds of psychological systems. It will therefore be important in applying a social systems perspective, to identify how these systems interpenetrate one another.

\section{Concept of communications}

Luhmann's second innovation in developing a theory of social systems was his unconventional definition of communication $(1992,1995)$. He defined communication as a unity of utterance, information, and understanding. These three units combined form communication. Communication can be deconstructed into the three units for observation, but in its operation, only the three together can be called a communication in Luhmann's social systems theory.

This formulation is a radical departure from how we understand communication today. The rapid development of information technologies owes a great deal to the communication theories developed by Shannon, a mathematician and an engineer (Gleick, 2011). In the 1940s, Shannon developed a mathematical theory of information for encoding information. His theory basically stripped out the semantic content of messages, and reduced information to bits and bytes subject to statistical analysis. For Shannon, information represented uncertainty, probabilities, difficulty of transmission and entropy (Gleick, 2011, p. 219). The resulting Shannon-Weaver model implied a transmission of information from a sender to a receiver through a channel. It represented a giant leap forward in the development of computers and networks. Without Shannon, there could not have been an Internet.

"The birth of information theory came with its ruthless sacrifice of meaning-the very quality that gives information its value and its purpose” (2011, p. 416) wrote Gleick in the book, The Information, a chronicle of communication theory. He referred to von Foerster complaining at a cybernetics conference "only when understanding begins, in the human brain, 'then 
information is born-it's not in the beeps” (p. 417). Gleick wrote that in information theory, "meaning, as ever, remained hard to pin down" (p. 417). He quoted a historian of cybernetics, Dupuy: "Ours is a world about which we pretend to have more and more information but which seems to us increasingly devoid of meaning” (p. 418). Luhmann was bringing meaning back into communication theory.

Luhmann (1992) insisted that the conventional concept of communication is incomplete. The commonly used metaphor of transmission was problematic, he wrote. An act of transmission "directs attention and demands for skillfulness onto the one who makes the utterance" even though an utterance is nothing but a proposal to the receiver of the information to make a selection. As Drucker said, communication makes demands. The metaphor of transmission, however, does not account for how the communication is understood (or misunderstood). Communication happens only when there is a reply.

Similar to Shannon, Luhmann's (1992) concept of communication strips it of the psychological and cognitive aspects. He did so by conceptualizing communication as a product of social systems. He cautioned that he is not saying that it is possible to have communication without life or consciousness. He is in essence, bracketing people out of the picture in order to maintain the contours and clarity necessary for a concept to be useful in the construction of theory. And in his formulation of communication, meaning played a central role.

According to Luhmann (1992), communication is a selection. It synthesizes three different units of selection: "selection of information, selection of the utterance of this information, and a selective understanding or misunderstanding of this utterance” (p. 252). None of the three can stand alone and must be united to establish communication.

Communication occurs only when a difference of utterance and information is understood. That distinguishes it from the mere perception of the behavior of others. In 
understanding, communication grasps a distinction between the information value of its content and the reasons for which the content was uttered. (p. 252)

The distinction of the three units, Luhmann wrote, was borrowed from the speech theories of Bühler (1934). Luhmann’s conceptualization differed because he did not view communication in terms of action. He did not see it as a transmission of messages being transmitted successfully or in error. Communication is a selection and synthesis of the three units. Luhmann defined information drawing from Bateson (1979) as the "difference that makes a difference" (Luhmann, 2003, p. 43). In accordance with Shannon and Weaver's model (Gleick, 2011), information is “a selection from a repertoire of possibilities” (Seidl, 2005a, , p. 28). A communication selects what is being communicated from a range of possible communications. Utterance refers to how (the form) and why (the reason) something is being said (Seidl, $2005 \# 1041$, p. 28).

The most important element of Luhmann's conceptualization of communication is the inclusion of understanding. Understanding refers to the grasping of "a distinction between the information value of its content and the reasons for which the content was uttered" (Luhmann, 1992, p. 252). In making the distinction, the content of the communication might be emphasized over how it was expressed, or vice versa. What matters is that the both aspects must be experienced to make such a distinction. If such a distinction is note made, the communication is “a mere perception” (p. 252).

Communication is not perception. Perception is a psychological phenomenon that belongs to the domain of cognitive systems, not social systems. It has no "communicative existence” (Luhmann, 1992, p. 252). Perception cannot immediately or directly connect to a perception in someone else's mind. "What another has perceived can neither be confirmed nor repudiated, neither questioned nor answered. It remains closed within consciousness” (p. 252). A perception can be externalized through language, whether bodily or through words. Individual 
perceptions must accord to the laws of communication system. "Communication leads to a decision whether the uttered and understood information is to be accepted or rejected” (p. 255). All communication, thus carries risk (p. 256). It bifurcates reality:

[Communication] creates two versions - a yes version and a no version—and thereby forces a selection. And it is precisely in the fact that something must happen (even if this is an explicitly communicated break-off of communication) that autopoiesis of the system resides, guaranteeing for itself its own continuability. (p. 255)

Luhmann wrote that communication was "an emergent reality” (p. 252). This is highly consistent with the social constructionist roots of AI. Explained Mohe and Seidl (2011) referring to Luhmann (1995):

People might utter words or make particular gestures but they have no control over the way in which these are understood, i.e. what communication is ultimately realized. For example, an uttered 'yes' might be understood as expressing a confirmation, a doubt or a negation (ironically). Thus, the meaning of a message, i.e. the concrete communication, is not produced by the speaker but by the listener, or more precisely: by the connecting communications. (Mohe \& Seidl, 2011, p. 8)

A social system is a system of communications. "Whatever the participants may understand in their own self-referentially closed consciousnesses, the communication system works out its own understanding or misunderstanding. And to this purpose it creates its own processes of self-observation and self-control” (Luhmann, 1992, p. 253).

In summary, under Luhmann's conceptualization, communication is not a transfer of information. Communication cannot be broken up into separate elements without losing its structural unity. "Information has its identity as something occurring at a particular point in time and not as something that endures in time and is able to be transferred” (Luhmann, 1990, p. 32). One of the key points of Luhmann's social systems theory is drawing a distinction between meaning and information. The concept of information must always "be understood relative to an actually given, constantly changing state of knowledge” (p. 31). The concept of meaning, transcends information and "refers to the way human experience is ordered and not, for example, 
to some particular fact or matter in the world” (p. 25). Information loses value when repeated, but its meaning does not.

\section{Organizations}

\section{Decision communications constitute organizations.}

According to Luhmann, organizations are an organized form of social systems, and therefore, are constituted by communication. Other organizational scholars including Weick (1995), Kuhn (2008), and Taylor (2000) have posited that organizing is a communicative activity. The body of literature around “communication as constitutive of organization" or CCO is relatively obscure yet growing (For an overview, see Cooren, Kuhn, Cornelissen, \& Clark, 2011). Like Luhmann, the CCO perspective rejects March and Simon's (1993) notion that “organizations are assemblages of interacting human beings" that resemble something of “a central coordinative system” (p. 23). Rather, “organizations are built, maintained, and activated through the medium of communication” wrote Weick (2001, p. 136), hence sensemaking is a central aspect of organizational life. Taylor (2000) proposed that organizations emerge out of episodes of conversations, and that the essence of communication is the transfer of intent from one actor to another. While scholars agree that organizations can emerge from communication, Schoeneborn (2011) noted that the debate on how communication constitutes organizations is far from settled. He suggested that Luhmann's social systems theory is a "prominent example” (p. 663) of CCO, and may help clear up the ambiguities surrounding the processes and minimal conditions of how communication constitutes organization.

Luhmann's perspective on organizations is unique in several ways. First, he defined organizations as a social system that reproduces itself through a specific form of communication: decision communications (Luhmann, 1995, 2003). Organizations are systems made of decisions. 
Organizations differentiate themselves by decision making, and "by doing so, recognizes what it is doing” (Luhmann, 2005c, p. 85). The organizational system is autopoietic, meaning that these decisions are produced from the decisions that make up the organization. It is self-referential, meaning that there can be no outside authority that decides what the organization does. All external references are understood as the organization's internal operations (Luhmann, 2003, p. 32).

Organizations are operatively closed. “An organization may only be defined based on its own decisions. It can only learn by itself” (p. 33). Here again, Luhmann strictly distinguished decision making from the psychological event engaging people. Decisions in and of themselves have no intent because decisions in the Luhmannian sense are strictly "a matter of communication” (p. 32). Therefore, they are ephemeral and vanish as soon as they appear. The implication for organizations is such that so little can be changed-its elements are so fleeting. Paradoxically though, the fact that an organization "cannot be changed may provide a cause for new decisions to surface” (p. 36).

Organizations are complex. They have a wide range of options at their disposal. All autopoietic systems try to limit their options by establishing structures. This is a necessary condition for maintaining their autopoiesis (p. 39). An organization distinguishes itself from others by specifying its structures. "Insofar as a decision serves as the basis for another decision" either in retrospect or in expectation, "a structure is formed" (p. 40). The structure may be momentary. But so long as they "somehow limit and thus enable a decision concerning how decisions are taken” (p. 40) they are deemed relevant. "It will draw upon the very structures it has organized in order to specify expectations that ensure that acts...may be dealt with as decisions by the system” (p. 33). 


\section{The paradox of decision making.}

One of the important features of Luhmann's theory of organizations is his recognition that decisions and therefore organizations, are rooted in paradox (Luhmann, 2003, 2005c). The paradox of decision making lies at the heart of organizations. "It is not that decisions are first made and then communicated; decisions are communications” (Seidl, 2005a, p. 39). Since decisions are communication events that do not last, they are constituted by paradox. A selection always has to be made because in complex systems, the possibilities always exceed what can actually be realized. Decisions are different from ordinary communications in that they imply that the decision could have been made differently. They are self-contradictory. Seidl borrowed Ruesch and Bateson's distinction of the "report" aspect and "command" aspect of language to explain this contradiction. "The more clearly the decision is communicated as a selection among alternatives (report aspect), the less the decision will be accepted by later communications as a decision (command aspect)" (p. 40). In Luhmann's words, "the decision conceals what is decisive” (Luhmann, 2005, p. 85).

Another paradox is the undecidability of decisions. "Something that has already been determined in all respects cannot be decided. Therefore, a decision involves some degree of unpredictability, even irrationality, which is precisely why people are tempted to exert influence” (Luhmann, 2005c, p. 85). If objective analysis yields a certain result, this is not a decision—it is simply a matter of deductions and calculations (Andersen, 2003). According to Luhmann, von Foerster made the point most clearly: "Only those questions that are in principle undecidable, we can decide” (Citing von Foerster, 1992, p.14 in Luhmann, 2005c, p. 86). The paradox is further complicated in that "the decision itself is neither something in the past nor something in the future, and it is neither the one side nor the other side of the alternative” (p. 88), as I noted earlier. 
Before a particular decision is made, several possibilities exist. Once the decision is made, although a second-order observer sees there were other possibilities which have been excluded, the contingencies are now fixed and are contingent upon the decision made. Decision making in essence, is a form of limiting contingency.

An organization is not operationally crippled by the paradox of decision making because it cannot observe the paradox. "It does not see that it does not see what it does not see" (p. 91). The function of an organization is to unfold this paradox of decision.

To unfold a paradox is simply to shift the observer's blind spot to a place where it is less troublesome (in family therapy, which is based on constructivism, we say: to a less painful place). Against one's better judgment new, stable identities are introduced, which can be maintained more easily. (p. 92)

I will now introduce two methods Luhmann proposed for unfolding the paradox of decision making that are relevant to this study: decision premises and uncertainty absorption.

\section{Decision premises.}

Decision premises enable organizations to reduce the complexity of decision making, while simultaneously opening up the horizon for subsequent decisions (Luhmann, 2005c, p. 95). “The system constantly oscillates between constraining and extending decision possibilities and in this way secures its own autopoiesis” (p. 95). There may be some overarching objectives—a company's vision statement, for example—-that serve as a self-description for guiding decisions. However, these can never be so narrow that the decisions funnel down towards an inevitable end. If it were so, Luhmann wrote, they would not be organizations but projects.

Luhmann identified three (Seidl, 2005b) organizational decision premises. These are programs, personnel, and communication channels. Programs pre-determine how a correct decision is made. They come in the form of "if-then" conditional scenarios, or in the form of goals to be achieved. Programs are often interchangeable with plans. Decision premises related 
to personnel determine the criteria for selecting and allocating personnel. Communication channels determine how communication is structured within an organization. The channels only run vertically in a classic hierarchical structure, whereas in a matrix organization they could run horizontally. The three decision premises converge in the form of positions. A position is guided by a certain program, filled by certain personnel and equipped with certain communication channels. These positions serve to constrain the possibilities for organizational change in the status quo. A position enables variation but also binds reality within certain conditions: “One can change the incumbent, the job profile or the reporting relationship—but not all at the same time” (p. 94).

A decision on decision premises is made "on the level of second-order observation” (p. 95). A manager decides on a position based on their observations of the situation at hand. Luhmann noted:

As a rule, we associate terms such as planning and steering with the notion that this is done from above and is thus justifiable on the basis of a better overview, though without precise knowledge of details. This may be the case in some instances. However, the theory of the second-order observer is not dependent on the mystifications of the hierarchy. It emphasizes that this is a very specific observation in very specific situations; and of course, an observation which has to base itself on upon what it cannot see. We cannot evade this fundamental paradox. (p. 96)

\section{Uncertainty absorption.}

A second mode for unfolding the paradox of decision making is through uncertainty absorption. It is a concept originating with March and Simon (1993). "Uncertainty absorption takes place when inferences are drawn from a body of evidence and the inferences, instead of the evidence itself, are then communicated" (p. 186). Uncertainty is absorbed "when decisions are accepted as decision premises and taken as the basis for subsequent decisions. ... And the whole point is: it is not the decision operation itself, but a process that connects decisions” (Luhmann, 
2005c, p. 96). It is analogous to Weick's (1979) reduction of equivocality in the sensemaking process between individuals in an organization. Uncertainty absorption is the mechanism by which organizations bring forth a reality. Wrote Luhmann (2005c):

Every organization operates in a world that it cannot know. This world is transformed through uncertainty absorption into a known world; it is replaced by a known world. This requires in retrospect a first decision, which inscribes a distinction into the world, for example, by defining a purpose, by forming a "coalition" of (future) members with a corresponding clientele as environment, or simply by establishing another organization. (p. 99, footnote omitted)

According to Seidl (2005b), an organization pulsates between the reduction and production of uncertainty. "Every decision produces new decisions; on the one hand, by reducing uncertainty, and on the other hand, by producing new uncertainty, which brings forth the need for a further reduction of uncertainty in the form of a further decision” (p. 43). When too much uncertainty is absorbed, organizational structures can ossify and result in core capabilities turning into "core rigidities” (Leonard-Barton, 2007).

\section{Relationship between organization and environment}

One of the confusing aspects of Luhmann's theorizing in particular and autopoiesis in general is the relationship between a system and its environment. Autopoietic systems are closed in their operations, but they cannot "operate without having an impact on and through the environment” (Luhmann, 2003, p. 40). An environment irritates a system. Such irritations become meaningful to an organization when it "can recognize the difference this will make for its decision-making activity, when the environment in some way or other is changed or not” (pp. 40-41). Information is always produced by the system. There is no "fact existing independently from observation and evaluation” (p. 41) and the system will tend to produce information according to its internal preferences. 
There are two structural limitations on the decision-making context, however. The first is the concept of redundancy. "Redundancy achieves its highest value when one piece of information suffices for a definition of the system” (p. 41). On the other hand, redundancy decreases when a "decision provides less and less insight into what has been decide before and what might be decided ahead” (p. 41). The other limitation is called variety. Variety describes the range of decisions it makes. If all the decisions are similar, variety is small. When the range expands, variety is greater.

Redundancy and variety are closely intertwined. The general tendency of organizations in relation to its environment is to increase the system's redundancy. This is due in part to uncertainty absorption. Structures are condensed, and as a result, “an improved overview of what still remains possible within the system is achieved” (p. 42). This is why aging organizations tend to have more rigid structures, Luhmann noted. But an organization may also increase the variety of its decisions in reaction to noise: turbulent changes in its environment. Luhmann cautioned, "the variety of decisions may well increase unnoticed, with the question of a structural adaptation appearing as a secondary matter and only in connection with the already changed decision-making situation” (p. 42). Luhmann imagined organizations "as continuously oscillating between acceptance and rejection of noise [from the environment] and between loss and reconstitution of redundancy [within the organization]” (p. 43).

\section{Organizational knowledge and nonknowledge}

The social systems lens imposes a processual view of organization. For the organization to maintain its identity and existence, it must constantly reproduce a ceaseless stream of decision communication events connected to future decision communication events. The specific mode of reproduction is uncertainty absorption, often through the use of decision premises. Organizations 
are always transforming in a state of flux like Heraclitus’ river (Morgan, 1997). Given this conceptualization, what then is organizational knowledge? Plato's notion of knowledge as justified true belief cannot apply to the Luhmannian organization, because social systems cannot think; only individuals can. Neither can individual knowledge ever be directly transferred to an organization, because they are two separate, autonomous systems that are operationally closed to each other. This is the point at which social systems theory diverges from Nonaka's (1994) organizational knowledge creation theory. Nonaka's theory hinges on the transferability of knowledge between individuals and organizations. It also assumes that knowledge is a resource that can be accumulated, managed, and shared. Luhmann's theory forces us to challenge this assumption.

Based on his interpretation of social systems theory, Seidl (2007) conceptualized knowledge as structures that determine how an organization deals with information. Knowledge orients a system's observations. It guides it in where to draw the distinction between noise and information (p. 17). Observations are structured according to two questions. First, does the difference make a difference? Second, what difference does the difference make? Both are a form of selection. The first distinction is a selection of what to observe and where to pay attention. Language plays a significant role by providing a schema for observation. The specific context of concrete observations such as time and space can be stripped away and "condensed" (Spencer-Brown, 1979, cited p. 17) into a generalized distinction like “dog” and "fast” (p. 17). These distinctions can be applied as a heuristic in concrete situations. The second distinction is a selection of the meaning of the observation. This regulates how one observation connects to other observations, both actual and potential (p.17). Seidl gave the following example:

Organizations might observe repeatedly that companies that put down the prices of their very high-priced luxury goods leads to a loss of customers. From this, one might 
condense the "knowledge" that putting down the price the very high-priced luxury goods leads to a loss of customers. (p. 18)

Broadly defined, knowledge represents all the structures of an organization. Seidl proposed that organizational knowledge can therefore be described as decision structures. An organization has two types of decision structures. The first are formal decision structures that are "the explicit product of earlier decisions" (p. 21). When an operation deviates from those structures, the expectation is that the system changes its structure. The second are decision structures based on organizational culture. These are undecidable decision premises that are not explicitly decided. Structures are expected to be retained in the case of deviating operations. Decision premises related to the values of an organization are hard to change because they are stabilized by norms not cognition.

According to Seidl, the purpose of knowledge is to both reduce and increase complexity. Complexity pressures a system to select, for a system has far more possibilities of operations than it can actualize (p. 19). Overtaxing the selection at each moment endangers the reproduction of the system (Luhmann, 1995). Knowledge pre-selects the possibilities available to the system by excluding and eliminating others, thereby relieving some of the pressure to select. "Structures draw a distinction within the possibilities—creating two different sets of possibilities—and indicate one of the sets, making it the subset of available possibilities” (Seidl, 2007, p. 19). The system is blind to the possibilities that have not been indicated. When knowledge is produced, it simultaneously produces what Seidl calls nonknowledge - the set of possibilities that were not indicated and lies beyond the boundary of the distinction (p.19). One might think of it also as latent knowledge. This mechanism is rooted in another paradox. Knowledge limits the available possibilities and reduces complexity. But the same mechanism serves to increase complexity because new possibilities open up by reducing the original possibilities (p. 20). 
The idea of nonknowledge is important for organizations, due to an organization's specific mode of operation, namely uncertainty absorption. "During the succession of decisions, he uncertainty involved in earlier decisions is absorbed; in the communication of decisions, the uncertainty involved in earlier decision making is not communicated” (p. 21). An individual might remember the uncertainty. A face-to-face interaction can question an earlier communication, recall the uncertainty, and select differently from the structural selection. But an organization is structured such that it forgets. Therefore, the unobservability of nonknowledge is made extreme.

"For a system, intelligence means that it orients its observation not only according to its knowledge but also according to representations of its nonknowledge” (p. 23). While a system cannot directly access its nonknowledge, its internal operations can make representations of the nonknowledge. In this sense, an AI summit is an interaction system that forces its participants to explicitly communicate about the organization's nonknowledge. It does so through selfdescriptions of the organization and its operations. It also overcomes organizational blindness through interactions with external stakeholders. External stakeholders, such as customers, can illuminate what the organization doesn't know by talking about their relationship. In either case, the information presented as nonknowledge is not the nonknowledge itself but the representations and interpretations of nonknowledge.

\section{Organizational interactions}

The interaction system is where people interact through face-to-face contact (Luhmann, 1995). It reproduces communication based on the interactions of the people present. This marks a point of differentiation to Nonaka's notion of $b a$ or shared context, which is neither bound by space nor time (Nonaka et al., 2000). Luhmann’s interaction systems are bounded. “They include 
everything that can be treated as present and are able, if need be, to decide who, among those who happen to be present, is to be present and who not” (Luhmann, 1995, p. 412). For example, in a meeting, if a participant is texting on their phone, the interaction system may mark that person is absent. If it were the CEO texting though, the system may mark her as present, and interpret her texting as an interaction-the other participants may understand this as an utterance containing the information "the CEO is ignoring us." The latter would be an example of interpenetration between the organization and interaction systems. The interaction system is penetrating the organization's system, effectively borrowing from the organization's decision making structure (the CEO’s position) in making the distinction between present/absent.

The same event (the CEO texting) would be observed and interpreted differently by the organization and the interaction system, because each system is operatively closed and produce different kinds of communications. In other words, the meaning and significance would differ. "Not everything that is communicated in the interaction has to be put in the form of a decision and thus made available to the organization" (Seidl, 2005, p. 160). If a participant wants to explicitly make a connection to the organization's decision making, they may articulate the communication as a declaration (p. 161). Recording the minutes of a meeting, for example, is a strong signal to the organization "that the communication lends itself to being treated as an organizational decision” (p. 161). Some interactions may be explicitly kept "off the record” to prevent being interpreted as a decision. Often, no decisions are made at all (p. 149).

Seidl conceptualized four types of interactions that can be deemed organizational based on empirical observation. Deciding interactions, decision-preparatory interactions, semidetached interactions, and unrelated interactions (pp. 149-150). Of these four, the first two will be significant in analyzing an AI summit. A deciding interaction produces "interactional 
communications that can be treated by the organization as (organizational) decisions” (p. 155). In other words, a deciding interaction contributes to the organization's autopoiesis. Decisionpreparatory interactions are interactions that lay down the conditions for later decisions, for example, by exchanging relevant information, but fall short of making a decision. Semi-detached interactions are interactions that "communicate about decisions without focusing directly on influencing decision making” (p. 150) such as gossip. Unrelated interactions are those that are not related to the organization at all.

\section{Towards a social systems perspective of AI summits}

Luhmann's theory of social systems is vast and complex. It is impossible to condense his theorizing into such a brief overview. Seidl and Becker (2005a) remarked "it is often said that when starting to read Luhmann it takes a hundred to two hundred pages before one actually understands anything” (p. 10). The purpose of this chapter was to distill Luhmann's ideas and focus only on those concepts that are relevant to the study of AI summits as a forum for knowledge creation. In summary, I would like to reiterate some of the key points of social systems theory that are important to the theorizing ahead. Luhmann posited that social systems, such as organizations and interaction systems, are autopoietic. They maintain their autopoiesis through an ongoing production of communications. Communication, according to Luhmann is a synthesis of information, utterance and understanding and is defined as an event that vanishes as soon as it is produced. Organizations reproduce decision communications. Interaction systems reproduce interactional communications. People belong to a separate autopoietic system, a conglomerate of an organic system and a psychological system.

In accordance with the biological theory of autopoiesis, all autopoietic systems in

Luhmann's social systems theory are operatively closed systems. They can only refer to 
themselves, so no outside authority can directly change their structures. However, organizations have a special relationship with the interaction and psychological systems they associate with. They are structurally coupled in such a way that the systems can penetrate each other and access the complexity of their respective structures. This is analogous to a relationship of intimacy between people. An analysis of the social dynamics of such structural coupling between the component systems of an AI summit will be the primary focus of this study.

Organizations do not have the ability to think; they can only communicate. Therefore, knowledge cannot be defined as an organizational version of "justified true belief" as Nonaka and others previously proposed. For this study, I am guided by Seidl's (2007) definition of knowledge. He proposed that knowledge in social systems theory should be considered the equivalent of organizational structures. Organizational knowledge determines how an organization deals with information. They orient how an organization observes itself. Decision premises, defined by Luhmann as personnel, communication channels and programs, are a form of organizational knowledge. They are what we conventionally refer to as an organization's structure. Seidl further proposed the concept of organizational nonknowledge, the knowledge that an organization can potentially access, but does not currently distinguish as information for making a decision. Organizational intelligence is increased when an organization has the ability to orient its observation towards such nonknowledge. An AI summit may be one method that enables such observations to happen. 


\section{Chapter 7 A Social Systems View of AI Summits}

\section{Introduction}

An appreciative inquiry (AI) summit brings together hundreds of stakeholders both inside and outside the organization to engage in intensive strategizing activities over several days. I concluded from a review of the existing literature that one aspect of AI that has not yet been fully explored is the capacity for large group methods such as the AI summit format to generate organizational knowledge. AI is deeply grounded in social constructionism. Of the various AI methods, the AI summit format evolved from research developments in group dynamics that eventually converged with systems theory. I then introduced the theory of autopoiesis, which not only provides a biological basis for the social construction of knowledge, but also extended systems theory beyond open systems. The notion of systems as interactionally open, but operatively closed, is an idea so radical that some scholars, such as Luhmann, consider it a paradigm shift in systems theory. Luhmann took the principles of autopoiesis, and applied it to social systems. The goal of this study is to apply a social systems lens to the practice of AI summits, to identify some of the systems dynamics and structures that differentiate it from other strategizing practices.

Recently, management scholars such as Seidl have begun studying organizational dynamics through the lens of Luhmann's social systems theory. While critics of Luhmann have objected to the extension of a biological theory to social systems, Seidl and his colleagues have shown that social systems theory is nevertheless a useful lens with which to analyze organizations. Seidl is a major contributor to an emerging research program in strategic management that focuses on strategizing activities and practice (SAP). In trying to understand how and why an AI summit as a whole functions the way it does, I situate the summit first and 
foremost as a strategizing practice rather than a change intervention. I posit that the purpose of an AI summit is to generate and accelerate the creation of organizational knowledge. This turns away from the conventional view that AI aims to generate transformational change.

Two streams of research by Luhmann scholars in the field of strategy are particularly relevant in applying a social systems lens to AI summits. The first is an extension of Luhmann's study of the communication problems inherent in management consulting. Mohe and Seidl used social systems theory to explore the communications dynamics of a consulting project. They looked at the relationship between the consultants, the organization and the contact system through which the consultants and their clients interact. Most AI summits are facilitated by external consultants who specialize in AI. An AI summit can therefore be conceptualized as a management consulting engagement. Building on Mohe and Seidl's work, I develop a conceptual model of an AI summit that incorporate Luhmann's system types and structural coupling mechanisms.

The second line of research expands Luhmann's concept of episodes to the routine strategizing practices of an organization. Their concept of strategic episodes is quite consistent with the findings of a study of AI summits reviewed in Chapter 3 that described an AI summit as a space that allows the temporary suspension of hierarchy and command-control type decision making (Powley et al., 2011). An AI summit, therefore, can also be conceptualized as an extended strategic episode that consists of a series of strategic episodes that unfold over multiple days. The degrees to which organizational routines are suspended differ quite substantially over the course of the 4D cycle. The constant oscillation between strategic and operational contexts appears to be a key dynamic that is unique to an AI summit. I conclude this chapter by proposing a topology of episodes that can be used to analyze such systems dynamics. 


\section{AI as management consulting}

Most organizations do not have the expertise or capacity to run an AI summit entirely on their own. The AI summit method is well documented (Ludema et al., 2003) and there are many resources available on how to conduct a summit. However, even those companies that use the AI approach as a routine practice in their business operations often choose to contract with an external AI consultant. AI summits, similar to most OD interventions, can be framed as a form of management consulting. An AI summit requires a significant investment in time, money and labor. The Brazillian company, Nutrimental, for example, shut down its entire operations for a few days so that all of their employees and major external stakeholders can attend. The resulting summit had 700 participants (Barros \& Cooperrider, 2000). Such an endeavor can be risky, especially if leadership is reluctant to allow lower-level employees into the inner circle of strategy (Powley et al., 2011). Contracting with an AI consultant can spread the risk somewhat. If an intervention fails, the company can always blame the consultant.

AI summits require months of planning. Cooperrider and Whitney (2005) wrote that the AI consultant supports the AI process in four ways:

- Introduce AI to the organization and train people as internal agents of inquiry, interviewers, and facilitators.

- Design the overall project flow through the AI 4-D cycle, providing guidance about when and how to involve the optimum number of stakeholders.

- Facilitate AI activities throughout the process.

- Continually seek ways to give the process away, to support organizational members in making it their own. (p. 46)

In an AI summit project, the consultant would facilitate pre-summit activities including training and planning meetings. They may also facilitate the actual summit conference. Although the overall consulting project for an AI summit is similar to other management consulting engagements, the AI summit itself has some very unique characteristics when compared to 
conventional off-site strategy workshops. I am guided by a recent theoretical study by Mohe and Seidl (2011) in developing conceptual model of AI summits using social systems theory that can highlight what those points of differentiation may be.

Mohe and Seidl published an article in the journal Organization, theorizing the clientconsultant relationship in management consulting using social systems theory. They were guided by insights made by Luhmann in a case study first published in German in 1989 (published in English in 2005) on the problems underlying management consulting engagements. Luhmann argued that in any relationship between consultants and their clients, there is a fundamental communication barrier. Regardless of the discipline the consultant draws from, Luhmann claimed that the basis for consulting usually consists of a specialized competence that comes from generalizations that are derived from empirical research.

Known statistical probabilities are applied to each individual case, even though they are meaningless in individual cases. One makes such mistakes discreetly, only to compensate for them by means of detailed analyses of the object in question. In certain rare cases, these analyses are subsequently evaluated for the purpose of controlling and correcting the scholarly hypothesis. (Luhmann, 2005b, p. 351)

In such a client-consultant relationship, Luhmann wrote, "there are no deep-seated problems of communication” (p. 351).

A social systems perspective shows a different picture. The thrust of Luhmann's argument was that communication barriers are inevitable because the consultants are operationally closed from the client company's organizational system. Consultants constitute the environment in which the client company operates. Luhmann emphasized that "no system can communicate with its environment” (p. 353). The typical consulting engagement masks a fundamental problem grounded in communication, the impossibility of direct communication and knowledge transfer between consultant and client (Mohe \& Seidl, 2011, p. 14). 
A Luhmannian perspective "directs the attention of the researcher towards specific issues, which have not been properly acknowledged before” (p. 18). Mohe and Seidl (2011) extended Luhmann's work, and developed a conceptual model of the client-consultant relationship (Figure 1) using social systems theory. The relationship is defined by the coupling of three social systems: the client organization, the consultant organization, and the contact system. The contact system is where the consultant interacts with their clients. Mohe and Seidl chose to bracket out the coupling of individual people to social systems, and narrowed their model to the interdependencies between the various social systems. Mohe and Seidl offered three methodological steps in examining client-consultant relationships empirically. First, the researcher must identify the different communication systems in the relationship and "reconstruct their respective communication logics" (p. 18). Second, identify the specific mechanisms of structurally coupling between the systems. Third, examine how the structurally coupled systems' “mutual perturbations are internally (re) constructed” (p. 18).

In a conventional consulting engagement, members from the consulting firm come in contact with members of the client company to meet a specific need, such as strategy development. The consulting firm and client are two different, autopoietic systems that are structurally coupled to each other through an interaction system that Mohe and Seidl (2011) called a "contact system" (p.13). Communication barriers are an issue because the consultants bring their idiosyncratic communication logics to the client company, which has its own set of idiosyncratic communication logics, further confounded by the idiosyncratic communication logics of the contact system. 


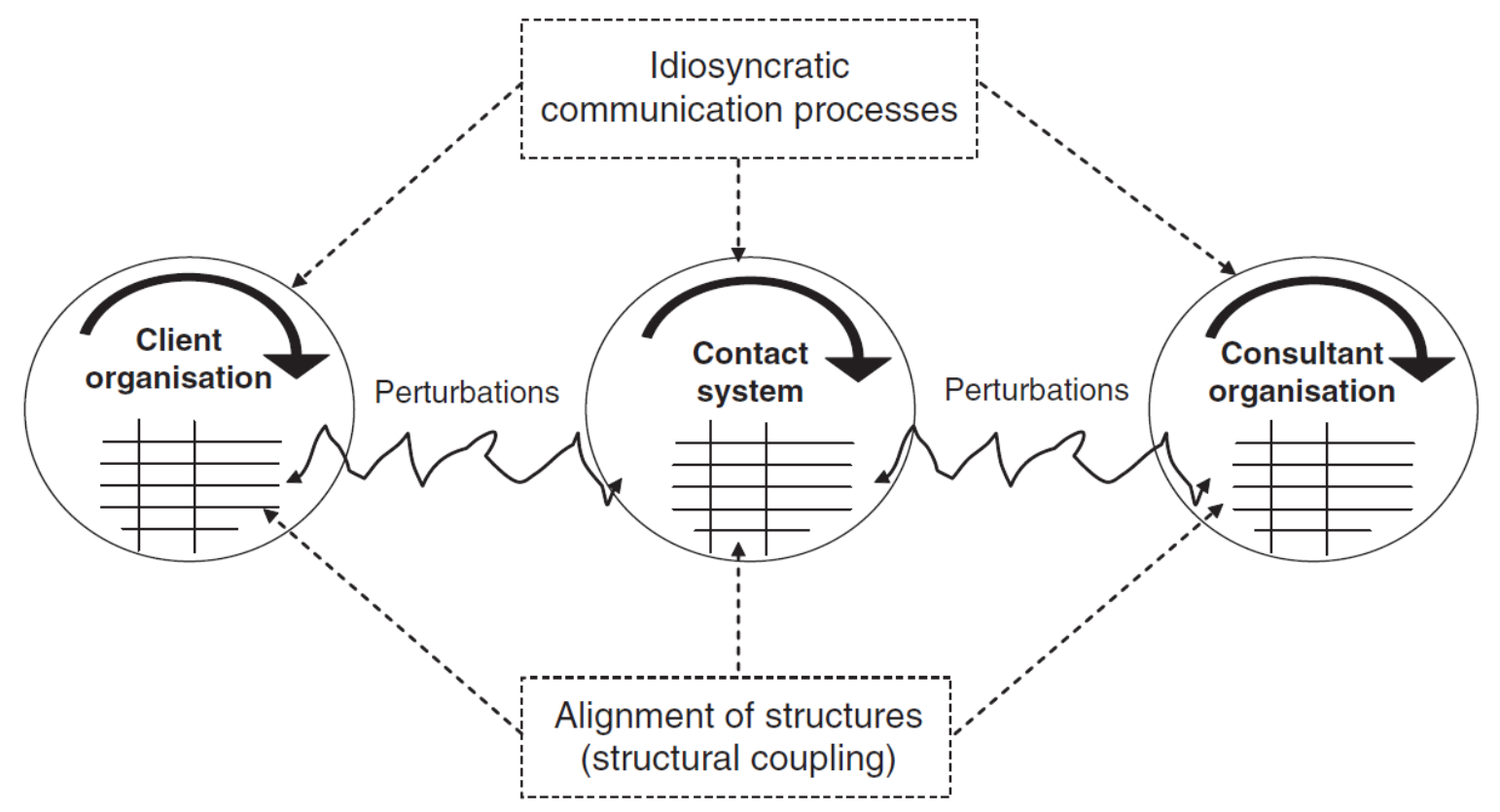

Figure 1. Mohe and Seidl’s (2011) conceptual model of a consulting intervention (p. 14).

In developing the "right" strategy for the company, the consultants inquire into the company's operations to gather and analyze data according to the consulting firm's proprietary methodologies and frameworks. Already, there is room for misunderstanding and misinterpretation by the consultants, as they are observing the organizational system as secondorder observers. A strategy workshop is often the forum in which the consultants present their findings to top management and the board. Seen through a social systems perspective, this is what is really happening:

The description of the client's problem and the consultant's methods for solving the problem are constructs of the contact system-they are themselves necessarily based on "productive misunderstandings." In other words, the "solution” presented by the contact system to the client system is not a solution to the problem as perceived by the client system. Consequently, rather than constituting input from the contact system into the client system, the "solution" constitutes an unspecific perturbation that the client system processes according to its own logic. The structural coupling between the systems merely ensures that the client system takes some form of action as a result of that perturbation. (Mohe and Seidl, p.13) 
Yet as Luhmann (2005b) noted, "For whatever reasons, the consultants may be inclined to present their knowledge as certain and their proposals as based on careful work” (p. 351). Communication problems are assumed away.

It is interesting to recall that OD consultants began experimenting with large group methods like the AI summit out of frustration with conventional methods for strategic change consulting. The Luhmannian perspective suggests that a core issue is one of communication barriers. One of the core characteristics of an AI summit is that sets it apart from conventional contact systems is in the way it puts the whole system in the room to engage in strategizing activities. This suggests that the dynamics of an AI summit is radically different from the contact system of a strategy development meeting comprised of a handful of consultants and core executives from the client company. I will now apply Mohe and Seidl’s three step methodology to examine the contact system of an AI summit from a social systems perspective.

\section{A social systems model of an AI summit}

The first step in Mohe and Seidl's methodology is to identify the communication systems in the client-consultant relationship. I modify this to enable us to model large group methods of strategizing. As I will argue later, large group methods are essentially strategy development workshops facilitated by an external consultant. I will limit the conceptualization of the method to the actual conference itself and exclude any planning and post-conference activities and meetings. What I am trying to model, therefore, is the relationships in a contact system during a strategy meeting. Although Mohe and Seidl only modeled the social systems of a contact system, I have chosen to incorporate the psychological systems of individual participants into the model. This is because the notion of "the whole system in the room" in AI implies that who is present and who is absent has implications on the outcome. I will also cover step two of the process, 
which is to identify the mechanisms of structural couplings between the systems. I will defer step three to Chapter 8.

\section{Generic strategy meeting model.}

I start with a model of a generic strategy meeting (Figure 2). The systems involved are the organizational system of the client, the interaction system, and the psychological systems of the participants of the meeting. Each system is operatively closed from one another; however, each can trigger perturbations in one another through interactional communications. The same event can trigger different perturbations in different systems, because each system operates according to their own internal logic. The purpose of the meeting is to develop strategy for the client organization. Therefore, I exclude the external consultant's organizational system from this model. In some special client-consulting relationships in which the consulting company has a deep and intimate relation with the client company, it may be necessary to include the consulting company system.

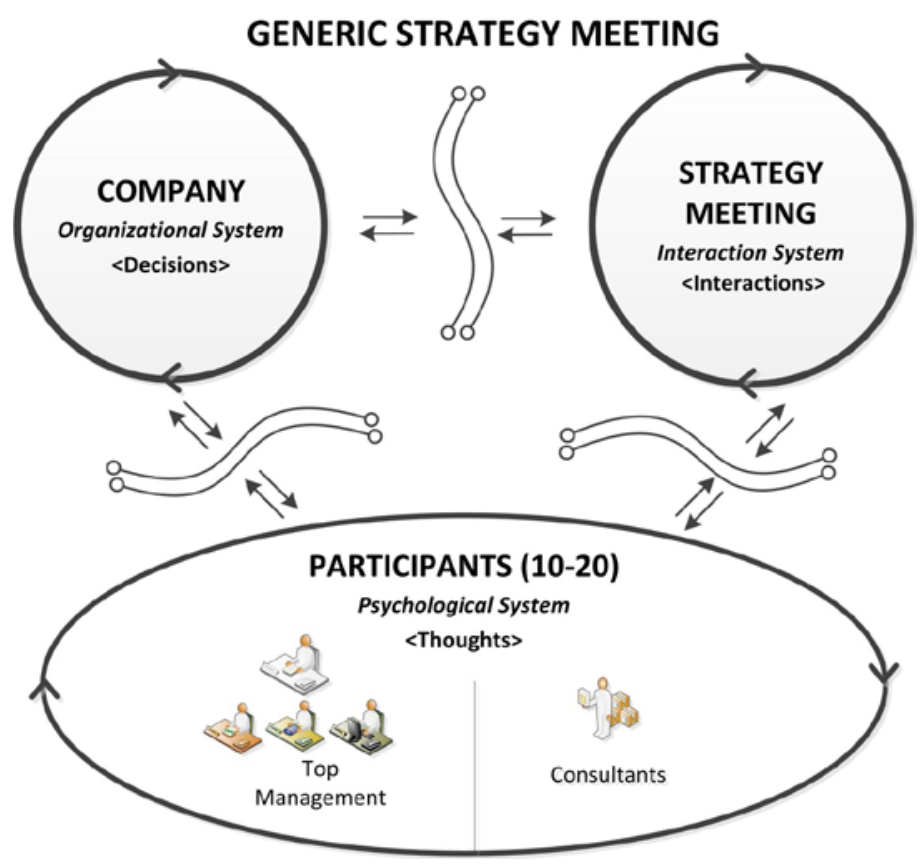

Figure 2 Social systems model of a generic strategy meeting 
A strategy meeting is usually considered highly confidential. It is an internal meeting, with participation is limited to the "inner circle" such as the top management team, board members and external advisors such as a consultant. The interaction system is structurally coupled to the organizational system as a strategic episode. The company temporarily suspends its operational routines so that it can reflect upon itself strategically. The interactions that take place at the meeting are organizational interactions. Since this is a strategy meeting, decision interactions and pre-decision interactions will tend to dominate.

The nature of the relationship between individual participants and the organizational system is governed by their positions. Only the top management team is present and therefore, any decisions they make during the meeting must connect back to the rest of the organization after the meeting. The decision may cascade down the organization, but the possibility of a decision not connecting to another somewhere down the line always remains. In other words, there are potential internal communication barriers. This problem is often referred to as problem of execution or implementation of the decided strategy. However, in Luhmann's framework, an organization only produces decisions—not actions—and therefore, an execution problem is really a breakdown of the decision production process in which a certain decision fails to produce another. The consultant and all the communication barriers Mohe and Seidl identified in the client-consultant relationship are all present as well. The relationship between the participants and the interaction system will depend on historical precedents of the company. Participants will conform to the meeting practices that are expected, in terms of turn-taking, voting, rituals etc.

\section{Large group method model.}

I now expand this generic model to a large group method in Figure 3. 


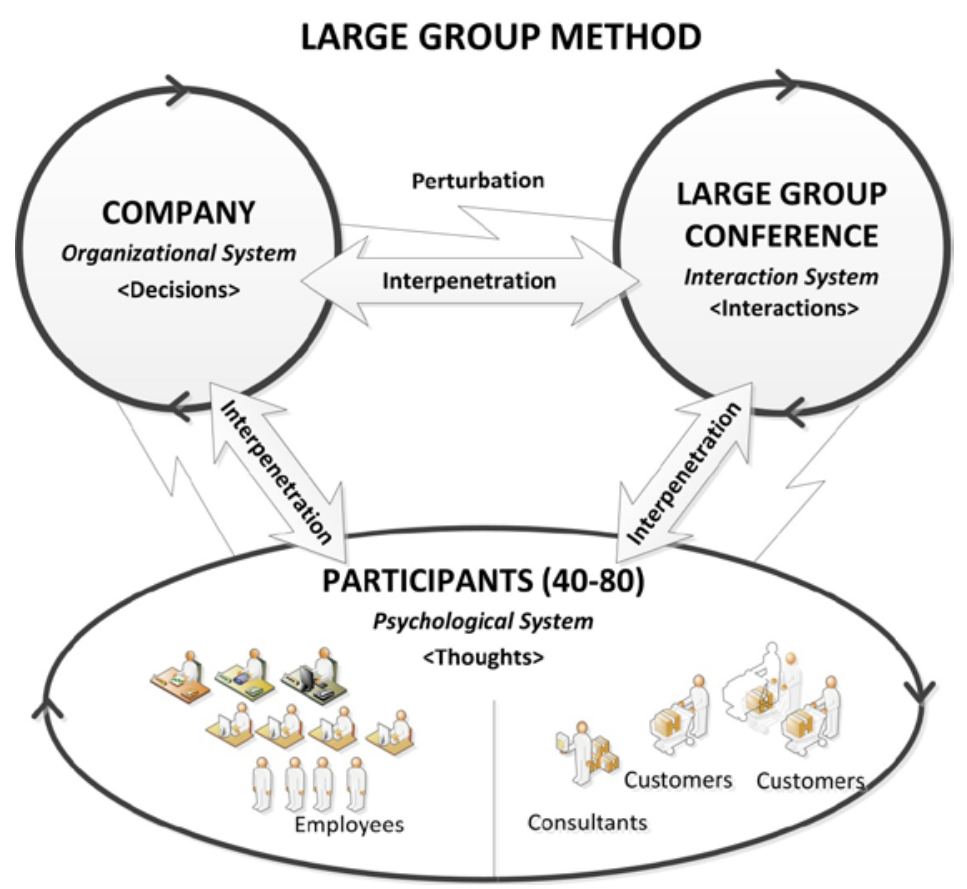

Figure 3 Social systems model of a large group methods conference

There are two major differences from the generic model: the composition of the participants, and the strategizing activities that take place during the strategic episode. More of the organizational members are present. Thus, the structural coupling between the participants and the organization is much tighter, as represented by the increased number of positions. Having lots of organizational members present should have the effect of reducing some internal communications barriers, as the level of redundancy decreases and variety increases. Furthermore, external stakeholders such as customers and suppliers are also participating. When a customer talks about their experiences with the company, they are perturbing the company's system in a manner that is likely consistent with the logic of the organization that the customer represents. Such perturbations may have consequences on the decision making interactions that take place. The consultant's role is that of a facilitator. They are not there to provide expert knowledge on strategy. Their role is to structure the interactions of the conference so that the participants can conduct their own data collection and analysis through the strategizing activities 
in order to develop and make strategic decisions. In this sense, if the methods are effective, the communication barriers between the consultant and client become a non-issue, because the organizational members themselves are the strategists.

\section{AI summit format.}

Finally, I further expand the model to a specific large group method, the AI summit format in Figure 4.

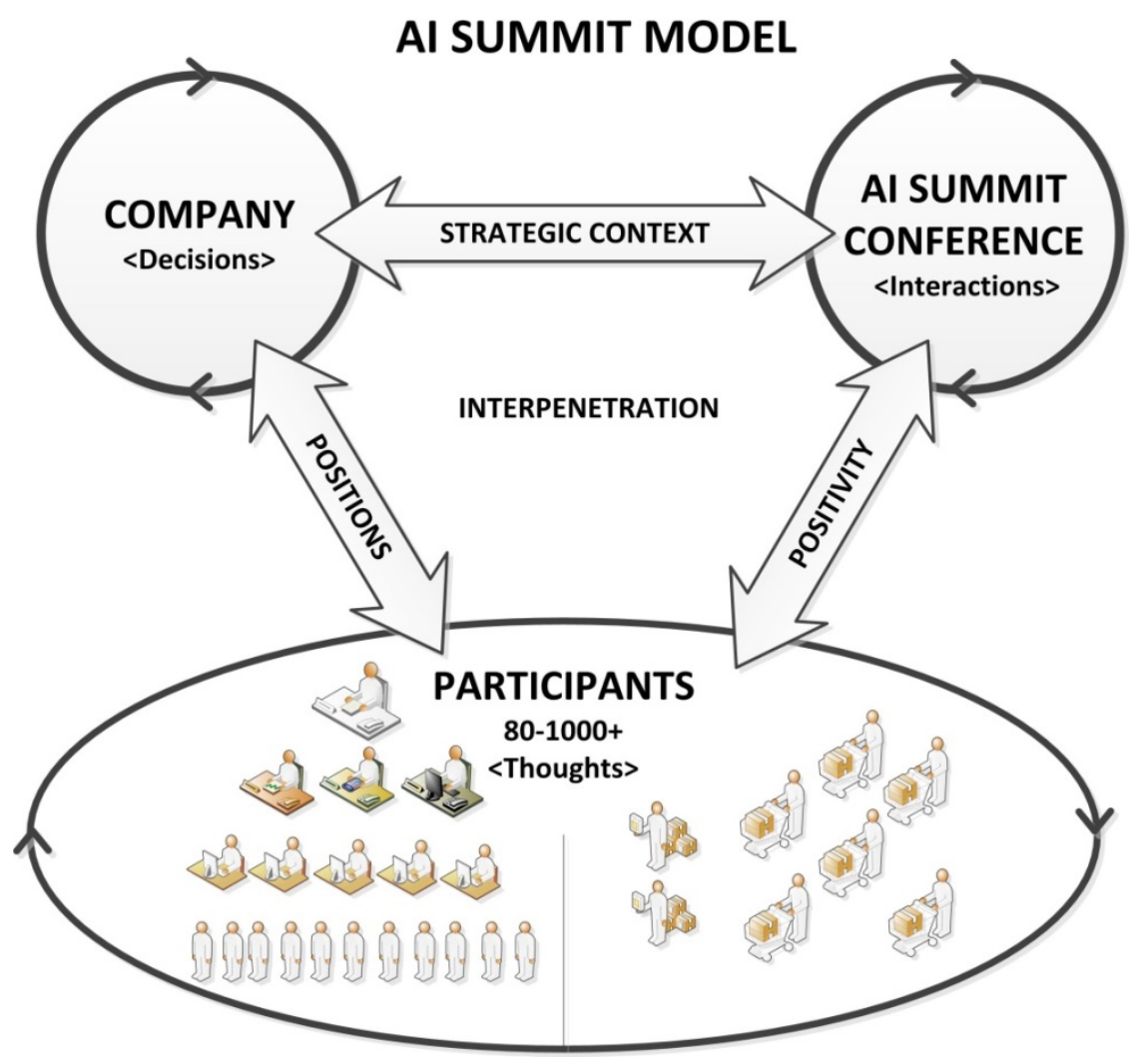

Figure 4 Social systems model of an AI summit

An AI summit differs from most of its large group peers in two major ways. First, the method adheres to the principle of positivity and focuses exclusively on strengths and opportunities. Second, the scale of the conference is much larger than most other methods. Using virtual conferencing technologies, for example, World Vision conducted a summit which had several thousand participants. How do these two points affect the dynamics of the conference 
compared to the two models I described above? Before doing so, let me reiterate the key components and relationships in the model for clarity.

I conceptualize an AI summit as a strategic episode comprised of three different types of autopoietic systems: an interaction system, an organizational system, and psychological systems. The interaction system is the actual proceedings of the strategizing conference. There is only one organizational system that is structurally coupled to the interaction system: the company hosting the summit. Organizations external to the company such as customers and consulting firms, are only indirectly coupled to the conference by virtue of the individual representing them. Every individual participating in the summit is a separate psychological system-closed, selfreferential and autonomous. For the sake of simplicity, the psychological system in the diagram in shows one system, but in reality, there is no "collective" psychological system. There are as many different psychological systems as there are participants. Furthermore, the composition of participants usually fluctuates as the conference proceeds, as not all participants are present throughout the entire conference.

Each system is self-referential and operationally closed. Each operates under idiosyncratic logics and assumptions. The interaction system is the environment for the organization and the individual participant. Systems can interact with one another, but cannot directly change what lies inside the other system's boundaries. Systems can merely perturb the other system, and the perturbed system selects its response based on its own logic, not that of a second-order observer.

As I mentioned in Chapter 6, Seidl has posited that the structural coupling of the organization with the associated interaction and psychological systems takes a special form called interpenetration. When systems interpenetrate one another, they become more 
interdependent. Each system makes its complexity available to the other, hence increasing the variety of possibilities that can be exploited in any given situation. An employee of an organization is structurally coupled to their organization system in a very special way. The relationship between the two systems constitutes interpenetration. An employee is an insider who knows their organization much more intimately than an outsider. An employee can make finer distinctions regarding an organization and its decisions, because they grasp the complexities of the organization. Activists may call for Nike to stop producing sneakers in factories that employ child labor, to which a Nike employee might respond, “It's not that simple.” The Nike employee may fully agree with the activists, but they also know of the barriers that prevent Nike from immediately making that decision.

Like other strategy meetings, psychological systems-the participants-are each individually coupled to the organizational system through their positions. Organizational members in particular, unlike external stakeholders, can penetrate into the organizational system and vice versa. The sheer number and variety of the organizational members present at an AI summit, means that in the gross, the web of couplings between the organization and the participants is extremely tightly and finely woven. But at the same time, the strategic context of the conference also temporarily releases the participants from the existing structures, such that ordinary channels of communication, programs, operational routines are suspended. Internal communication barriers can therefore be substantially lowered. AI’s emphasis on positivity may have an additional impact on the participant's psychological systems through the effects of positive emotions. Positive emotions may have a role in further lowering communication barriers by broadening cognition (Johnson, Waugh, \& Fredrickson, 2010) and enhancing psychological safety (Edmondson, 1999). Emotional contagion seen in large groups can stimulate the levels of 
positive emotions even higher. Such positive emotions could have a priming effect that carries over to some of the activities later in the $4 \mathrm{D}$ cycle that are more conventional forms of strategizing that do not necessarily emphasize the positive.

The relationship between the interaction system (i.e. the actual summit proceedings) and the organizational system is also moderated by the AI method, but in a different manner. In the case of individual participants, the interaction system can penetrate the complexities related to human psychology and their bodily functions. People produce thoughts in order to maintain their autopoiesis. They are subject to their biological makeup, such as the physical embodiment of emotions and feelings for example. This suggests that the principle of positivity will impact people mostly in terms of positive psychology. AI's deliberate focus on the future and on strengths may orient their thoughts on experiences that they have forgotten or had not even imagined.

The events of an AI summit influence the organizational system differently. First, the principle of positivity orients an organization to deliberately develop self-descriptions that draw on the positive dimensions of an organization. An organization maintains its autopoiesis by producing decisions that try to absorb uncertainty. Consequently, an organization tends to ignore the historical details leading to a particular decision. Decisions are further condensed into decision premises relating to roles, personnel and communication channels. An organization, therefore, is forgetful.

The working assumption of AI is that people have a tendency to pay attention to problems. If this is so, then the organization's operational routines are conditioned to deal with problems. Drucker has suggested otherwise: to starve the problems and feed the opportunities. An AI summit affords an organization the opportunity to reflect upon a blind spot-areas of 
strengths and opportunities that may have been relegated to an organization's nonknowledge (Seidl, 2007). For example, an entrepreneurial company that is growing rapidly runs the risk of forgetting the core competencies and values upon which it was founded as it adds new layers of management and hires new people. An established company that is stuck in a rut may be able to reassess its portfolio by purposefully seeking pockets of innovation that are hidden in organizational nooks and crannies. In both cases, such information may have been either taken for granted, or overlooked and pushed into the dark side of knowledge. AI's positivity principle affects the organization in large part, because of the novelty and rarity of orienting its attentions to areas of strengths.

The AI summit format adds a crucial dimension to the strategic episode: the impact of a democratic form of strategizing. It is the combination of a positive orientation with participative decision making that is at the heart of AI summits. It is possibly the source of the "positive energy" that so many AI practitioners and participants talk about in their descriptions of an AI summit. In my opinion, the metaphor of energy unwittingly masks the underlying social dynamics that are driving the summit. Luhmann's social systems lens draws our attention to the structural coupling between the organization, the interaction and psychological systems, enabling a more nuanced view of what is going on. Individual participants are coupled to the organization system through their positions in a special way-through interpenetration. AI summits can therefore take advantage of the fact that hundreds of its employees are present.

The AI summit effectively establishes a web of temporary communication channels among its organizational members that enable decisions to be produced and connected in novel ways. One would expect that the sheer volume of decision-making and pre-decision making interactions would be significantly higher than a traditional strategy meeting. It is also significant 
that the summit is heavily oriented towards decision-making interactions, not just pre-decision making interactions. This is possible because of the intense structural coupling between the hundreds of organizational members to the organization system through their positions. Having the whole system in the room is the equivalent of having the organization's structure physically present in the room through the presence of the vast number of participants. The organization can tap into the complexities of its participants, including institutional history, subject matter expertise, transactive memory (Wegner, 1987), skills, cognitive biases, personalities and subjective experiences, that are accessible by the participant but to which the organization is blinded. Not only does the interaction system structure interactions to facilitate strategic reflection, but it also provides an opportunity for decisions to be produced in real time while the strategic episode is ongoing. I expand on this in the next section, drawing on literature about strategic episodes.

\section{Strategic episodes}

Luhmann's social systems theory compels us to see organizations and other social systems as an intricate intertwining of processes. It is consistent with a growing body of literature in strategic management that emphasizes the study of strategy process. In 1992, van de Ven made some suggestions for “understanding how organizational strategies are formulated and implemented and the processes of strategic change” (p. 169). Of the four types of theories of process that van de Ven identified-life cycle, teleology, dialectics, and evolution (p. 176)— Luhmann's theory would loosely fall under evolution, as it draws on a theory of biology in which "change proceeds in a continuous process of variation, selection, and retention" (p. 179). Such factors like timing, the sequence of events, the variety of options available, the premises for 
selection and changes in structure, play a crucial role in understanding how strategy is formulated in an organization.

As in any evolutionary approach, temporality is of crucial significance in Luhmann's theory. To facilitate his theorizing of societal change, Luhmann developed a concept he called episodes. An episode is a sequence of communication marked by a beginning and an end. At first sound, this seems trivial. But the notion of episodes is vital in explaining how a closed, selfreferential system can achieve structural change. Luhmann developed the concept of episodes in reference to societal change. Hendry and Seidl (2003) extended it to the context of organizational change. "Episodes provide opportunities for the normal constraints of communicative practice to be suspended and alternative communicative practices explored” (p. 180). They defined a strategic episode as the mechanism by which organizations can temporarily suspend its operating structure to reflect upon and change those structures. It allows for an organization to reflect upon its nonknowledge, the blind spots in its knowledge.

Here, we must once again, jump into the rabbit hole of Luhmann's theorizing. The original concept of episodes captured the temporal aspect of the relationship between the societal system and its associated interaction systems. In the context of the greater society, Luhmann (1995) explained that episodes are possible because of our "certainty that societal communication has been going on before the episode begins” (p. 407) and that we presuppose that there will be "sediments of earlier communication" in the episode. Episodes "are possible only because one knows that societal communication will still be possible after the episode concludes" (p. 407). Episodes "serve to achieve structures that cannot be made congruent with society and yet equip it with complexity by building in differences” (p. 407). Noted Luhmann, 
"Complex societies are stable precisely because they can be broken down; they acquire permanence because their composition can change” (p. 407).

Luhmann's concept of societal episodes can be extrapolated to organizations. It is through episodes that an organization can be relieved of the stress of being an organization-the constant stress of absorbing uncertainty—-to explore its nonknowledge, and possibly change its existing structures and decision premises—its organizational knowledge.

A strategic episode is an episode in which the context of the participants' conversations temporarily switches over from an operational context to a strategic one. From an organizational systems perspective, this switch is not about a change in mindsets. Mindsets belong to the cognitive domain and, as such, are confined to psychological systems. An organization is a social system and cannot have a mindset of its own. What changes in a strategic episode is the context in which the organization observes itself. It temporarily suspends the decision making premises of the organization, so that it can make modifications to those premises if necessary. It can do so because of the temporal and special nature of strategic episodes. "The episodic strategic communications are marked as exceptional and take into account that they will come to an end at some point, after which a switch back into the established (operational) context, with its established structures, will take place” (Hendry \& Seidl, 2003, p. 184).

The way in which interactional communications during a strategic episode are structured will clearly have consequences for the outcome of the episode. Noted Seidl and Hendry, "If all those involved are allowed to voice their concerns, a specific topic will be discussed differently from when only the more senior staff are allowed to voice any criticisms” (p. 184). The selection of who gets to participate and how will be an important factor to consider when analyzing 
strategic episodes. Hendry and Seidl suggested an analytical framework for studying strategizing by attending to three critical aspects of episodes:

(1) the ways in which they are set up, within which the focus is on the determination of which structures are or are not suspended and on the necessary 'decoupling' of the episode from the organization as a whole;

(2) the ways in which they are terminated, within which the focus is on the mechanisms for 're-coupling' the strategic reflection with the organization; and

(3) the ways in which they are conducted, within which the focus is on the discourses generated and the types of reflection achieved. (p. 189)

An AI summit can be conceptualized as an interaction system which functions as a strategic episode for the organization. The organization decides who participates in the episode according to the principles prescribed by AI, such as whole system participation. The conduct of the episode is constrained by the processes prescribed by the AI summit format, including the expectation of pre-defined deliverables at the end of the strategic episode. The episode terminates when the summit ends. The end time is decided by the organizers before the summit. Situating the AI summit as a strategic episode has the advantage of enabling a more systematic comparison with other strategy workshops. An AI summit can be further conceptualized as a special type of strategic episode which consists of a series of back-to-back strategic episodes over multiple days. This surely has implications for the outcome of an AI summit compared to a regular strategy workshop. For example, the cumulative amount of man-hours devoted to collective strategizing during an AI summit is exponentially higher than a typical strategy meeting. Other characteristics can be observed as well by analyzing each individual episode. Later in this chapter, I introduce a typology that can aid such an analysis. Before doing so, I would like to diverge slightly to make an important point, namely that strategic episodes are valid not only as a method for changing strategies, but also for stabilizing and reinforcing existing ones. 
Jarzabkowski and Seidl (2008) used the Luhmannian framework in their study of strategy meetings at a university in the UK. An interesting finding was that in a "loosely coupled" (Weick, 1976) professional organization like a university, strategic episodes serve to stabilize and steady its strategic orientation. A loosely coupled organization is one that is flatter and more autocratic. The suspension of structures during strategic episodes in such an organization appear to have different connotations relative to "the traditional tightly structured machine bureaucracy implied by Hendry and Seidl” (Jarzabkowski \& Seidl, 2008, p. 1417). A strategy meeting at a university enables its participants to relinquish departmental and/or professional interests. Powerful faculty members, for example, may be more willing to accept the "authority structures implicit in a meeting” (p. 1418). This raises the profile of administrators and top managers whose authority tend to be corroded in the day-to-day reality of university life (Citing Cohen and March 1974 and Denis et al. 1996, 2001 in Jarzabkowski \& Seidl, 2008). The authors speculated: "Given the fragmented, goal-divergent, pluralistic interests within universities, meeting practices might serve an important function in stabilizing the university's overarching orientations and giving authority to one group to shape the university in particular directions” (p. 1418). This implies that the effect of suspending the everyday assumptions of an organization will depend on the context of each organization.

Many case studies of successful AI interventions deal with organizations and communities that are "tightly coupled." If a company is seeking transformational change, the implicit assumption is that it is stuck in its past, unable to adapt to the turbulent changes in its external environment. Internal conflict, bureaucracy, and/or a command-and-control culture, may be the barriers to change. AI can provide the means for the organization to suspend those realities by temporarily uncoupling the organization from its everyday operations to discuss and 
create an alternative future. More recently, AI summits have been successfully deployed in more loosely coupled environments. The City of Cleveland, for example, has been conducting annual AI summits since 2009 to galvanize a scattered community toward a common purpose. Their goal is to generate concrete projects aligned to the mission of building "a green city on a blue lake” (Jackson, 2009). This is an intra-organizational effort in which the organizations involved are coupled very loosely, if at all. Such initiatives suggest that an AI summit can be useful in various contexts.

\section{Typology of strategic episodes}

Not all strategic episodes are created equal. The context, participants, and activities will differ from episode to episode. Moreover, the nature of the coupling relationship between the organization and the interaction system needs to be considered, as this will influence whether decisions made during the episode can reconnect back to the ordinary operations of the organization. A strategic episode marks a temporary suspension of existing structures, routines and assumptions. Put another way, it is a temporary suspension of organizational knowledge.

Each dimension of an episode can be coded according to the degree of suspension it achieves ranging from extremely high suspension (strategic) to no suspension (status quo). I conceptualize the AI summit as a strategic episode that is made up of a series of episodes. Each episode will vary in the degree to which existing structures are decoupled. Sometimes, organizations will conduct routine business during the AI summit-after all, it is rare for so many of its organizational members to be present at the same time in the same place. I posit that one of the unique social dynamics of an AI summit is the constant oscillation between strategic and operational contexts. I suspect that such oscillations may play a role in how decisions produced during the episodes connect back to the autopoiesis of the organization. 
I would like to point out the intended unit of analysis in this typology is episodes, and not individual participants. An alternative approach would be to code each individual participant separately. The strategic orientation of the action planning exercise in the Destiny phase will differ widely from individual to individual. For middle managers, strategic planning may be a routine activity that is not much different from what they do on a day-to-day basis. While they may be more inclined to think strategically due to the nature of the overall context of the conference, they nevertheless will be prone to ground themselves in reality, especially if they are to be held accountable for future results. In contrast, for employees at the fringes of the organization as well as external stakeholders, the exercise is so out of the ordinary that they may be better able to think out of the box. Conflict, gridlock or breakthroughs may ensue, depending on the dynamics of the group. Luhmann's theory is not very helpful in understanding the dynamics between individuals, however. Other theories drawing from social psychology, behavioral economics and philosophy (e.g. critical systems heuristics, W. Ulrich, 2005) may have more utility when the unit of analysis is the individual.

In this typology, I categorize episodes according to the strategic orientation of the overall episode, group composition, the nature of the activities and the degree of structural coupling between the interaction system and organizational system (Figure 5). Figure 5 shows the overall picture of the typology I am proposing. An individual episode can be broken down into at least four components: overall strategic orientation of the episode, activities, diversity of the group, and the degree of decoupling from the organization's existing structures. One can imagine a dial that increases or decreases the degree to which the status quo is suspended ${ }^{1}$. Each component has its own dial that controls the level of suspension. The components in concert produce the

\footnotetext{
${ }^{1}$ The image of a dial was inspired by Scott Page in his lectures on complexity in The Great Courses.
} 
episodes of the interaction system. Over time, these episodes produce interactions that perturb the organization system, which may respond by producing decisions. Some of these decisions may have an effect on existing organizational structures-namely the organization's knowledge base.

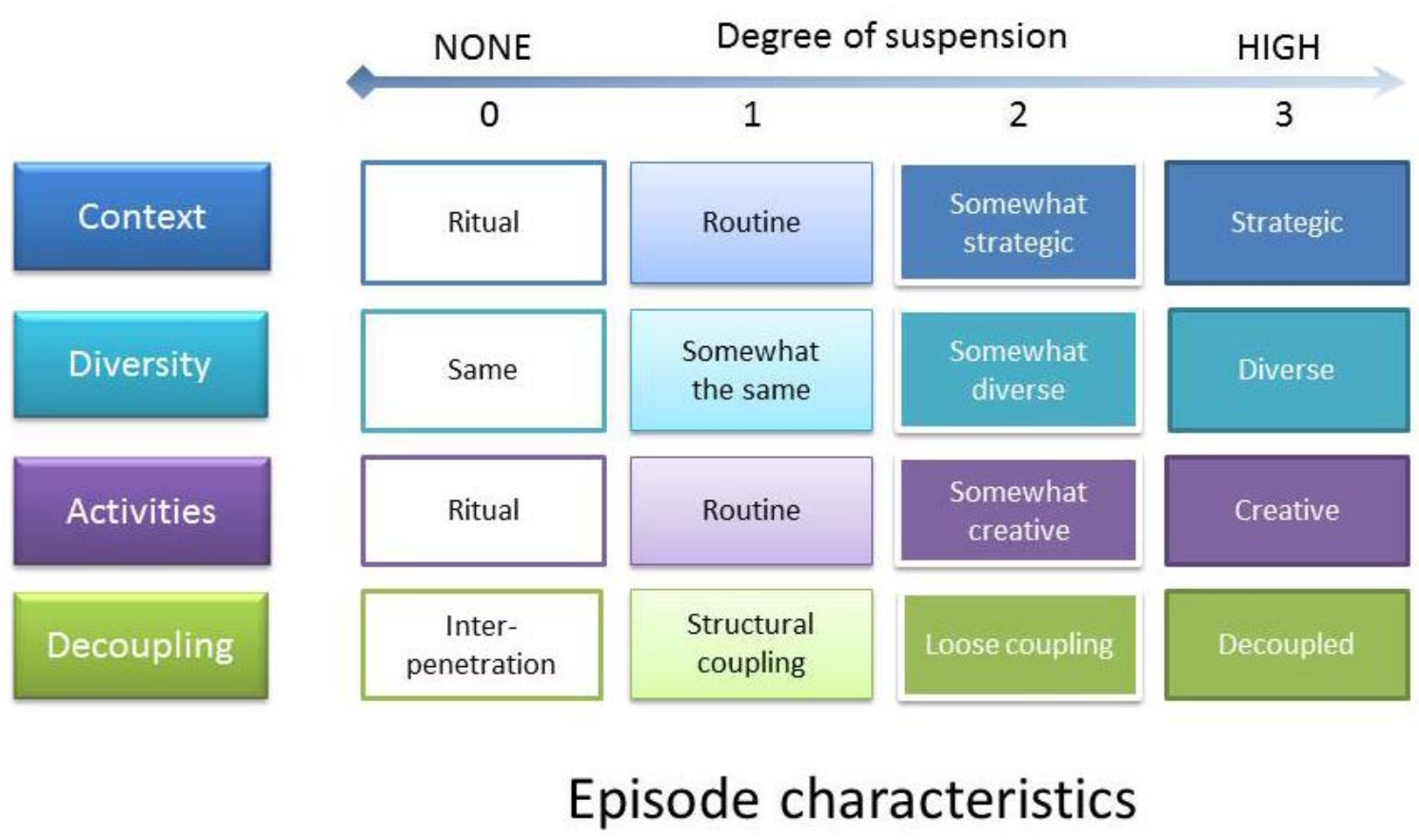

Figure 5 Topology of episodes

\section{Strategic context.}

An individual episode can be described by the overall degree to which the episode expect its participants to suspend organizational routines and reality. A sliding scale ranging from high suspension to no suspension can characterize the strategic orientation of the episode. I propose the following four point scale in descending order of suspension: strategic, somewhat strategic, business-as-usual, and ritual. Detailed coding criteria would be required for an empirical study. This scale is useful in showing how a series of episodes oscillate between the two extremes over 
time. Many of the episodes in the Discovery phase could be coded as "strategic" as the participants engage themselves in activities like appreciative interviews, which focus their attention specifically on the organization's strengths. In contrast, a presentation by the CEO on industry trends can range anywhere from "strategic" to "ritual” depending on the content and context. It could be coded as "somewhat strategic" if the majority of the participants were frontline employees. For them, receiving such information from the CEO is not a routine event. If this were a smaller strategy workshop involving only the top management, the episode could be coded as "business-as usual." An award ceremony during the summer recognizing high performers can be characterized as a "ritual” that reinforces the existing incentive structure.

\section{Diversity.}

The composition of groups changes quite dramatically during the course of the summit, creating another level of oscillation between the strategic and the routine. This has implications because heterogeneous and diverse groups—the so-called "max-mix" groups—will inevitably produce new communication channels. If those temporary channels become permanent, then it opens up the potential for novel decisions to be produced. A homogenous group does have the potential to produce new pathways, if the topic of discussion during the episode is highly strategic in nature. Otherwise, a min-mix group is more likely to gear towards the routine.

In this typology, group configurations are categorized along the degree of suspension of existing functional roles within the organization. Four categories are proposed: diverse, selfselected but mostly diverse, self-selected but mostly routine roles, and routine roles. The plenary, large group session in which every participant is present would likely represent the highest level of diversity in the room. In contrast, an episode that divides the participants up into groups according to their corporate functions could be coded "routine." In the second half of the 4D 
cycle, Design and Deploy, participants often self-select themselves into groups. Some groups may be skewed more towards routine than diverse or vice versa.

Diversity indices that are used in biology can be applied in the analysis to quantify the different levels of diversity of groups. The Simpson Index (Simpson, 1949) calculates the degree of concentration of certain species in a given population. This diversity index takes into account both the richness of species and the evenness with which individuals are spread out among species. Statistical software packages such as PAST (which was developed for paleontologists) can be used to compare the diversity indices of different populations. I will give an example of how the index can be used in Chapter 8.

These diversity indices only show the level of diversity and not the qualitative difference between groups that are more or less in alignment with existing functional roles and positions in the organization. These would have to be coded separately. Care is needed in the unit of analysis. One of the hallmarks of large group methods is the use of small groups in large group configurations. Comparing the large group session against other small group activities may be comparing apples to oranges. Luhmann's theories give no guidance for analyzing group or individual dynamics on such a micro-level. I defer to future studies that may better describe and explain the different impacts of group composition on the knowledge creation process.

\section{Activities.}

The actual strategizing activities of an AI summit episode are decided by the organizers. Most if not all are strategizing activities that conclude with a particular deliverable. Common activities include discussions, interviewing, cognitive mapping, presentations, prototyping, strategic planning, and brainstorming. These activities can be coded according to a scale 
developed corresponding to the relative creativeness and unusualness of the activity, such as creative, somewhat unusual, normal, and ritual.

Some summit activities are unique to the AI methodology. Appreciative interviews, positive core mapping, and creative dreaming (Ludema et al., 2003, p. 33) are hallmarks of AI. These strategizing activities focus attention on strengths and opportunities in a format that is outof-the-ordinary for most participants, and could be coded as "creative." Others, such as brainstorming, practical tactical planning (Ludema et al., 2003, pp. 197-198) and the formation of innovation teams (Ludema et al., 2003, pp. 193-196) are more traditional planning exercises. It is the context in which such exercises are conducted-the unconventional setting and unusual combination of the individuals who are participating-that makes them creative, not the activities themselves. These could be coded as "somewhat unusual” or "normal” depending on the organizational context.

\section{Decoupling.}

The final dimension I identify is the degree to which the organizational system is tightly coupled to the interaction system. The tighter the coupling, the more likely a decision may endure and produce further decisions, because the decision can enact existing decision premises. If the coupling is loose, a decision may vanish for lack of communication pathways that can produce more decisions. The level of coupling affects how a system selects decisions and interactions for further consideration. An interaction system that is not coupled to the organization system at all will have great potential for working with innovative ideas. The community summit on sustainability organized by the City of Cleveland is an example of a summit with little coupling to any one organization system, due to the wide variety of organizations participating. On the other end of the spectrum, if the two systems are structurally 
coupled (e.g. a summit in which all of organizational members are participating), then the decision making premises of the organization likely to carry over to the summit and vice versa.

The consequences for such coupling on organizational knowledge creation depends on the structural rigidity of the organization engaged in the summit. At a summit of a highly rigid, bureaucratic organization, a decision by a person in a certain position during the strategic reflections at an AI summit will automatically connect back to the existing organization and become an organizational decision, if the summit is structurally coupled to the organization's system. If the CEO seems wildly in favor of an innovative idea, then it is more likely that the middle managers who can execute the idea will align themselves around it, and subsequently involve themselves in a project team. Conversely, a disruptive, innovative idea may have less chance of being selected during the summit if a high-ranking executive who feels threatened by the idea shoots it down, and as a result, prevents any further decisions related to the idea from being produced. Furthermore, if some key decision makers who yield significant power over a bureaucratic organization are missing from the summit, the coupling between the organization and interaction system could be characterized as loose. What happens at the summit may have little bearing on the organization because of the absence of those decision makers. An innovative idea might have legs during the summit, only to lose momentum after the summit concludes. The absence of front-line employees could have similar consequences.

The impact of decoupling in the context of organizations that are loosely structured is less clear. Having all the organizational members present at a summit (i.e. structurally coupled) may serve to temporarily tighten the couplings within a loosely structured entrepreneurial startup. The summit can help stabilize organizational knowledge in this case. The flipside is that if the summit is only loosely coupled to the organizational system, then the conference might not have 
much impact on the knowledge base of the organization. One could speculate that positive momentum would not be enough to produce changes in organizational knowledge in this scenario. There is relatively little research on the impact of AI interventions on entrepreneurial companies. Luhmann's theory guides us to study the nature of the coupling between the interaction and organization system. Further theoretical and empirical studies are necessary to develop frameworks for understanding the consequences of these couplings on the outcome of AI summits, especially on entrepreneurial companies.

\section{Summary}

In this chapter, I drew on research by Seidl and his colleagues to begin developing some conceptual frameworks for viewing AI summits through a social systems lens. An AI summit can be observed as a strategic episode which allows an organization to suspend its existing structures to reflect upon itself in a strategic context. The social dynamics of the episode are driven by the structural coupling of three types of autopoietic systems, the organizational system (the AI summit's host organization), an interaction system (the AI conference proceedings) and hundreds of psychological systems (individual participants of the AI summit). The structural couplings of the three systems are special. Not only can they trigger mutual perturbations in their respective systems, they can penetrate the system and leverage the internal complexities of the other system. Employees of an organization come to know their organization so intimately, that they will take into account the complexities of organizational life when performing their organizational duties. For example, employees might anticipate the subtle but inevitable internal power struggles that could result from a certain decision, and adjust their actions accordingly.

I posit that this coupling mechanism reduces both external and internal communication barriers in developing and executing strategy. As a consequence, the organization is also better 
able to access knowledge that is ordinarily inaccessible — its nonknowledge — and use this knowledge as the basis for producing decisions. The coupling mechanism also serves to orient the interactions such that decision interactions are produced while the strategic episode is ongoing, condensing the time required to execute a chosen strategy.

In order to further identify some of the signature social dynamics of an AI summit, I develop a typology for comparing different episodes. I focus on the strategic orientation of the episode, the degree to which the episode requires a suspension of the organization's existing structures. I identified four dimensions of an episode: the general context, diversity of participants, creativity of activities, and the degree to which the interaction system is decoupled from the organization. Compared to other practices of strategizing, the AI summit is differentiated by the variety and number of episodes that occur during the course of the overall strategic episode. Each episode can be coded by these dimensions along a scale that denotes the degree to which organizational routines are suspended. More detailed coding criteria need to be defined for an empirical study. Based on how an AI summit is typically conducted, an AI summit can be conceptualized as a series of interlocking episodes that together, systematically comprise a strategic episode. As the summit progresses, the episodes oscillate between varying degrees of suspension that create a dynamic that is unique to the format. In the next chapter, I develop these ideas further and connect them to how an AI summit might generate organizational knowledge. 


\section{Chapter 8 The AI Summit as a Knowledge Creation System: An Illustrative Case}

\section{Introduction}

In this chapter, I explore in more detail the third step in Mohe and Seidl's (2011) proposed methodology for analyzing the "contact system” of a consulting project, as it applies to an AI summit. A contact system is where consultants and their clients meet during the course of a consulting engagement, often to discuss and develop strategy. As I argued in the previous chapter, the AI summit can be viewed as an OD consulting project, as there is usually an external AI consultant involved during various stages of the AI summit project lifecycle. For this study, I limit the analysis to the actual AI summit conference itself. It is a part of the overall contact system in the client-consultant relationship.

In Chapter 7, I conceptualized the AI summit as a contact system that consists of the hosting company's organization system, the conference proceeding's interaction system, and the hundreds of psychological systems belonging to the individual participants. These systems interpenetrate one another, enabling not only mutual perturbations in their structures, but also giving them an ability to take advantage of each system's internal complexities. To borrow a term Luhmann used for interpersonal relationships, the structural coupling between the systems is intimate. The principles and activities of the AI approach influence and serve to structure the interactional communications that take place at the strategy conference.

Having identified the component system and the relationship between the systems, I move onto the third step: “examine how their mutual perturbations are internally (re)constructed” (Mohe \& Seidl, 2011, p. 18). By now, the concept of mutual perturbations and closed but simultaneously open systems is hopefully familiar. All three components of the contact system are autopioetic. They also share a common feature in that they are meaning-making systems. 
Each system operates using different modes of production. An organization produces decision communications, an interaction system produces interactional communications, and a psychological system produces thoughts. They are closed from each other in terms of how they produce meaning. Nevertheless, the systems are structurally coupled. This means that the same event can simultaneously trigger mutual perturbations in their internal structures in such a way that they are able to co-evolve.

Mohe and Seidl (2011) concluded in their theoretical study that a consulting project can be described by a third-order observer (such as a researcher) as processes of "co-evolutionary knowledge creation...between the client, consultant and contact system” (p. 18). The word coevolutionary should not be taken lightly. Mohe and Seidl's controversial argument was that under Luhmann's theory, knowledge transfer between the consultant and client is "entirely impossible because these [systems] are operatively closed" (p. 17). All a consultant can hope for is that the misunderstandings with their clients "be productive to some degree” (p.17). Clegg and his colleagues (Clegg, Kornberger, \& Rhodes, 2004) described the parasitical role of management consultants "as a source of 'noise' that disrupts established ways of doing and being by introducing interruptive action into the space between organizational order and chaos” (p. 31).

What is noteworthy about an AI summit is that the social dynamics of the contact system differ significantly from a typical consulting project by design. The origins of AI lie in action research, a mode of inquiry where the ideal state is a partnership between scholar/consultant and practitioner/client in building theory. Large group methods evolved, in part, in response to the deep-seated communications problems that Luhmann identified. That the consultant's role drastically diminished in AI is only one of the points of differentiation. More significant is the active engagement of hundreds of organizational members who are traditionally excluded from 
the inner circle of strategy. Not only are they present, but they are also expected to contribute to the organizational outcome.

This brings me back to my original research question: How and why does an AI summit, as a whole, create organizational knowledge? The question implies that one of the purposes of an AI summit is to create organizational knowledge. I use examples from a case study of an AI summit I attended in 2008 to examine in more detail the co-evolutionary processes of knowledge creation. But first, I would like to clarify what organizational knowledge creation means in social systems theory, and how it might be created at an AI summit.

\section{Knowledge creation at an AI summit}

Some scholars have situated AI as an incubator for innovative ideas. Richer and her colleagues looked at an $\mathrm{AI}$ intervention at a hospital in terms of how the participants generated innovative ideas that might transform the workplace. They drew on Nonaka's knowledge creation theory to explain how AI created a shared context from which organizational knowledge emerged. If we are to accept Mohe and Seidl's argument regarding the impossibility of knowledge transfer, however, this has detrimental consequences for knowledge management in general, and Nonaka's theory in particular. Luhmann essentially made the case that knowledge is not a resource that can be transferred, shared, controlled and managed. If so, then the resourcebased view of the firm (Barney, 1996), upon which Nonaka's theory is based, can not apply to knowledge.

According to Seidl's interpretation, knowledge, in the Luhmannian sense, is defined as how systems deal with information, not the information itself. This is an important distinction. As Spender (Spender, 2007) noted, theories of knowledge often implicitly or explicitly use a schema that distinguishes between data, information, knowledge and wisdom. According to 
Spender, this is known as the DIKW model, proposed by Ackoff in a 1989 paper (p.183). The model is like a ladder "of increasing cognitive power" (p. 189). The bottom rung is data which has no meaning. A step up is information-meaning added to data. Knowledge is "useful aggregations of information." At the pinnacle is wisdom, "bringing understanding into the context of the human condition” (p.189). Spender wrote that this widely-used model "may be more popular than useful since its axiomatic differences remain submerged beneath poorly defined terms” (p.189).

In social systems theory, knowledge is analogous to a lens. How the system sees will depend on the type of lens it uses. The same object will look wildly different through a telephoto lens than through a fisheye. "Observation is not knowledge. Rather, knowledge is something that guides observation” (Seidl, 2007, p. 16). Each lens is constructed using a particular structure. The structure of a fisheye lens, for example, creates an image that widens what the camera can see. The camera can see more of what is in the frame, but with a price: fisheye lenses strongly distort vision in such a way that the object looks as though it is curved. In this analogy, knowledge is not the image that the camera sees. Knowledge is the lens itself. Knowledge is therefore structure. And it follows that organizational knowledge is the equivalent of organizational structure.

Organizational knowledge determines the organization system's evolutionary path and process. The system's structure-that is its knowledge-determines and selects whether the difference makes a difference, and if it does, what difference it makes. "From the infinite number of possible observations, [knowledge] selects certain possibilities of observations and excludes the remaining possibilities” (p. 18). Since knowledge is the system’s internal structure itself, it is not a resource that can be transferred in and out of the system. An organization's internal 
structure determines how it selects and produces decision communications. This is what decision premises do, and thus, decision premises are an important element of organizational knowledge.

Taking a Luhmannian view of knowledge does not mean we ought to discard Nonaka’s theories and other theories drawing on a resource based view of organizations. On the contrary, the SECI model is extremely useful in understanding how organizations can fully leverage the collective knowledge of its individual members both inside and outside the organization. Operationalizing tacit knowledge through cognitive mapping (Ambrosini \& Bowman, 2001), for example, is a technique that is often used in an AI summit to identify strengths and opportunities. Viewing knowledge as structure fixes our gaze onto a different part of the organizational landscape. We are simply transforming one side of the equation into another form. The concept of knowledge as cognition is only possible for systems with a cognitive system, in other words, a psychological system in Luhmann terms. For organizations, knowledge is the equivalent of its organizational structure that determines how it deals with information in order to select and produce decisions.

In this brief illustrative case study, I limit my observations to one type of organizational knowledge/structure, decision premises. Structure, broadly defined, can extend to an organization's culture, including its normative values. These are typically harder to change and more difficult to observe. Structural changes in the cultural domain might happen during the course of an AI summit, but it would be a stretch to attribute such changes only to the summit. Decision premises on the other hand are malleable. New decision premises are much easier to create than a new value system. Decision premises are decidable. The structures are changed if the operations/observations are inconsistent with the structures (Seidl, 2007). 
To recap, Luhmann (1995) defined decision premises as consisting of a combination of personnel, communication channels and programs. These are often bundled into positions. In an AI summit, individual participants (i.e. psychological systems) are structurally coupled to the organization through the positions they hold. An essential element of an AI summit is that hundreds of organizational positions are coupled to the interaction system by virtue of the presence of so many employees. The summit is not an exact replica of the organization. An AI summit is in essence, a strategic episode in which existing structures (i.e. knowledge) are temporarily suspended (Hendry \& Seidl, 2003). But it comes close to simulating the organizational system because of the intimate connection participants have with their organization through their positions.

An AI summit allows an organization to not only modify, stabilize or reinforce existing decision premises (i.e. knowledge), it also opens up opportunities to generate new ones. The most obvious is the production of new channels of communication. Temporary communication channels are established that are expected to last until at least the end of the strategic episode. At the very beginning of a summit, table groups are usually deliberately set up for maximum diversity. A marketing executive may be placed next to a truck driver for example. Some channels may persist beyond the strategic episode. At the U.S. Navy, informal communication networks emerged after the summit (Powley et al., 2011). This would be an example of a mutual perturbation-a perturbation in the internal structures of the organization and psychological systems - that facilitate the production of more decision communications and thoughts into the future.

The summit is designed to stimulate reflections on the blind spots within the organization, especially an organization's positive aspects. Knowledge that lies outside an organization's field 
of vision — its nonknowledge-is made temporarily available through the strategizing activities that take place. Areas of strengths and opportunities that were mere potentialities prior to the summit can be made explicit, and become the object of decisions. New programs and initiatives are generated as a result. Figure 1 is a visualization of this process.

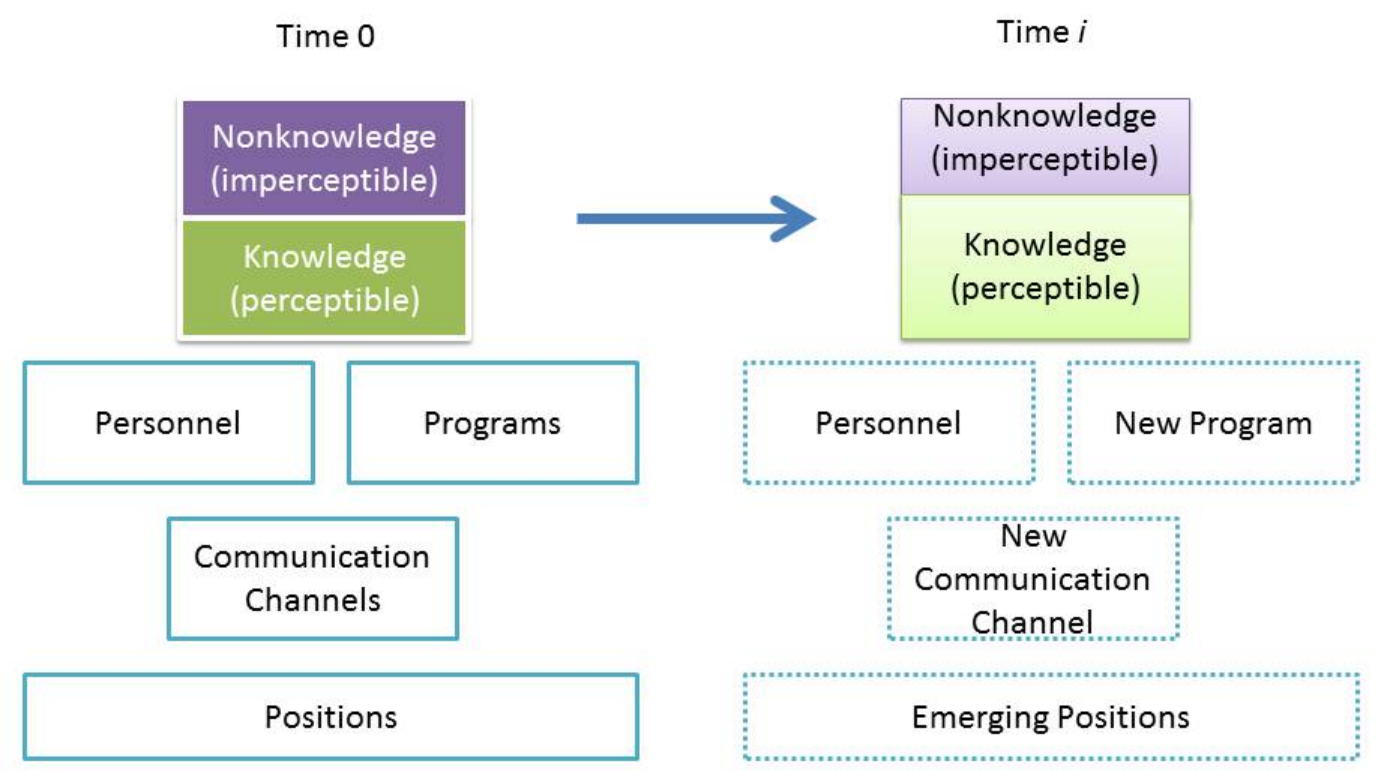

Figure 1. The translation of nonknowledge into knowledge enables new positions to emerge during the strategic episode, often in the form of self-organized project teams.

Time 0 represents the decision premises and organizational knowledge base at the beginning of the summit. The distinction between knowledge and nonknowledge shifts as a consequence of strategic reflection. Some personnel may self-assign themselves to a particular new initiative. Communication may happen through new channels. Such emerging positions, however, are tentative arrangements. Only when they can carry over to the organization's regular 
operations after the summit, will the dotted lines of the emerging organizational structure (i.e. knowledge) become solid. This is why the self-organizing project teams that often emerge from the strategizing activities are so crucial to a summit's success. These are the vehicles through which an organization can continue to produce decisions long after the summit continues. This suggests that maintaining a positive “momentum” after the summit is not enough. The key to an AI summit's success may be dependent on whether the organization decides to convert these tentative arrangements into more permanent structures. If the knowledge structures stick, they would form the basis for producing new options for decisions, allowing the organization to follow a different evolutionary path.

A social systems view of an AI summit requires one to focus on how decisions connect to decisions that produce decisions about its decision premises. It begs us to pay more attention to the relative fragility or robustness of connections between decisions. Depending on the resiliency of the connections between communications, any tentative changes made to existing decision premises during the AI summit will vanish when the strategic episode ends, and the status quo is restored.

Diffusion of innovation theory (Rogers, 2003) suggests that decisions related to disruptive, innovative ideas, are fragile. As Schumpeter put it, innovation is creative destruction. Those who are on the receiving end of destruction will likely resist. Some people may be supportive of the innovation, but may not have the means nor the knowledge to adopt it. The structures and premises needed for the innovation to diffuse may conflict with existing ones. New communication channels, programs, and people will most likely need to emerge. This is why Drucker (1993) advised companies to set up entrepreneurial ventures outside and beyond the reach of the organization's normal operations. 
Given the social dynamics I identified earlier, an organization wide strategic episode like an AI summit, may function to make more robust, the pathways for connecting decisions relating to fledgling, innovative ideas that would otherwise disrupt the existing organizational structures. This is achieved through a temporary suspension of the status quo to enable strategic reflection. The more disruptive an idea, the greater the requisite degree of suspension. An incremental improvement would not require as much suspension, and hence, the connections between decisions will not be as fragile as a novel innovation. Nevertheless, existing decision premises may still need to be modified to accommodate the incremental improvement. Figure 2 shows the relationship between the degree of suspension and the impact on existing structures.

\section{Impact on existing}

structures

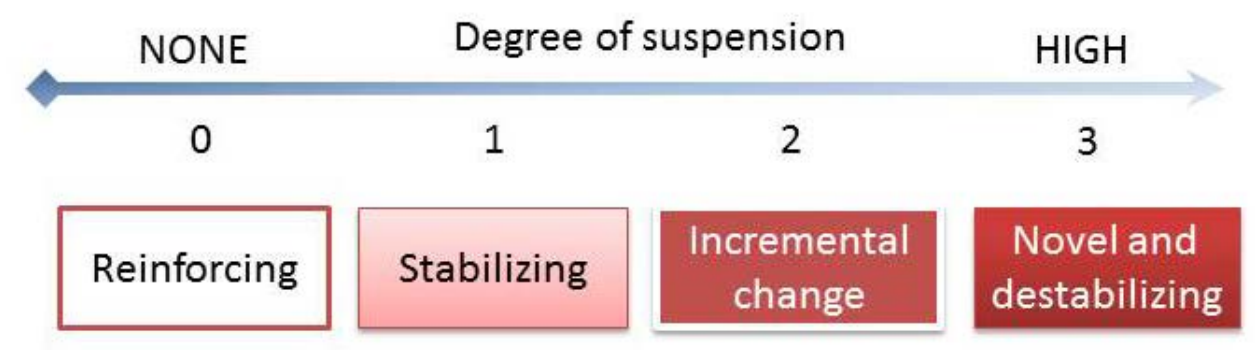

Figure 2 The degree of suspension differs leads to different impacts on existing organizational structures.

In the subsequent section, I draw on my own experience of attending a corporate AI summit to illustrate some of the points I have made above and in the previous chapter. 


\section{The TireCo AI sales summit - an illustrative case \\ Case background.}

In February 2011, I was given the opportunity to participate in a corporate AI summit of a tire company in the mid-west. Many of the most famous case studies of AI interventions involve established companies that were seeking transformational change. This company, which I will call TireCo in this study, was very different. The US automotive industry had been hit hard by the financial crisis. The US government had to bail out GM. Yet this small, young tire company in Ohio was growing at nearly $40 \%$ a year. About 10 years earlier, the privately-held company introduced a new business model for selling tires. Most tires in the US were sold through retailers in the aftermarket for cars. Few consumers considered car dealers as a point of purchase for tires. TireCo saw this as an opportunity. Their mission was simple: find ways to help car dealers sell more tires. TireCo began as a niche player catering to the tire needs of car dealerships. Despite the bleak state of the auto market, TireCo’s business grew at a tremendous clip. By 2011, TireCo had grown its reputation in the tire market and had contracts with many of the auto industry’s largest players including Mercedes Benz and Toyota.

About five years after its founding, TireCo brought in a team of executives who had previously worked for a Fortune 500 company that had used AI in their strategic business planning process. TireCo’s top management team decided to incorporate AI into its business in order to manage their next stage of growth. Among them was the Chief Sales and Marketing Officer (CSMO), who Cooperrider (Personal communication, 2011) regarded as among the most seasoned practitioners of AI summit. In her capacity as an executive in HR and OD, she had overseen dozens of AI summits at her previous company. She had been working with Cooperrider for over 10 years. By 2010, TireCo had been conducting AI summits on a regular 
basis, usually once a year. Each summit focused on a different challenge that reflected the company's phase in their lifecycle. For example, two years prior, TireCo developed its core values and guiding principles using the AI summit format. This was followed by the development of a roadmap for the future—a mid-range strategic plan.

In order to keep up with their double-digit growth in revenues, TireCo found itself in a hiring frenzy. New personnel came on board on a weekly basis. By 2011, the company's head count had risen to about 700 . The past year's AI summit was attended by $80 \%$ of its employees. However, with the growth spurt in headcount, there were no local hotels that had the capacity to hold a corporate-wide AI summit. Management made the decision to conduct two, back-to-back summits, one focused on sales, the other on the supply chain. Cooperrider was the external consultant for TireCo. He introduced me to the CSMO, who invited me to participate in their four day summit as an external stakeholder.

\section{Methodology.}

The reflexivity of the observer is an important consideration in adopting a social systems view. I will therefore briefly describe my involvement in the summit. Less than a year before TireCo's summit, I took an MBA course on AI under the instruction of Cooperrider. I had been interested in AI for several years, having come across a book on AI (Fry, Barrett, Seiling, \& Whitney, 2002) in 2007 while doing informal research on grassroots leadership. As part of the

course requirement, I worked on a group project to design a community AI summit that could bring stakeholders together to discuss and develop plans to alleviate the transportation challenges of Los Angeles. That same year, I entered the doctoral program. My original research plan was to investigate the effects of positive psychology on the outcomes of an AI summit. I was particularly interested in Csikszentmihalyi's (1990) concept of flow, the psychological state of 
being completely immersed in the task at hand. Previous accounts of AI summits, including video footage from the US Navy summits, suggested that participants may be experiencing flow during the conference. In January 2011, I proposed a pilot study to Cooperrider that could help me gauge the feasibility of measuring participants' flow states during an AI summit using a method called experience sampling (Hektner, Schmidt, \& Csikszentmihalyi, 2007).

When I initially proposed the study to Cooperrider, I was planning to be a detached, neutral observer of a summit. He told me that he was facilitating a major AI summit of a tire company, and that he would be happy to refer me to their CSMO under one condition: I would fully participate as an external stakeholder. This made me slightly nervous. Most of the research methods I had studied as a graduate student emphasized the importance of the independence and neutrality of the researcher. I am trained as a journalist, a field that takes a similar approach. Participant observation is tricky, and can take years to master. On top of this, I was not sure that I could contribute much to the sales summit, given that I knew next to nothing about tires. I was skeptical as to what value a complete outsider with no vested interest in the company could bring. TireCo's CSMO however, saw no issues at all, and immediately extended me an invitation. I would pay for my own travel expenses. TireCo would cover all conference expenses, in exchange for a post-summit writeup I would submit to the company later that spring.

Attending TireCo's summit for four days straight, morning to evening, as a second-order observer (i.e. participant-observer) completely changed my perspective of what an AI summit was about. So much of the literature on AI focused on the positive and transformational aspects of AI. But at a summit in the context of a corporate setting such as TireCo, I observed (and also experienced) negativity and conflict during the activities, especially in the second half of the 4D cycle, Design and Deploy. Such conflict though did not appear to have a detrimental effect on 
the outcome of the summit. At the end of four days, the summit delivered 15 business plans that promised to enhance its competitive edge in tire distribution. Prior to going back to graduate school, I spent nearly 10 years as a conference interpreter specializing in meetings and conferences in the business sector. I have participated in hundreds of meetings at many different companies ranging from routine business meetings to highly sensitive board meetings. Often, these meetings were related to strategic planning. I was therefore in a position from which I could compare TireCo with other companies' practices. Indeed, I did leave the summit with positive energy and a general sense of excitement. What I had not anticipated was the practical utility of the AI summit format as a generic strategizing tool. Three things struck me about the 15 business plans that were presented at the end of TireCo's summit: the speed with which they were produced, their quality, and the organic formation of implementation teams.

At the same time, I found issues with my original research agenda. It was not clear to me how the psychological states of an individual could be aggregated to the meso (group) and macro (organization) levels over the course of the four day summit. Flow is a construct developed to measure individual states. While there is some research suggesting evidence of flow contagion (Bakker, 2005), the study of flow in groups and its impact on organizational performance is underdeveloped. The social dynamics that the summit generated were extremely complex on many different levels. For example, I had not considered the level of impact different group configurations have on the conduct of activities, emotions, and outcome. Personalities, positions, and the types of activities seemed so interdependent, that it would be challenging to develop a useful model. In fact, this same issue would apply to other psychological constructs as well. I felt at the time that there was just so much going on during the conference on a macro level that deconstructing it into observable elements may be counterproductive. 
I decided to change my research focus. I went to TireCo's summit with literally no knowledge of the company, beyond a few news articles and what little information they had available on their website. The company was financed through venture capital. It was still at a stage where they were laying low, consciously staying under the radar as they ramped up their business. After four days of participating in intense and strategic planning activities, I left the summit with the sense that I had an intimate understanding of the inner workings of TireCo, which would have taken me months, perhaps years to accumulate had I been working as a journalist or interpreter. No amount of reading reports and articles could have given me what I felt I knew about the company after the summit. It was the experience of being in a microcosm of the organization in which results mattered and people were held accountable to those results that was the source of this knowledge.

\section{Summit overview.}

Annual sales conferences are a common business practice for many companies. Once a year, sales people from different geographies assemble in a conference room to listen to their executives present the sales strategy and business plan for the upcoming year. This was what TireCo's Chief Sales and Marketing Officer was referring to in her opening remarks: "We're not here to present you a business plan.” She talked about how TireCo's conference was different. "We are asking you to create the plan," she emphasized. The summit was taking place in the ballroom of a luxury hotel, about a 10 minute drive from TireCo's corporate headquarters. Roughly half of the entire company was present in the room. The entire selling organization was there. There were also 40 customers in the room-mostly dealerships and representatives of auto makers. The fact that customers were also part of the strategizing activities was emphasized several times during the day by both executives and the facilitator. The topic statement guiding 
the work for the entire three and a half days had been formulated by the pre-summit steering committee. "Efficiency. Effectiveness. Execution. Accelerating leadership at every level to drive dealer solutions which will positively shift the consumer experience.” The statement was also printed in a 41 page handbook, which we used throughout the conference.

The sales summit is conceptualized as a strategic episode in which existing decision premises, such as positions and rank, are temporarily suspended so that participants can reflect upon and describe TireCo from a strategic point of view. Following the social systems model developed in Chapter 6, the organization system was TireCo. The interaction system was the conference proceedings of the AI sales summit. According to the scheduled participant list, just over 360 people were registered to attend at least part of the conference. For the remainder of this case study, I will be using the scheduled participants list as the basis for analyzing participation. At any given point in time during the summit, the number of participants ranged from about 280 and 330 for the strategizing sessions. Participation was lower for social events. Each individual represents a separate and operatively closed psychological system. They are closed because one cannot directly access the thoughts of another. Of the registered participants, 315 were TireCo employees, executives or board members. This means that 315 psychological systems were structurally coupled to TireCo's organizational system through 315 positions. Roughly two thirds (66\%) of the participants belonged to TireCo's sales departments, 20\% were other TireCo employees, executives and board members, and just over 10\% were customers.

For the purpose of the present study, I define an episode as a block of time that the summit organizers have distinguished as a distinct session. In the TireCo case, the organizers drafted a timed agenda that listed all the planned activities at the summit. There were over 50 episodes throughout the summit, including scheduled breaks. These episodes varied dramatically 
in strategic context, group configuration, type of activity, and the degree to which the interactions were decoupled from the organization system. While the majority of participants attended all the episodes, there was a conspicuous absence of customers and executives during the action planning activities of Day 3 and Day 4 in the Design and Deploy phases of the 4D cycle. Furthermore, there was a dramatic contrast between the group activities in the second D of the 4D cycle, the Dream phase, and the business planning exercise in the final $\mathrm{D}$, the Deploy phase, in terms of positivity and the creative nature of the exercise. In terms of a strategy episode, creating and presenting images of the future through group skits required high degrees of suspension of existing structures. Developing actionable business plans, on the other hand, was an activity that is much closer to a routine activity, not necessarily for the individuals involved, but from the organization system's perspective. Existing structures and the social dynamics that come with it appeared to play a greater role in the Deploy phase. The upside in terms of knowledge creation is that when people in positions to make changes in existing premises for decision making, the changes are more likely, thereby increasing the possibility of the interactions during that episode to connect back to the organizational system.

Some episodes were unrelated to the AI methodology and could be considered more a routine business practice than a strategic episode. For example, the morning of Day 2 was devoted to training and professional development sessions. There were also various social events such as a team-building social, employee recognition ceremonies, and divisional dinners. Since it was rare for so many sales employees to be in one place at one time, a fair amount of regular business was also conducted in between sessions, especially over breakfast and dinner. Therefore, conversations would constantly shift from the purely strategic, to straight business talk, and sometimes to topics completely unrelated to TireCo. 
The explicit goal of the summit was to produce 15 business plans that would help achieve the three goals in the topic statement: develop leadership at all levels, create solutions for dealers, and improve the consumer experience of buying tires. The CSMO further clarified the task by translating them into the language of sales. She identified six goals:

1. Help dealers and OEMs be more profitable

2. Retain customers in the face of declining units in operation

3. Provide dealers innovative solutions

4. Respond to new OEMs

5. Expand current service offerings to OEMs

6. Make it easier for dealer and OEM customers to be in the maintenance and light repair business

The summit covered all four Ds and for the most part, and incorporated activities that were considered standard for an AI summit. Each group activity was followed by a report-out or presentation to the large group. Sandwiched between these strategizing episodes were presentations by key executives, which would not be considered a typical AI summit activity. These presentations appeared to have a vital effect on the activities that followed. Customers were allocated extra time to report-out to the large group on Day 1 (60 minutes for customers, 45 minutes for internal stakeholders). While internal stakeholder groups reported by table with some tables not presenting at all, every single customer was asked to present their comments at least once. This implied that their voice carried considerable weight. The literature on AI tends to focus on the democratic and participatory nature of the summit format. But the presence of key executives and customers and the form in which they participate nevertheless do much to shape 
and frame the conversations that take place. AI summits draw on the experiences, the memories and complexities of all participants, but not necessarily in equal proportions.

Presentations by the top management team provided context and information for the subsequent discussions. TireCo's co-founder and CEO gave a 45 minute presentation in which he elaborated on the industry trends that he regarded as having a significant impact on TireCo's business. He was describing what he envisioned were the near term strategic challenges for TireCo. Using Seidl's typology, such a presentation would qualify as a decision-preparation interaction. All the information was being presented directly from the CEO to the employees and external stakeholders, thereby alleviating the problems of internal communication barriers. Many of the questions from the floor came from customers, which provided some insight into what the customers cared and worried about. The CEO's presentation came after the customers' report outs on Day 1. It served as important background information in developing ideas and business plans. Sensitive and strategic details were reserved for Day 4, the final day. Right before groups went to finalize their action plans in the Deploy phase, the CSMO provided detailed financials to the participants including current revenues, profitability and other key indicators. Again, these numbers set the stage for the discussions that followed in developing actionable business plans that aligned with the goals of the summit. Without disclosing such information, participants may end up creating plans that did not reflect the realities of the business and are therefore less likely to be executed.

TireCo's top executives take a lot of pride in practicing a policy of open book management. Providing detailed, strategic, confidential, proprietary information to everyone present at the summit might be considered a substantial risk at some companies. But it is also clear that sharing such information is critical if the expectation is to generate strategic plans that 
can be executed. Top management's perceptions about the company's future heavily influence the decision premises of an organization. Their primary job is to engage in interactions that produce of decision communications. TireCo had been using AI as a routine business practice for nearly half of its life at that point. Top management clearly recognized that positivity alone will not get results. They were also willing to be transparent about the company's financial and competitive data. Such information can be considered one type of self-description of the organization, a crucially important description by top executives incorporating their personal knowledge, expectations and images of the future.

I will now provide examples illustrating the main elements of organizational knowledge creation during an AI summit.

\section{System intelligence.}

Seidl (2007) defined organizational intelligence as the ability of an organization to access and leverage its nonknowledge-information and structures that are potentially accessible, but lie hidden from view, completely outside the organization's field of vision. Seidl also called it the dark side of knowledge. Although the organization is functionally blind to its nonknowledge during the normal course of its ongoing production of decisions, there are ways to bring that knowledge back into its field of vision. An organization actively forgets the premises and history that went into a particular decision, in order to absorb uncertainty. This is one way an organization system deals with complexity. Following Ashby's law, the environment is exponentially more complex than the system. The system can either reduce the complexity by making simplifications about its environment (e.g. condensing premises to absorb uncertainty), or it can increase the complexity of its system by adding more variety. An organization system 
can achieve the latter by purposefully orienting its vision towards areas of nonknowledge. Examples of this were plentiful at TireCo's summit.

One of the first episodes of TireCo's summit was a presentation by three partners about the early days of the company's existence. As Seidl (2007) and Schoeneborn and his colleagues (2011) have noted, organizations have a tendency to forget its history of decision making in order to absorb uncertainty. Although TireCo was a young company, it was adding employees at a feverish pace. The President and co-founder described what it was like when TireCo was little more than a business idea and a handful of employees. "Our job is to kind of walk you down memory lane and talk about where we came from and how everything is changed yet nothing really hasn't," he said. He pulled up the PowerPoint slides that TireCo used in pitching the first tire program, which became the deal that launched the company. The Chief Supply Chain Officer recalled her shock when she was recruited to the company in 2000. The Chief Supply Chain Officer talked about how she was given a great sales pitch by a co-founder when she came to TireCo in 2000. "A couple of mistakes that I learned. One, make sure you see the warehouse before you take the job. Two, ask about the computer system," she said. "We had no computer systems for the warehouses. None. It was unbelievable. I knew I had to be mistaken.” The company went on to implement a complicated ERP software package called J. D. Edwards. TireCo defied the experts who claimed it would take them two years. "We were able to do it over the weekend—all the warehouses went live. And it was fantastic. So that same energy, that same passion that we had then, we still have today" she said. The CFO talked about "how we made ends meet” and the tradeoffs the company had to make in order to secure equity financing right after the 9/11 terrorist attacks. TireCo had to guarantee a 35\% compounded rate on return in exchange for equity financing. Such stories provided a rich layer of information and context, 
especially for those of us who were new to the company. We were hearing about the complexities of the business, sensing the nuances of the organizational culture and its core values of innovation, fairness, accountability and playing-to-win (TireCo, 2011).

The positive orientation of the AI methodology also played a role at TireCo's summit in bringing attention to its nonknowledge. I offer two examples, one that highlights its effect on an individual's psychological system, the other on the interaction and organization system.

\section{Positivity and individuals.}

A psychological system reproduces thoughts. Positivity affects individual thoughts through psychology, specifically positive psychology. AI summits are structured to stimulate conversations that lift emotions and positive affect. Theories of positive emotions suggest that they help broaden cognition to allow individuals to see the forest from the trees. In the context of a strategizing conference, positive emotions may broaden the perspective of the individual participants so that they are better able to see the macro issues facing the company. If an employee can see how they fit within the greater organizational context, they may be more likely to adjust their perspective so that they seek solutions that further the organizational goals rather than their own self-interest. Studies have shown that the physical act of smiling appears to reduce own-race biases in facial recognition (Johnson, Waugh, \& Fredrickson, 2010). When people smile authentically, they are better able to make finer distinctions in the facial expressions of people of a different race than one's own. The authors concluded that facially expressed positive emotions broadened attention. On an individual level, this might translate into a heightened ability to empathize with people in a different department.

If an individual's interests are in direct conflict with organizational ones, positive emotions, therefore, would increase the likelihood that the individual changes how they think 
about an issue. If I am an outstanding sales person, and have cultivated best practices through experience, would I be willing to share those practices with others? If I do, it could reduce my relative competitiveness against my peers, and may even result in a lower bonus. Given the theory of positive emotions, if I were overwhelmed by negative emotions, my cognition would zoom in on my self-interests; I would want to preserve and protect them. Conversely, if I were filled with positive emotions, my cognition would broaden. I might see how sharing my experiences could benefit others, and in the long term, benefit me. Losada and Heaphy (2004) demonstrated that business teams with higher levels of positivity had better outcomes than those that were negative.

AI summits are designed to build up tremendous positive emotions at the very beginning of the conference. The first major activity of an AI summit is the sharing of high-point experiences through paired interviews. High point interviews are a hallmark method of AI in general. But they are taken to greater heights when literally hundreds of these interviews are conducted simultaneously in the same room.

Cooperrider served as the facilitator of TireCo's summit. Shortly after the conference began, he gave a 25 minute presentation on the AI approach. He began with the concept of appreciation. "The word appreciation comes from the dictionary and I love the dictionary definition; it has a double meaning. To appreciate means to see value,” said Cooperrider as he began to explain the AI approach, about 30 minutes into the conference. "But it also means to increase in value.... So there's an interesting double relationship here between what we take time to appreciate and the process of further appreciation or development of greater value.”

About an hour into the conference, the participants began conducting their paired interviews. Due to the limitation of time (20 minutes per person), many pairs, including mine, 
did not cover all four questions in the workbook. My partner and I spent most of our time on the first question, which asked:

Think about a time that stands out to you as a high point - a time when you felt most energized and passionate about your work, when you were really proud to be a part of the TireCo selling organization or proud to work with the TireCo selling organization. (TireCo, 2011, p. 15)

The conversations bring back some of the positive emotions felt during a high-point experience. My interview partner talked about her recent performance evaluation. It was her first evaluation since she took a sales position at TireCo’s corporate headquarters. She recounted how she was overwhelmed with emotion when her supervisor gave her a glowing evaluation. For her, this was a great accomplishment. Previously, she was in the restaurant business; she had no experience selling tires. She joined TireCo because the recruiter had sent her a one page fact sheet summarizing the core values and guiding principles of the company. Those values convinced her that TireCo was a good fit. With 330 people participating in the activity, 115 conversations were unfolding simultaneously in the ballroom of the Intercontinental Hotel. One had to talk extremely loudly to be heard, further enhancing the perception of the high energy levels in the room. Theories of emotional contagion (Hatfield, Cacioppo, \& Rapson, 1994) and mirror neurons (Rizzolatti \& Craighero, 2004) might also explain the heightened levels of positive emotions. Emotional contagion is "the tendency to automatically mimic and synchronize facial expressions, vocalizations, postures and movements with those of another person" (Hatfield et al., 1994, p. 5). It is a multidimensional package of "psychophysiological, behavioral, and social phenomena" (p. 4). The mirror neuron system in our brains is thought "to play a fundamental role in both action understanding and imitation” (Rizzolatti \& Craighero, 2004). Mirror neurons partly explain the phenomena of emotional contagion. 
The positive emotions generated at the initial stages of the conference through the paired interview process, may also have a priming effect (Tulving \& Schacter, 1990) on the participants that influences the subsequent strategizing activities. Priming is "a nonconscious form of human memory, which is concerned with perceptual identification of words” (p. 301) that functions independently of other memory systems. Whether or not positive emotions increase the cognitive ability of participants at an AI summit is open to further empirical research.

During the TireCo summit, the level of positive affect during the course of the conference appeared to fluctuate. My own emotional level dipped markedly around Day 3, the beginning of the Design phase. After two full days of strategizing from 8am to 5pm, participants were noticeably fatigued. Furthermore, the activities of the last two days-Design and Deploy in the 4D cycle-are not as differentiated from conventional strategic planning meetings as the activities in the first two days. While the underlying positive approach is still there, there are no provocative positive questions to guide the design of an executable plan. The three main activities of the last two days are brainstorming, rapid prototyping, and business plan development. The final deliverables for TireCo's summit were 15 business cases that could potentially be presented to the board. There was no formal facilitation or structure, and the usual dilemmas of discussing in larger groups outlined in the literature section-dilemmas of voice, egocentrism etc.—crept back in. In my group of 17 people, a senior sales executive assumed the role of moderator. Some people chose to stay on the sidelines while others dominated the discussions. The exercise felt very different from the "images of the future" activity in the Dream phase on the second day. What participants were being asked to do was to develop business proposals to which people will be held accountable. The pressure to deliver was palpable. 


\section{Positivity and social systems.}

Despite the decreased levels of positive affect, however, positivity still played a role in shaping the conversations that took place. Positivity in this context is differentiated from its effect on psychological systems. Positivity increases the degree of suspension of an interaction system during a strategic episode. This is simply because organizations tend to orient its communication (and attention) towards problem areas. The dominance of deficit-based thinking is one of the core assumptions of AI. People are not used to analyzing the root causes of success. Organizations obviously cannot think though, so the organizational consequence of a deficitbased orientation is that its decision premises are more sensitive to decisions and communicative events around problems rather than opportunities. This may inhibit an organization's potential for entrepreneurship, innovation and growth. Drucker (1993) noted that entrepreneurship is about shifting resources to areas of opportunity. A deliberate focus on opportunity areas during a strategic episode encourages interactions and decisions that are generative and more likely to lead to the production of more interactions and decisions.

One of the groups at TireCo’s summit had a breakthrough on the last day, as they struggled to develop measures to increase the effectiveness of each and every dealer visit. When they presented their "prototype” during the Design phase on Day 3, the group identified time as their key constraint. “Those things that we are doing in the dealership are very effective,” said the group 4's presenter. "We just really need more time.” Their idea was to hire administrative assistants who could help them with "activities that take away from our time at the dealership," such as updating reports. The group received feedback from other participants that they ought to look at what is possible — the opportunities_-rather than the constraints. "We actually took a step back today and regrouped a little bit,” said the presenter of group 4 on the final day. They asked 
themselves: "What does it look like now when we do a fantastic job with that, and what pieces are we missing if time was not an obstacle?” Of the 18 members of the group, 10 represented TireCo’s outside sales force, and 3 were upper level account managers.

The group scrutinized its best practices, and articulated immediate and longer term action items for five tactical areas such as commitment and awareness, inventory, and inspection. Action items in the "immediate" category were very specific and specialized: e.g. physical touch of inventory, availability of a strategic elevator speech, weekly emails to general managers. In Nonaka's organizational knowledge creation theory, these would be examples of “externalization,” in which tacit knowledge is made explicit. A social systems perspective would suggest that these ideas were made explicit because the reflections were taking place during a strategic episode, and in addition, participants oriented their thinking towards the positive. The resulting conversations are more likely to revolve around areas of strengths and opportunities. Such conversations open up new pathways for decisions that could not have emerged otherwise, and can trigger changes in the organization's knowledge structures.

\section{Diversity and the production of decisions.}

Next, I explore the implications of participant diversity and its effect on producing decisions while the AI summit is still ongoing. A defining characteristic of an AI summit as a strategic episode is the large number of participants representing different stakes and interests. The organizers of TireCo’s summit would consistently describe the summit as having about 400 participants, of which 40 were customers. This description masks the subtle shifts in the composition of people who are actually present in particular episodes. The composition of groups changes quite dramatically during the course of the summit. Individual participants are structurally coupled to both the interaction system (the conference proceedings) and the 
organization system (TireCo) during the course of an entire strategic episode (sales summit). Since the coupling between the individual and their organization is special—one of interpenetration, a deeper form of structural coupling — who is present and absent will affect what structures can be mutually perturbed. Put another way, decision interactions that lead to a change in an organization's internal structure, triggered by a change in how an individual thinks, are more or less likely to happen depending on who is present in the interaction system.

In order to show how the composition of groups changed from one episode to another, I calculated the diversity indices for the report-out for appreciative interviews on Day 1, the report out for the action planning session on Day 4. Both episodes were among the most diverse in terms of group composition because they are plenary sessions involving all participants. However, the Day 4 report-out had both fewer people and stakeholder groups, as there were no customers scheduled to be present on Day 4. The Simpson Index (Simpson, 1949) is a measure of diversity used in biology to study ecological systems. It calculates the degree of concentration of certain species in a given population. This diversity index takes into account both the richness of species and the evenness with which individuals are spread out among species. Statistical software packages such as PAST (which was developed for paleontologists) can be used to compare the diversity indices of different populations. Using PAST, the Simpson index (1-D) for Day 1 was 0.58 for Day 1, compared to 0.45 for Day 4. The difference was significant ( $\mathrm{p}=0.004)$. The diversity was measured across five "species" for which I arbitrarily used affiliation according to the following five categories: Sales, Supply Chain, Corporate, Canada and Others. Customers fall in the category "others." How these categories are chosen will have an impact on the index, but this is beyond the scope of this study. The limitation of the Simpson Index is that it does not take into account how different one category is from another, in other words the 
distance between the categories. The qualitative difference between customers and internal sales people is far greater than that between sales people and corporate employees. Other indices may be applied depending on the nature of the research question.

The Simpson Index is useful only when there are enough data points in the population, such as the large group report-outs. It cannot measure the changes in group composition during the strategizing activities, which can have a dramatic effect on social dynamics.

At TireCo's summit, the highest level of diversity was achieved at the plenary session, where every participant is present. The min-mix groups were grouped according to stakeholder groups including corporate roles such as inside sales and external stakeholder groups such as Dealers. These groups would be characterized as routine. The action planning groups in the last two days were self-selected. The level of diversity varied from group to group. Some had representatives from many stakeholder groups in roughly equal proportions. Others skewed towards the routine, such as one group which was almost completely made up of outside sales and account representatives.

The dynamics of an AI summit are such that its decision making capacity is temporarily expanded, while simultaneously cutting the time required to produce decisions. Hundreds of personnel—chosen specifically to cover as much of the decision premises of the organization as possible-participate in the strategizing activities. Ashby's law says that a system is better able to compensate for the variety of perturbations from the environment when there is a large variety of actions available to it. Interaction systems are severely constrained by time and space. The variety of its participants is usually limited. Putting the whole system in the room means that the interaction system's level of complexity is raised almost to the level of the organization's 
complexity. The presence of external stakeholders has the effect of temporarily enhancing the organization's complexity to better match the complexity in its environment.

In addition, the organization has the ability to make decisions during the summit. At a typical strategy workshop, the re-coupling of self-reflections to everyday operations can occur only after the strategic episode. If top management decides on a new strategy for the company during a strategy workshop, the change in strategy has yet to be communicated to the vast majority of the company's personnel. Although the individuals in the top management team may think they have decided on behalf of the company, it does not constitute an organizational decision event until their decision produces other decisions. This explains why a strategy decided by top management may take on a life of its own during its execution, leading to unintended consequences.

If an idea emerges during the summit to change the way the company is marketing itself to its customers, the idea is presented to the whole system at once because many of those people affected by the idea are physically present. For items that are immediately executable, decisions can be made on the spot whether or not to implement that idea. A group at TireCo's summit developed a business case to ensure that the General Manager of a car dealer understands and can articulate the value of TireCo and its offerings. All 12 people in the group were subject matter experts - mostly account managers who talk to General Managers on a regular basis. One of the deliverables presented by the group was a one-page spreadsheet which aggregated the key pieces of information that clearly and concisely represented the value TireCo was adding to that dealership. The group mentioned that they had added some metrics based on feedback they had received on Day 3 from one of the group member's customers. "He really wanted to see those key metrics that we at TireCo want to affect change in, like service absorption” said the group’s 
presenter. "I'm actually going to start using this when I get back to work. It's fully functional," she said. Enough information was provided for other account managers at the conference to decide whether or not they would like to use the one-pager.

What is important in the context of a strategic episode is that the decision to create a onepager for the company's customers produced subsequent decisions, namely the decision to use or not to use the spreadsheet. The decision to put all the key metrics valued by the customer onto one page was produced from the decision to develop ideas that enable dealers to understand and articulate the value of TireCo. This decision was a result of the organization's self-reflection in the early days of the conference. The development of the one-page spreadsheet during the conference is an example of self-reflections connecting back to the organization while the strategic episode is still ongoing. Decisions are made in vivo so to speak. The time required between decision-preparation interactions and subsequent decision making interactions is significantly reduced, thereby accelerating the pace at which a decision premise—organizational knowledge - is modified or in some cases created from scratch.

\section{Dreaming the ideal future.}

I now describe an episode guided by the typology of episodes I introduced in Chapter 6. Of the many episodes during the summit, one of the most unconventional activities took place on Day 2 in the Dream phase. I have excerpted portions of the post-summit report I wrote for TireCo, which describe the group activities and the presentation to the large group. These two episodes are representative of an episode that is characterized by a high degree of suspension in nearly all of the dimensions of the proposed typology. The excerpt has been edited for clarity and to preserve anonymity. Following the excerpt, I will discuss the case in light of the typology of episodes. 
The main event of Day 2 was to visualize what the future of TireCo looked like. In Dr. Cooperrider's classes, I had watched video clips showing skits, pictures, and other outcomes of such futuring and visioning exercises. So I had a sense for what the best of these outcomes looked like. But I had also assumed this type of amazing output was possible due to a special, creative spark that I did not possess. In addition, there were 18 people in our extended group. How could we possibly put together a skit or other creative way of presenting the envisioned future of TireCo with such a large group of diverse individuals?

I decided to trust the process and find ways to make as much of a contribution as possible. Our task was to visualize the TireCo selling organization in three years' time. How are we driving dealer solutions that positively shift the consumer experience? What is TireCo's competitive advantage? We could portray our vision in any form we liked.

Our first challenge was a logistical one. More than 20 other groups were doing the same exercise. Finding a quiet space to discuss became a priority. We wandered out of the conference hall and eventually took over a small enclave where pay phones used to be, the booths still there but serving no purpose. It was a subtle reminder of the effect of technological obsolescence. For the next hour or so, we were to hole ourselves up in this enclave, bouncing off one idea after another with the goal of performing a skit in which all 18 of us had a part.

At first, we could not come to much agreement over the content of the skit. We shared a vague sense that developments in technology would play an important part of TireCo's future. But our group was comprised of people from very different backgrounds, age groups, affiliation and technical expertise. I tried to listen more than speak. But as we struggled to look for common ground, I could not help feeling a little discouraged about whether we can come together as a group, let alone develop and perform a skit. Some of the themes we were trying to work with were how mobile phone apps would change the consumer experience.

At some point in the conversation, I spoke up. I couldn't help it. What specific question I asked, I honestly cannot remember. I remember feeling slightly frustrated that we were not thinking through what the app would do for the consumer. Soon, we began talking about what the ultimate consumer's experience would look like if they unexpectedly had to change their tires. Why not contrast that experience with a Walmart or Costco? Someone pointed out how we had some shiny heads in the room. We had four people with varying degrees of hair loss. Couldn't we use these heads to represent the wear and tear of tires?

Two of us in the group had brought an iPad to the summit, one person from marketing and myself. Tablet computing was an important development in technology. In three years' time, there were bound to be corporate applications of tablets. So I suggested taking photos of the shiny heads and putting them on the iPad. An engineer at the dealer can look at the iPad to diagnose wear and tear. Soon, I was snapping away on my digital camera, taking photos of bald heads which I uploaded onto my iPad. My conversation partner from Day 1 would play the part of the field engineer diagnosing the tires, utilizing her knowledge of tires gained through her position in inside sales. In the meantime, a field trainer was making props. We decided on Walmart as our competitor. One of our group members was a dealer in Cleveland so naturally, we decided it would be his dealer that appeared in the skit. 
A college student and his date are driving on the freeway when the car's system alerts them to tire problems. "There's an app for that," says the student. They pull over, and the app walks them through the process. His girlfriend takes pictures of each tire and sends it to the dealer. They are then directed to "Take 3, Route 3" to the dealership. On another part of the stage, friends of the student are at Walmart getting their tires changed. The tire change at the dealership is quick, easy and professional, and his girlfriend is impressed. Over at Walmart, his friends are still waiting.

Everything came together extraordinarily quickly. We even had time for a dry-run. All of us were psyched at the prospect of performing and were quite confident it would be very funny. Luck was on our side. The randomizer had chosen our table to perform. I would be playing the part of the app. We played to the audience as professional improvisers would. The thunderous laughter when my conversation partner pulled out my iPad with the shiny, bald heads made the performance memorable for all of us on stage. (Makino, 2011)

The creative dreaming activity took place in the afternoon of Day 2. The morning was devoted to training and education. I spent the morning with other external stakeholders learning about the AI method from Cooperrider and staff from TireCo's human resources department. Employees of TireCo trained in topics of their choice, ranging from career development to a maintenance program for a global auto manufacturer. After lunch, employees gave feedback on the morning's programs. Then, Cooperrider gave a presentation titled "Positive Image, Positive Action," an overview of the theory and research underpinning the AI methodology. So for the TireCo's employees, the day had proceeded with episodes that leaned toward the routine in that all the activities had been tied to corporate education, including Cooperrider's presentation. Cooperrider introduced the activity around 2:30pm. The groups began work at 2:40pm and returned to the ballroom for a report-out just over an hour later at 3:45pm, according to the video transcripts.

After lunch, participants were seated at their table groups in the max-mix condition. There were about 40 table groups in all. TireCo's master planning document shows 309 people scheduled to take part in the creative dreaming activity. Of these, 198 scheduled participants were in sales, 15 in supply chain, 52 in corporate (including partners), 12 from Canada, and 32 
external stakeholders of which 24 were customers and one was a board member. The Simpson index (1-D) as calculated using the software PAST, was 0.55 for the plenary group compared to 0.58 for Day 1 and 0.45 on Day 4. The difference between Day 2 and Day 4 was statistically significant ( $\mathrm{p}=0.04)$ while that of Day 1 and Day 2 were not $(\mathrm{p}=0.33)$. The composition of the plenary group on Day 2 was slightly different from Day 1 some of the customers only attended Day 1. Day 2 was significantly different from Day 4 mostly because there were at least 24 customers participating versus none on Day 4 .

In terms of the plenary group then, the group configuration could be categorized as diverse. The max-mix table groups were combined to form a larger group of up to 20 participants each. In my report, I mention that our combined group had 18 people, but in the master planning document I could account for only 15 . There may have been some people who were added to the table group after the conference began. The planning document shows that by combining the two table groups, the group added diversity. The master plan had 34 categories for affiliation that aligned with internal divisions for employees and stakeholder affiliations for external stakeholders. Our table group had 7 categories represented, which expanded to 11 after combining with another, including a customer.

The overall episode required a high level of suspension in terms of existing organizational structures. We were being asked to depict an ideal future based on TireCo's strengths and on industry trends. Our group assumed that TireCo had the capacity to develop apps. We also assumed that dealers would want an app like the one we presented. The skit was grounded in our assumption that TireCo can provide value to its dealer customers by offering a better solution than other tire retailers. These were extrapolations from TireCo's current situation that were strategic in nature. 
The activity was highly creative. The rules required us to have every single group member play some kind of role in the skit. What worked well for our group was that we tried to entertain every idea, and to incorporate them in some way into the skit. In her book Bossypants, the comedian Fey (2011) wrote that the first rule of improvisation in comedy is to always agree to what your partner says. We seemed to implicitly follow this rule. It appeared that for most of us, including myself, this was an unusual and slightly awkward exercise, given we knew practically nothing about each other. The creative element of the exercise raised the level of psychological safety (Edmondson, 1999) for the participants, lowering the barrier for people to make contributions. As a result, I was able to contribute my idea of using an iPad. For many in the group, tablet computing was not very familiar to them. Similarly, I was clueless in gauging the degree of tire wear by looking at tire treads. For TireCo as a whole, tire related information is an integral part of their working knowledge. However, newer IT trends like tablet and mobile computing, was likely still a part of its nonknowledge. The organization had the potential to tap into their nonknowledge base, but cannot easily access except through a strategic episode.

The coupling of the interaction system to the organizational system, at least during this particular episode, was loose. Although the group was diverse, there were only 18 people representing different parts of the organization. The highest ranking person in terms of title, would have been the customer in the group, who was the president of a local dealership and therefore an external stakeholder. Most were mid-level and frontline employees. We did not have any senior executives in our group. Some people were very familiar with IT including smartphones and apps while others were not.

Our group was fortunate to have the opportunity to present our skit to the large group in the subsequent episode: the report-out. The interaction system of the report-out is far more 
tightly coupled to the organization because of the vast number of positions represented. Our skit showed how technology might be leveraged in the future through a story acted out using props, including a real iPad. In the previous session, other participants had referred to the use of technology as one of TireCo's strengths. Our skit connected to those interactions and extrapolated them into the future. Tablet computing may have been part of TireCo's nonknowledge prior to the summit, especially if it had no concrete plans to develop an app. A concept that was still abstract for many people at the time—-tablet computing—may have gained more meaning by linking it to TireCo's operations. The insights of early adopters were presented to the organization in a non-threatening manner: a funny skit. In the subsequent action planning activities, plans to develop mobile apps was a recurring theme, suggesting that the organization was producing decisions in the forms of new initiatives and teams to pursue this opportunity.

\section{Conceiving new programs and initiatives.}

At an AI summit, the presence of so many organizational members at the same time in the same room engaged in the same activities temporarily increases the nonknowledge available to the organization. The redundancy of positions that are coupled to the organization system reduces the risk of particular individuals blocking access to strategic, nonknowledge. At the same time, the temporal constraints of the interaction system-such as the need to break for lunch, or for the conference to end-enforces some discipline on the interactions so that conversations do not verge onto an extreme tangent. The topic statement also guides the discussions towards a specific goal. Unless an idea (in the form of an interaction) resonates and triggers a selection by either the individuals or the organizational system as relevant to the goal, no new interactions on that idea will be produced. 
One of the common themes that emerged over and over again at TireCo's summit was the relevance of mobile apps and social media to TireCo's business. Many of the images of the future presented by the groups incorporated some kind of smartphone or tablet app. Our group, for example, presented a skit in which a car owner snapped photos of their tires using an app on their phone. The app sent the photos to the dealership, where a technician diagnosed the varying degrees of each tire's wear and tear on an Apple iPad. The underlying idea was that this would reduce the time the car owner would have to wait for a new set of tires. This was February 2011, one year after the iPad had launched. Smartphone and tablet use, while already prevalent at the time, was not nearly as pervasive as it would become only a year later. For non-users, apps and social media are situated in their nonknowledge; it is difficult to imagine a future around such technology. TireCo had embraced LinkedIn and Twitter for its recruiting practices, but there were key personnel at the summit who were openly ambivalent about leveraging social media for internal communications. Many aspects of apps and social media were therefore hidden from TireCo's organizational line-of-sight. Such information resided in its organizational nonknowledge. TireCo had no specific plans for app development at the time, and therefore, the decision premises related to such an effort remained in their nonknowledge—as a potentiality not an actuality.

The business plan presentations on the last day of the summit reinforced the idea that apps and social media were trends that TireCo must begin to grapple with. So many of the plans incorporated these new technologies that one participant remarked to me, "They all look the same.” One group's entire plan was around developing a specialized app for dealers. Another group tasked with recruiting strategies showed a video clip from the internet titled "What the HELL is social media - in 2 minutes" (timetogetsocial, 2010). The video gave 10 reasons why 
we should care about social media, including not so trivial information such as "reason \#6: Because the next 3 billion consumers will access the internet from a mobile device" and "reason \#7: If Facebook were a country it would be bigger than the USA and $3^{\text {rd }}$ largest in the World" as Facebook adds 0.5 million users a day and users spend 5 billion minutes a day there. These statistics were at least one year old — the video had been uploaded in February 2010. Nevertheless, they were a stark reminder to the summit participants of how rapidly the world was evolving.

Similar information may have presented itself in a small group strategy workshop. The dynamics would be different, however. Depending on who was present, changing the decision making premises of the organization based on these trends can easily be met with resistance or euphoria. At an AI summit, information coming from an organization's nonknowledge reservoir can be tested to some extent. This lowers the risk that an organization overweights or underweights the impact of a specific piece of information. A piece of information is incorporated into the communication and interactions of a summit, and if that information is a difference that makes a difference to the social system, then the system will produce more decisions and more interactions related to that information. If an important decision maker shoots down an idea to use Twitter at the corporate level, this may be cause enough for experienced Twitter users in that group to refrain from contributing their strategic knowledge to the organization. However, those same users may be encouraged to speak up, if they see that another group at the summit is pushing for strategic Twitter use, opening up new pathways for interactions and decisions. At a smaller meeting, such pathways would have closed as soon as the idea was shot down. 
In the previous example of the one-page fact sheet for dealers, feedback from the customer was used to make changes to the final deliverable. Getting such customer feedback was extremely easy for TireCo, given that the conference's purpose was to generate strategic plans that would benefit solutions for its customers. Moreover, the customer was right there at the conference, ready and willing to answer questions. The accessibility of customers and other external stakeholders at the summit lowers the threshold in obtaining information that would have otherwise been confined in the organization's nonknowledge.

\section{Self-organizing project teams.}

I will now explore a phenomenon that is arguably the most important outcome of an AI summit: the emergence of self-organizing project teams. Given the nature of innovation as “creative destruction,” an innovative idea is disruptive to the existing organizational structure. In the context of social systems theory, an innovative idea can only be implemented if an organization can continuously produce a stream of decisions regarding the innovation. But the innovation will likely disrupt the organizational structure. The organization is faced with a choice. It can select decisions to change its structures and its organizational knowledge to adapt to the disruptions, or it can make the decision not to change. The stream of decisions regarding the innovation would be blocked from producing further decisions, if it decides not to modify its organizational knowledge. In summary, when an organizational system decides to adopt an innovation, it must modify its decision premises so that they are consistent with the innovative idea. If the idea is highly disruptive, the organization may need to create new positions, filling them with new personnel, incorporating new communication channels and deploying new initiatives. 
The social systems view of organizational innovation is consistent with Rogers' diffusion of innovation theory. Diffusion is a "process by which (1) an innovation (2) is communicated through certain channels (3) over time (4) among the members of a social system” (Rogers, 2003, p. 11). In the previous section, I argued that AI summits can accelerate changes in organizational knowledge because it creates new communication channels, produces decisions while the strategic episode is still ongoing, and therefore, condenses the time required for self-reflections to connect back to the day-to-day operations of the organization. If the emerging idea is an innovation, an AI summit can significantly accelerate its diffusion.

That said, the benefits for diffusing innovative ideas may last only as long as the interaction system is in place. Once the conference—namely the strategic episode—comes to an end, all the members of that social system —-the interaction system—inevitably return to their routine operations. There is no guarantee that the stream of decisions produced at the conference will over time, actually continue. This risk is especially acute for innovative ideas, but is equally applicable to incremental improvements. Incremental improvements are not as disruptive, but nevertheless require some modifications to an organization's structures and knowledge. Whether it be an innovation or an incremental improvement, if the decisions made during the strategic episodes are subsequently rejected by the organization at a later time, this may have the unintended effect of reinforcing and fortifying the existing structures, making it more difficult for decisions regarding the innovation or improvement to be produced.

In Luhmann's social systems, systems reproduce themselves based on ephemeral communication events that vanish as soon as they appear. New ideas are particularly fragile in an organization because the decision premises to back them up may not exist. Each time a decision related to the idea produces another decision to carry it forward, the connections and pathways 
required to produce more decisions are made durable. At an AI summit, new communication channels are always created, simply by virtue of the multiple configurations of groups. The problem is that these channels may be temporary and not survive beyond the conference.

This is why one of the most important outcomes of an AI summit is the emergence of self-organizing project teams. These teams become a vehicle for which the decisions produced at the conference can produce more decisions after the conference ends. These teams are crucial for an AI summit's success. Without them, the novel connections and pathways for organizational knowledge cannot be made permanent. The design and deployment phase is a hotbed for project teams to form organically. If the idea is novel and innovative, the self-organized project team represents a brand new set of decision premises. The positions on a project team are filled with existing personnel in new roles, communicating through new channels about a new initiative. If there is great excitement about the idea, these project groups may evolve into hot groups (Lipman-Blumen \& Leavitt, 1999), an "impassioned collective state of mind" (p. 15) that can ignite organizational change and innovation.

Self-organized project teams emerged at TireCo's summit on the fourth and final day of the conference. This was the Deployment phase of the $4 \mathrm{D}$ cycle. Of the 15 action planning groups, several mentioned in their final presentations that they had already formed or will be forming a "task force" or a "team" or a "steering committee" to facilitate the implementation of the plans generated at the summit. These teams were conceived through a two-step selection process. At the beginning of Day 3, participants were asked to join one of 15 groups. Each group had a specific task. Although the reasons for selecting one group over another no doubt varied from individual to individual, the important point is that it was a matter of self-selection. 
By this point of the conference, customers were no longer officially present. The number of scheduled participants had dipped to 280. Of that number, only 210 participants were represented by name in the final PowerPoint slides that were submitted to the summit organizers. About 15 participants belonged to a group that did not put their names on their slides. It is not clear why the remaining 50 or so participants apparently were not part of any action planning group. In my group, the senior executives who were active participants in our discussions were not named in the PowerPoint slides. It also appears that employees from some of the corporate divisions may not have taken part, perhaps because the 15 tasks were heavily oriented towards sales issues. None of the nine partners of the company appeared to take part either, although they were present at the report-outs.

The second selection step happened during the action planning process. Since I could only observe one group, I have no direct observations on how the project teams formed except in my own. Our group had 17 members, and represented 12 different stakeholder groups/divisions. Our task was to find ways to ensure that the collaborative DNA of the company lived on. Participation and contribution varied greatly. Some people hardly spoke up. One participant remained mostly quiet until the final day, when she made it known that she was the program manager for an existing, online initiative designed to facilitate collaboration using the intranet. My personal perception of our group discussions was that they lacked the energy and enthusiasm of the group activities of the first two days. No specific project team formed during the conference. Instead, it was noted in the PowerPoint slides that "Team \#10 will form a team (for the inaugural year) to move these ideas forward."

Other groups also talked about the formation of cross-functional project teams as the first step in implementation. The more committed these groups, the more likely that the decisions 
produced during the summit will connect back to the organization's existing system to produce more decisions, thereby strengthening the organization's autopoiesis. Tracking the progress and development of these organic, self-organizing project teams beyond the summit should provide additional insight into why some initiatives succeed and others do not. 


\section{Chapter 9 Discussion of Findings}

\section{Introduction}

In Chapters 7 and 8, I applied a social systems theoretical lens to describe the strategizing activities of an appreciative inquiry (AI) summit. Luhmann's social systems theory assumes a very radical view of organizations and knowledge. The strength of Luhmann's theoretical lens is the clarity with which one can delineate and identify the social dynamics of a complex system like an AI summit. The dynamics inherent to social systems are differentiated from the dynamics that belong to the domain of human psychology. Macro (organization) and micro (individual) level phenomenon are distinguished so as not to muddy the waters of analysis. The relationship between the macro and micro levels is kept squarely in view so that one level is not bracketed out at the expense of the other.

This approach introduces a finer distinction between organizational knowledge and personal knowledge. Organizational knowledge includes decision premises such as communication channels, organizational roles and programs. It does not include thoughts or beliefs because these are personal knowledge. Knowledge in social systems theory is interchangeable with structure. Knowledge orients how the system deals with information. Human beings use mental models, schemas, emotions and other cognitive and physical structures as knowledge. Organizational knowledge in the broadest sense is any internal structure that guides how it observes itself. Organizational structures determine how an organization selects an appropriate response to a particular event from its portfolio of possible responses. Organizational knowledge is merely analogous to the mental structures of a cognizing individual. But they are not the same. Organizational knowledge therefore cannot be described as an extension of personal knowledge or as justified true belief. 
New knowledge is created in an organization when new structures emerge through patterns of decision communications. I framed an AI summit as an extended strategic episode to examine how it changed or created organizational structures, specifically decision premises. An organization can modify existing structures, reinforce them by keeping them the same, or create new structures. I applied Luhmann's social systems lens to an AI summit to identify the structural features of the conference that affect its organizational decision premises. The most obvious knowledge outcome of a summit is the establishment of new communication channels. Some may be formalized. Others may remain informal but nevertheless affect an organization's decision making.

In this concluding chapter, I summarize the key findings from Chapter 6 and 7. I then juxtapose the social systems perspective of AI summits against the five core principles of AI to highlight the contributions and limitations of a Luhmannian approach. I consider the relevance and implications of this study in the broader field of management studies, including possible research areas. Finally, I contemplate the future by looking back in history. I draw on work by a pioneer in management studies, Mary Parker Follett, who foresaw many of the ideas discussed in this study.

\section{Social systems model of an AI summit.}

In Chapter 6, I developed a conceptual model of an AI summit based on social systems theory (Figure 1). There are three primary component systems: the organization system (company), the interaction system (AI summit conference), and the individual participants' psychological systems (psychic systems in Luhmann’s terminology). Each system maintains its identity through different modes of production. The organization produces decision communications, the interaction system produces interactional communications, and the 
psychological system produces thoughts and perceptions. It is extremely important to remember that in the context of this analysis, individuals do not make decisions. Individuals are not "agents" acting on behalf of the organization. Only an organization can produce decisions in the form of communication events that vanish as soon as they are produced. Simply documenting decisions in the form of memos and emails does not constitute a communication. Under Luhmann, such documents must be understood by someone and produce another decision to qualify as a communicative event. Decisions may be incorporated into processes, procedures, and programs, at which point they become structures—in other words, organizational knowledge.

Figure 1 is a simplified diagram of this model. It is simplified because each individual participant is an autonomous, closed system that is coupled separately and independently to the organization and interaction system. So there should be as many recursive circles of psychological systems as there are participants. The double-headed arrows represent the systems' structural couplings. The coupling between the organization and interaction systems is influenced by the nature of strategic episodes. The interactions take place in a strategic context in which existing structures are temporarily suspended. Participants are coupled to the organization through their positions. The coupling between the participants and the interaction system is moderated by AI's emphasis on positivity. Effects from positive psychology are limited to this particular coupling. 


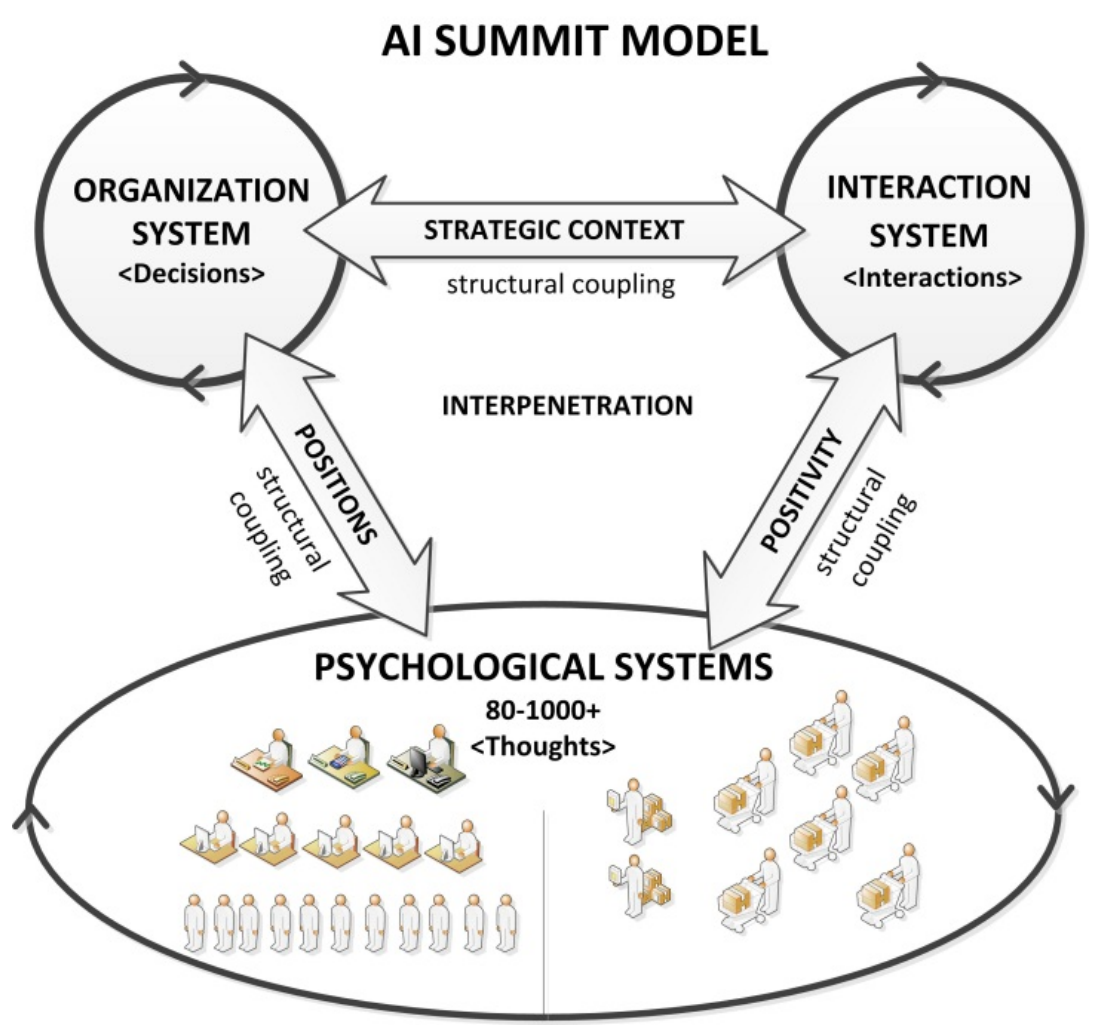

Figure 1: Social systems model of an appreciative inquiry summit

The structural coupling between each of the systems in an AI summit is of a special type called interpenetration. Closed systems cannot directly access the internal structures of another system. A core principle in autopoietic theory is that a system can merely trigger a perturbation in another. A perturbation can be so great that it has catastrophic consequences for a system. A different system may respond differently to the same event, and thrive from the same perturbation. Over time, systems can become structurally coupled such that a particular event can trigger mutual perturbations in those systems. The social behavior of ants for example, is made possible through such structural couplings. In an interpenetrating relationship, the coupling is so tight and intimate that a system can penetrate the other system's internal complexities. The penetrating system can use that complexity to its advantage in constructing its identity. The systems actually achieve greater degrees of freedom even though the interdependency between 
the systems increases. At an AI summit, system interdependency is especially high because of the diversity and large numbers of people in the room. This increases the system's complexity. Further empirical study is needed to determine exactly how much diversity and how many people are necessary. Complexity theorists are currently developing computational models to simulate diversity in systems and their impact on innovation (Page, 2010) and could serve as a guide to developing benchmarks. At an AI summit, the organization system essentially gets the best of both worlds_-variety and redundancy_by virtue of having so many organizational positions physically represented at a summit. A summit temporarily boosts the ability of an organization to compensate for the complexities and uncertainties in its external, competitive environment. This gives the format an edge over its small group peers in its capacity to generate organizational knowledge.

Key features of AI summits.

An analysis of an AI summit using a Luhmannian lens yielded five features that differentiate an AI summit from conventional strategizing workshops and meetings. They are summarized in Figure 2.

\section{Structural features of an Al summit}

1. Internal and external communication barriers are reduced

2. Access to latent knowledge (nonknowledge) is enhanced

3. Structural decisions are produced in vivo

4. Decisions reconnect back to routine operations even before the strategic episode ends

5. Episodes continuously oscillate between strategic and routine contexts

Figure 2: Five key structural features of an AI summit identified by a social systems theoretical lens. 
First, both internal and external communication barriers are significantly reduced by virtue of the large numbers of people participating in the conference at the same time and in the same place. The organization can adopt and apply the AI methodology to their internal strategy development process as it pleases and on its own terms. The AI consultant is more a guide than a strategy expert. The organization's own members collect and analyze the data necessary for strategizing. Luhmann brazenly claimed that consultants and their clients cannot truly communicate or transfer meaning because they each operate using logic that is idiosyncratic to their respective organizations (Luhmann, 2005b; Mohe \& Seidl, 2011). During an AI summit, the AI consultant's role is diminished so much that the communication barriers inherent in a client-consultant relationship become essentially irrelevant. Furthermore, the presence of hundreds of internal stakeholders reduces internal communication barriers between different departments and hierarchical levels.

The second feature I identified is increased levels of access to knowledge that an organization cannot normally access in its day-to-day operations-its organizational nonknowledge (Seidl, 2007). An organization has a tendency to forget its history of decision making (Luhmann, 1995). An organization is constituted by communication events. It does not have a memory system. People do have memories; lost history may be recalled by individuals who remember. For example, TireCo incorporated presentations by executives who had been at the company in its early years. The active participation of external stakeholders plays an additional function. Their presence allows an organization to incorporate into its decision making, information that usually lies outside its system boundary. Here again, the complexity an organization can handle gets a boost. 
The third feature is that organizational decision communications (distinguished from a decision made by individuals) are produced during the strategic episode. Importantly, those communications connect back to the organization's routine operations during the episode as well. This is the fourth feature. Decision communications are both produced and reconnected in vivo so to say. The third and fourth features accelerate the production of decisions, and are the most striking aspects of an AI summit compared to traditional strategy meetings. A decision in the organizational sense is a special type of communication, not an action taken by an individual. A decision is only a decision when it produces and connects to another decision. It is the ongoing production of decisions that allows an autopoietic, organizational system to maintain its identity and existence. An utterance becomes a communication only when there is understanding (or misunderstanding) between two or more individuals. A typical strategy meeting rarely produces organizational decisions of the social systems variety, because the communication events of the meeting have yet to connect to the rest of the organization. A “communication rollout" is typical at organizations after an executive strategy meeting. At an AI summit, decision premises such as programs, communication channels and the people who fill positions, can change during the conference. The table groups at the beginning of an AI summit encourage the production of new communication channels by seating people next to someone they are likely not to know. Even though the episode is strategic in nature and existing structures are suspended, it is as if the organization in all its entirety and complexities is present at the summit in its operational context as well because so many stakeholders who are intimately coupled to the organization are present for an extended period of time, participating in the same activities. It is as though the summit is a simulation of organizational life. 
This leads us to the fifth and final feature: the constant oscillation between strategic and routine contexts during the strategic episode. This social dynamic moderates the production and reconnection of decision communications at an AI summit. It makes the connections between decision communications more resilient and robust. I proposed a typology of episodes that is a point of departure for analyzing the impact of such oscillations on the summit outcome. I conceptualized an AI summit as a sequential series of episodes that unfold over multiple days. Episodes have a definite beginning and an end. They provide organizations relief from the constant stress of having to absorb uncertainty all the time. Episodes enable closed, selfreferential systems to change its internal structure and composition (Luhmann, 1995). TireCo's summit was comprised of about 50 episodes or segments that the organizers had broken out in their planning documents.

A central observation of this study is that the degree to which existing structures are suspended differs from episode to episode. The typology I proposed looks at four dimensions of an episode: the overall strategic context, the levels of diversity in group composition, the nature of the activities, and the level of decoupling from the organizational system (Figure 3). The level of suspension of existing structures can be depicted on a sliding scale from no suspension to high suspension. 


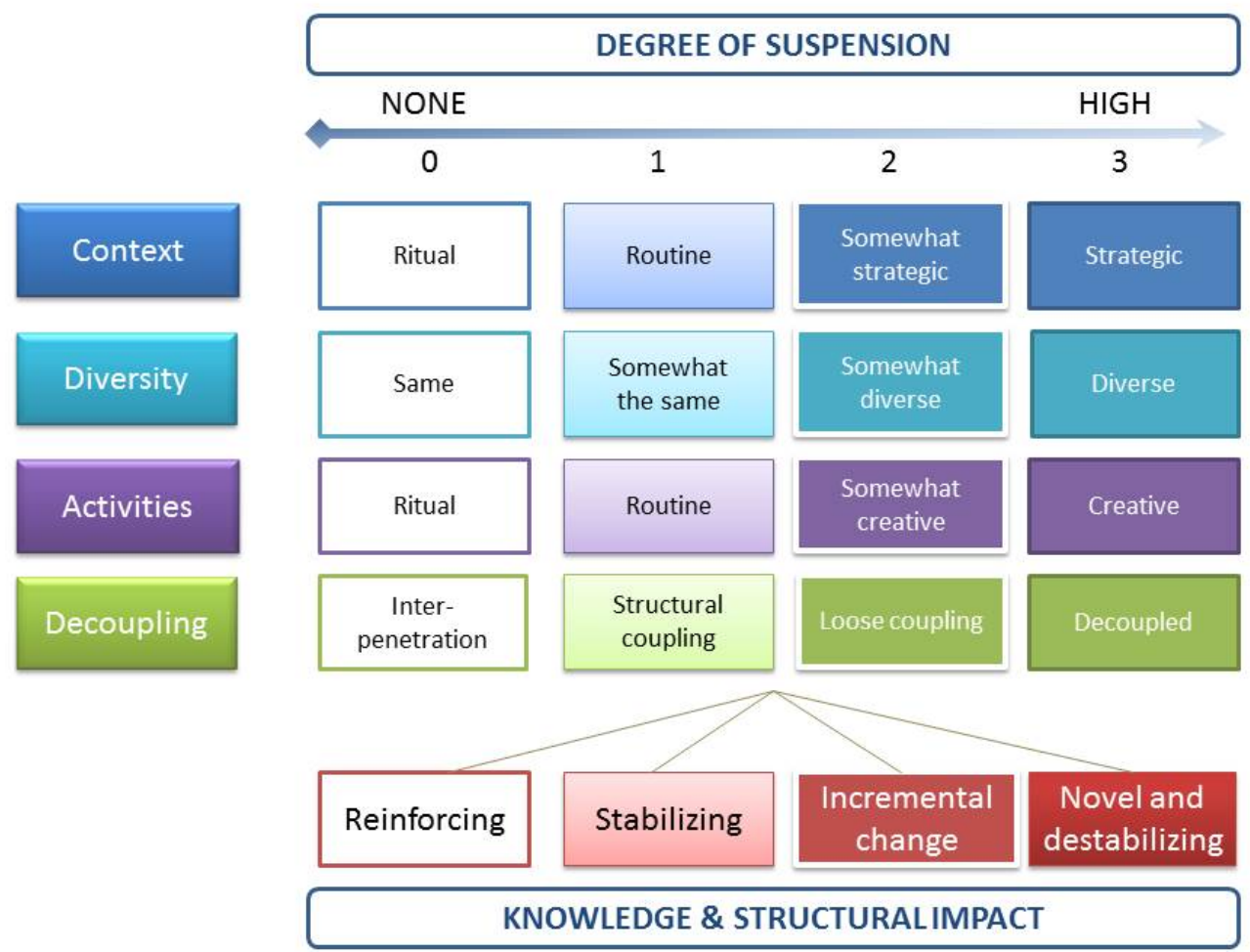

Figure 3: Typology of episodes

Certain configurations of episodes are more likely than others to lead to certain impacts on the organization's structures. For example, diffusion of innovation theory would suggest that novel and destabilizing changes to an organization's structure would require configurations that result in a higher degree of suspension and more decoupling from the organization's existing structures. An innovative idea would require a higher degree of suspension in order to diffuse compared to an incremental improvement to existing processes. Innovation is disruptive. Existing decision premises may block its diffusion, and those structures may need to be modified for the innovation to take hold.

An interesting feature of TireCo's summit was that not all of the episodes had high degrees of suspension. Episodes that fell in the last D of the 4D cycle, Deploy, had lower degrees of suspension. This increased the likelihood that the decisions produced during the AI summit 
would reconnect back to the organization's routine. Participants were held accountable for the plans they were developing. This incentivizes people to think and act based on their positions within the organization. Some changes to decision premises were produced on the spot. For example, project teams that were formed during the action planning sessions qualify as new decision premises. These teams are an important vehicle through which the organization can connect decisions from the summit to potential decisions after the summit ends. Without such a mechanism, the plans and ideas from the summit degenerate into good intentions, not results.

\section{Discussion}

The AI summit is a highly complex phenomenon. In fact, its social dynamics suggest it is almost as complex as the organization itself. The summit is attended by hundreds of stakeholders representing different interests, roles, and responsibilities. A significant variety of organizational positions are represented, including those at the peripheral. Consequently, the dynamics that come into play at an AI summit are more likely to resemble the organizational dynamics that exist in its day-to-day operations. This is not so in more conventional styles of strategy development in which strategy meetings are confined to the inner circle of top management.

I draw on an analogy with computing. Traditional strategy development is much like the early days of computing. Computers could only handle one application at a time. A spreadsheet application needed to close before one could write a report using a word processing application. Similar to such linear computing processes, strategic decisions in most organizations are produced sequentially. Executives might decide on a strategy at a strategy meeting, senior managers decide on how the strategy is implemented at the department level, front line employees decide how to execute in practice, and finally, the customers decide whether they like what they are being offered. 
In contrast, the AI summit format can handle multi-tasking. Multiple applications can be open and running in parallel. The strategizing process of the AI summit allows multiple small groups to work on the same task. The groups operate like multiple processes running in the background. Their work is then consolidated at the large group session, much like the reporting function in an Enterprise Resource Planning system. In computing, parallel processing not only increased raw computing power; it also changed people's thought and behavioral patterns. The introduction of multi-tasking in computing coupled with networking technology has profoundly affected how people deal with information, in other words, their personal knowledge. Evidence can be found in our working vocabulary. "You can Google that," we casually remark when someone asks for information.

The AI summit and other large group methods of strategizing represent a similar paradigm shift. The structural coupling between the organization and the vast number of members who are collectively strategizing in parallel, has implications for how an organization produces decisions, which will then influence how that organization deals with information, its decision premises and organizational knowledge. The AI summit is complex. So many of its parts are interdependent, it is very difficult to analyze using classic systems theory. Trying to model a summit using inputs and outputs can be overwhelming, given the massive number of variables to consider. Deconstructing the summit into more manageable parts, for example, group processes, brings challenges of its own. There is no way of determining whether the dynamics driving group processes can be useful for explaining the dynamics at an organizational level. A systems perspective assumes that the parts are different from the whole. Describing an AI summit from a systems perspective is rather like describing the inner dynamics of the current 
generation of personal computers. One can get very quickly bogged down by the complexity of the system.

This is why a Luhmannian perspective has utility. Although there are scholars who object to the application of autopoiesis to social systems, nevertheless, a theoretical framework that emphasizes the coupling mechanisms between interdependent but autonomous systems can shed light on the systemic dynamics that have a major impact on the overall system. At the heart of Luhmann's social systems theory is communications. His take on communications is radical. It is hard to swallow on the first bite. Luhmann asks us to reconsider notions we have come to believe as common sense, such as the notion that people communicate. Communication cannot happen without people. Even Luhmann admitted that. Luhmann's contribution was to bring meaning back into communication theory. Meaning is reduced to bits and bytes in the fundamental communication theories that gave birth to personal computing and the Internet. Luhmann adds understanding (and misunderstanding) to the definition of communication, and brought meaning back into play. When understanding becomes part of communication, communication leaves the domain of individuals. Communication is a social interaction, and therefore can only be produced by social systems. Luhmann also asks organizational scholars to question a commonly held assumption that organizations can have beliefs, perceptions, and knowledge in the cognitive sense of those words. Cognition belongs exclusively to the domain of individuals. Cognition in this context refers to embodied cognition, which includes emotions and motivations that an individual may or may not be aware of fully conscious of.

Luhmann's radical view of organizing and knowledge when applied to the dynamics of an AI summit, makes a distinction between decision communications and individual cognition. I 
will now discuss the five principles of AI that underlie the AI summit format as seen through a social systems lens to highlight how this approach complements AI theory.

\section{AI principle 1: Constructionist.}

Social constructionism is fundamental to AI. Autopoiesis and social systems theory provide additional support to the notion that words create worlds (Cooperrider et al., 2008; Gergen, 2009). Autopoiesis in its original theoretical form under Maturana and Varela, explains how our minds are biologically wired to socially construct reality. Language allows cognitive systems to construct structures and mental models that orient how a person describes themselves (their self-identity) and their environment. Language shapes reality. If we are to take autopoiesis seriously, language can only be a social phenomenon, never a personal one. According to Maturana and Varela (1987), we exist in language. Language "cannot be used as a tool to reveal the world” (p. 234) they asserted. Language coordinates behavior, which brings forth a world. "We work out our lives in a mutual linguistic coupling, not because language permits ourselves to reveal ourselves but because we are constituted in language in a continuous becoming that we bring forth with others" (p. 234). This means that the world we see "is not the world but $a$ world which we bring forth with others” (p. 244). This is fully consistent with the AI approach which aims to bring multiple realities together to co-create a future.

Words do create worlds. The Luhmannian perspective demands more rigor in determining the implications of this notion. Social constructionism came out of the broader, postmodernism movement. Postmodernism in general seeks a reappraisal of widely held perceptions. It focuses on the role of language and power in the social construction of beliefs and values. Seen in the postmodernist light, AI can be viewed as a method for empowering those who have no voice. The emergence of alternative narratives and discourse during an AI summit 
are of central concern. Luhmann draws a strict line between language and communication. People can language, but that does not constitute communication. When this line is drawn, narratives become confined to the domain of individuals. They only become relevant to an organization if it produces decisions such as a decision to change its existing structures. The durability and resilience of the connections between decisions gain greater significance.

The AI summit is a strategic episode that temporarily suspends existing organizational structures for the sake of strategic reflection. Participants engage in activities as if they are all equal. This does not mean that the existing structures do not matter. They do. They matter because participants are intimately coupled to the organization through their positions, which were defined by pre-existing programs and initiatives. The impact of existing organizational structures on an AI intervention tends to get buried in conventional descriptions of AI. The context of the specific organization such as its organizational culture, dictates the degree to which structural elements matter. Suspension of structures had an important impact at the summits conducted by the U.S. Navy (Powley et al., 2011). They may not be as significant at a loosely coupled, entrepreneurial company. Or, in the case of a university, the suspension might matter for different reasons_-to tighten organizational controls (Jarzabkowski \& Seidl, 2008).

It is naïve to think that the effects of hierarchical order, power, and culture are somehow moderated by the positive energy generated at a summit. In fact, a social systems perspective would deem that such a conclusion is wrong. Positive emotions and high levels of motivation do not influence organizational decisions because they belong to the domain of an individual's behavior, not an organization's. Such reasoning lends credence to concerns raised by Aldred (2009) of the possibility that ideas generated during an AI intervention by organizational members with lesser power could “become co-opted into a corporate agenda” (p. 69). 
A suspension of existing structures increases the options from which the organization system can produce decisions. The potentiality of the organization is by definition outside the boundaries of the actuality of the existing organization. It resides in the organization's nonknowledge, which can be accessed during a strategic episode. Potential decision making criteria and information can re-enter the system. Once they re-enters the organization system, the organization can utilize such information to produce decisions. The doors to an organization's nonknowledge are open only temporarily. Inevitably, they close with a thud at the conclusion of the summit. Ideas that were generated from information that re-entered the system during the summit must produce decisions and reconnect to the organization. Otherwise, the organization has essentially de-selected that idea from its decision making considerations, and the idea will vanish.

Richer et al. (2009) noted that not all of the innovative ideas initiated by nurses during the AI intervention subsequently received the support of management. "During management meetings, external context issues, and new emerging internal pressures, took precedence over discussions of ideas proposed in the action plan” (p. 952). In contrast, the ideas that were implemented "mainly involved the mobilized actions of individuals who participated in the AI process” (p. 952). The same situation can occur the other way around. It is the all-too familiar scenario in which management decides on a strategy that, for whatever reason, fails to get implemented in the field.

A social systems perspective emphasizes the connections between decision communications. Ultimately, if a decision does not connect to another decision, then the game is over. New knowledge can emerge in the form of new or modified communication channels, programs or personnel. The changed organizational structure, though tentative and fragile, allows 
decision communications during the summit to connect to decisions that will be made once everybody gets back to work. This is why the emergence of self-organizing project teams is so important. The team members become the vehicle through which decisions can connect back to the organization's routine operations. Evolutionary theory would suggest that the emergence of such project teams is to some extent random. This does not rule out the possibility that the constant oscillation between strategic and operational contexts over an extended period of time might moderate the conception and incubation of such teams. Empowering those at the peripheral to create alternative narratives may tentatively change the existing organizational decision premises. Whether those changes carry forward and turn into more stable, robust and permanent structures depends largely on the durability and resilience of the decision communications that follow after the summit ends. Social constructionism in the AI literature emphasizes concepts such as collective narratives and the inner dialogue of an organization (Cooperrider et al., 2008). Social systems theory suggests that even if such narratives emerge during the interactions of an AI summit, they are prone to vanish as soon as they appear. Emerging narrative accounts must impact the organizational structure in such a way that they change the premises—communication channels, programs and personnel—for decision making. Otherwise, they will end up on the dark side of the organization's field of vision to be forgotten.

\section{AI principle 2: Simultaneity.}

The principle of simultaneity assumes that change is generated the moment one asks questions. Inquiry and change go hand in hand. "One of the most important things a change agent or OD practitioner does is to articulate questions” (Cooperrider et al., 2008, p. 9). A social systems perspective distinguishes between individual and organizational change. A provocative question is effective because it is an unexpected one. It opens up options to which a system may 
have been blind. More nonknowledge is accessed, increasing the system's intelligence. This does not guarantee changes in an organization's structure, however. A social systems perspective suggests that it is the intimate relationship between the individual participant's psychological system and the organization's decision communication system that triggers change. The conceptual model I propose shows that participants are structurally coupled to the organization through their positions.

A participant's position within the organization will frame how that person will think and act. Structural coupling is the mechanism by which systems co-evolve through mutual perturbations. An individual can penetrate the structural conditions of an organization in perceiving the events that unfold during a summit. Conversely, an organization can reach into the structural conditions of an individual to select what decision communications to produce. This special kind of structural coupling is called interpenetration (Luhmann, 1995, pp. 210-254). Interpenetration is "the contribution of complexity to the construction of emergent systems" (p. 216). Luhmann drew on an empirical study by Stager (1967) on decision making in small groups. Groups whose members could conceptually deal with higher levels of complexity (high conceptual level) required less structure to make decisions. This led Luhmann to posit that "social systems that can enlist more complex psychic systems need less structure” (p. 217). Such systems can cope more effectively "with greater instabilities and quicker structural change” (p. 217).

In practice, this plays out as interpersonal conflict. I described how at TireCo's summit, there was a noticeable shift in both emotional affect and strategic context as the conference entered the second half of the 4D cycle. The final two phases—Design and Deploy—were where the proverbial rubber hit the road. Participants were now being held accountable to results. An 
account manager might work on a plan to increase the effectiveness of a customer visit because their performance evaluations may be directly linked to the outcomes of such a plan. Rather than being suspended, existing structures may weigh heavily on the interactions that take place. There was a great deal of conflict during the breakout sessions. Suddenly, a person's rank within the organization mattered. Several newer and younger employees chose to literally sit on the sidelines in my group. Descriptions of this kind of conflict have rarely made their way into the AI literature, perhaps because they run counter to AI’s principle of positivity. Stager's (1967) research showed that interpersonal conflict was high in two of the four group compositions: the groups with the highest and lowest conceptual levels. The curvilinear relationship was significant ( $\mathrm{p}<0.01$ ). Interestingly, the high conceptual level groups were much more likely to synthesize such conflict into their decisions compared to lower conceptual level groups. Observational ratings of conflict utilization increased linearly $(\mathrm{p}<0.01)$, and the group composition effect on the use of generated conflict was also significant (p. $<0.01)$.

The interaction system of an AI summit can also penetrate the organization and individual psychological systems. The interaction system can leverage the complexities of both the organization and individuals. A social systems perspective therefore suggests that it is the interpenetrating nature of the structural couplings that enable organizational structures such as decision premises to change more quickly. An extended strategizing session with hundreds of organizational members can enlist much more complexity than a meeting limited to the top management team. As a consequence, less structure is necessary to institute more rapid change.

\section{AI principle 3 \& 4: Poetic and anticipatory.}

The poetic principle of AI emphasizes the notion of building new narratives (Bushe, 2011). The anticipatory principle assumes that images inspire action. Organizational members 
are free to choose what they want to study and how they frame the topic of inquiry. Metaphors and stories are used to describe an organization's structures. The paired interviews on peak experiences are an innovative way for people to share stories that can make explicit some of the tacit assumptions they hold about the organization (Bushe, 2011). Cultural norms and values, for example, can be so deeply engrained in organizational structures that they are taken for granted. Normative structures are much more resistant to change than operational structures such as decision premises. In situations where the norms of an organization are mismatched to its operational realities, a strategic episode like an AI summit offers an opportunity for the organization to come to grips with its new realities. The organization can produce decisions to adapt its theory of business to better align with its norms and values. On rarer occasions, it may decide to change its norms and values. The topic choice need not be positive for such decisions to be produced, however. The organization simply needs to recognize that its internal structures and the environment are out of alignment.

An AI summit can be a forum for aligning the inner dialogue of an organization to areas of growth and opportunity. I would point out that both these principles are grounded in human behavior. Narratives are a form of linguistic behavior. Actions in this context imply actions by people. Under a social systems framework, these principles cannot directly apply to social systems. Narratives and images structure the perceptions and actions of an individual.

The analog of narratives for social systems is the AI summit process itself. The format and activities of an AI summit essentially structures the interactions generated during the strategic episode and the decisions produced by the organization. Storytelling and cognitive mapping exercises benefit individuals by facilitating tacit to explicit knowledge conversion, thereby increasing organizational intelligence. The structured group activities prevent the 
interaction system from breaking down into chaos. The time-bound nature of strategic episodes provides pressure to get things done. The oscillation between strategic and operational contexts serves as added assurance that the interactions do not deviate too wildly and unrealistically from existing structures, while allowing room for strategic reflection. Such interactions may lead to the creation of new decision premises, or in some radical cases, novel self-descriptions of the organization that result in decisions to change the organization's identity.

\section{AI principle 5: Positivity.}

The principle of positivity assumes that change requires significant amounts of positive affect (Cooperrider et al., 2008). “Organizations, as human constructions, are largely affirmative systems and thus are responsive to positive thought and positive knowledge” (p. 10). This view is not consistent with social systems theory. Organizations are social systems that are constructed from communications. Whether or not social systems are more responsive to positive rather than negative thoughts that are uttered by people is an open question and beyond the scope of this study. Losada and Heaphy’s (2004) study of high performing teams offers some indication that at the meso-level, positivity is correlated to performance. I can only speculate that a social system's responsiveness will largely depend on the context of the situation. As I noted in the previous chapter, positive psychology can only have an indirect effect on an organization's structure because it operates independent of a human being's cognitive and psychological systems. An organization's identity is maintained through a different mode of production, namely the production of decision communications. This does not exclude the possibility that the organization can take advantage of a person's broadened cognition and higher levels of intrinsic motivation that are stimulated by positive emotions during an AI summit. If the participant is an 
organizational member, the organization can penetrate that person's cognitive system and use it as a basis for selecting and connecting decision communications.

The bigger implication of positivity for organizations stems from the AI methodology's insistence that we focus on opportunity areas. Drucker (2008) strongly advocated that for an organization to perform, it must consistently direct its attention to opportunities. "Of course, problems cannot be neglected. But the problem-focused organization is an organization on the defensive. It is an organization that feels that it has performed well if things do not get worse” (p. 284). Other scholars have shown that in an age of global hypercompetition (D'Aveni, 1994), defensive strategies are unsustainable. An environment of hypercompetition is one where "advantages are rapidly created and eroded" (p. 2). Product cycles are compressed, and the pace of innovation increases. The fervent rise and fall of so many new ventures in Silicon Valley is a testament to how low barriers to entry have become. "Every advantage is eroded,” (p. 7) warned D’Aveni (1994). Trying to sustain an advantage distracts an organization from developing new advantages. "It is like shoveling sand against the tide rather than moving to higher ground" (p. 8). Drucker (2008) put it this way:

One has got to face up to a very simple, very brutal, very harsh rule-one starves the problems and one feeds the opportunities. And above all, one puts the resources into tomorrow, where the results are, and not into yesterday, where the memories are. (p. 285)

In a hypercompetitive environment, D’Aveni (1994) argued, cost and quality advantages in and of themselves are unsustainable. The only enduring advantage is "the skill of generating new cost and quality advantages” (p. 234). Painstaking planning processes are a luxury in a highly dynamic, ruthlessly competitive environment. "Strategy in the current environment is more a process of fine-tuning reflexes and searching out or creating temporary opportunities” (p. 237). D’Aveni proposed a seven point framework to develop dynamic theories of business that 
can deal with hypercompetition. They include superior stakeholder satisfaction, positioning for speed and surprise, and simultaneous and sequential strategic thrusts (pp. 243-244). These aspects can be accommodated by an AI summit when hundreds of stakeholders are made available to the organization for strategic reflection.

An AI summit's deliberate focus on positive aspects of organizing also compensates for the tendency of people to pay more attention to problems than opportunities. At a meeting attended by 45 executives from companies and major public institutions, Elliott (1999), a management scholar and consultant, asked the attendees to list 20 adjectives that most accurately reflect the flavor of their organizations. All of the executives were well integrated into their organizations. The results were astonishing. An overwhelming majority of the words (72\%) were negative. Only $15 \%$ were positive. The negativity bias occurs at the level of people's consciousness. Such biases at the psychological system level likely have implications in how an organization produces decisions. Without processes for systematically articulating strengths and opportunities, an organization risks producing decision premises that are systematically biased towards a defensive strategy. I conclude that an AI summit is an advanced form of strategy meeting particularly suited for developing dynamic strategies in a hypercompetitive world.

\section{Limitations of the study}

There are several limitations to this study. First, autopoietic theory in general, and Luhmann's social systems theory in particular, have yet to be generally accepted by management scholars. Not only is autopoiesis a radical type of systems theory, it is also notoriously difficult to comprehend. Many of the concepts are counterintuitive for those of us who have grown up in a world dominated by open systems theory. The notion that an organization's operations are

closed to the environment sounds very misguided and downright wrong to an analyst used to the 
conventions of open systems. On the surface, social systems theory looks as cold and impersonal as the frameworks developed using microeconomics, frameworks in which there is a curious absence of human actors. Reducing organizations to communications rather than people seems as offensive as reducing people into data points. And the conclusion Luhmann reached about management consulting - that consultants can never overcome the communication barriers inherent in the client-consultant relationship-would be vehemently opposed by those who practice consulting.

I have argued in this study that it is precisely the radical nature of social systems theory that can shed light on the unique social dynamics of an AI summit. AI methodologies have, for the most part, defied evaluation. A Luhmannian perspective allows one to begin tackling the complexities embedded in an AI summit. Modeling an AI summit using an open systems approach is both complicated and wrought with challenges; there are just too many variables and different levels of analysis involved. A social systems perspective brings to the forefront the various system interdependencies between the organization, participants, and the conference proceedings. Although the theory itself is complex and unorthodox, it is relatively simple to apply. By analyzing episodes and structural couplings, a third-order observer can begin identifying the systems dynamics that matter to an AI summit which can then be compared with other strategizing formats. The emergence of self-organizing project teams, to which I will return later in this chapter, is an example of an outcome that is physically impossible in small group strategy meetings.

A second limitation is that Luhmann's theory does not adequately address dynamics at the group or meso-level. Large group methods such as the AI summit depend heavily on small group activities. In an AI summit, group activities are self-facilitated. The groups decide what 
ideas ought to be presented to the larger group. The redundancy and variety of participants, as well as the oscillation between strategic and routine contexts, assure to some level that significant issues will bubble to the surface. However, this does not exclude the possibility that important issues get shoved under the carpet, whether arbitrarily or systematically at the group level. The role of positivity at the group level may be different from the individual or organizational levels. Theories from social psychology would be the more appropriate lens to analyze such group dynamics. How those dynamics affect the organization and interaction systems is another question this study is unable to address.

Another major limitation of this study is its methodology. This study was exploratory and went through several iterations of theorizing and analysis conducted by a single researcher. While I have tried to make explicit my personal biases in this study, one is usually blind to such biases, as autopoietic theories of the mind would suggest. Here, I point out some obvious ones. I have had to rely heavily on the work of Seidl and his colleagues in interpreting Luhmann’s social systems theory and its application to organizations. Only a relatively small portion of Luhmann's work has been translated into English. His work on organizations in particular, has yet to be fully translated. I made an effort to compensate for this through discussions with Schoeneborn and Seidl at the annual meeting of the Academy of Management in 2012. While I am confident that I have a working understanding of Luhmann's theories, I am limited in the depth and breadth compared to scholars who are able to read his writings in German. My experience with AI summits is also limited to what I have read in the literature and what I experienced and observed at the one AI summit that I have ever attended: TireCo's sales summit. I could physically only participate in one group—my own—during the summit, and therefore, cannot generalize what I observed in the group activities. The description of the skit my group performed during TireCo's 
summit is based on my personal experience and observations. Another participant may have described the same episode quite differently. Much of the intense theorizing was conducted more than a year after the summit. The video footage of the large group sessions was indispensable for both the theorizing and data analysis phases. I was limited in my analysis to what I observed in the video, as well as other notes and documents I had gathered during the data collection phase. This study was intended to be exploratory, and as such, I hope these limitations I have noted will be addressed and corrected through future research.

\section{Relevance and implications for research}

This study set out to examine alternative ways of evaluating the effectiveness of the AI summit format. My approach was to situate the AI summit as a strategizing practice that generated organizational knowledge. This marked a departure from existing studies on AI, which positioned the approach as an intervention for transformational change. I focused on organizational knowledge as an outcome variable because it is a recognized source of competitive advantage in the strategic management literature. Transformational change, in contrast, is harder to link to firm outcomes. Previous studies suggested AI interventions were a source of new knowledge (Bushe \& Kassam, 2005) and innovative ideas (Richer et al., 2009). I reasoned that by understanding how and why an AI summit generates, and possibly accelerates knowledge creation in an organization, we can begin to identify what makes the AI summit an effective method of strategizing, and open up new avenues for evaluation.

I adopted Luhmann's social systems theory, which is grounded in the biological theory of autopoiesis. Use of this alternative lens provided a more granular and complex view of an AI summit, by delineating the macro-level social dynamics from the micro-level psychological and behavioral dynamics. A social systems perspective of AI summits contributes to the AI literature 
in three primary ways. First, it identified five features that are unique to the AI summit strategizing process (Figure 2). These features demonstrate how an organization can produce intelligent decisions quickly as a result of the structural coupling mechanisms between the host organization, its stakeholders and the conference proceedings. They complement AI theory by providing a more detailed account of how and why having the whole system in the room generates organizational knowledge. In particular, the extended duration of an AI summit creates a dynamic in which the strategic context of an episode continually shifts. The constant oscillation between strategic and routine contexts is a dynamic that has not been explicitly recognized in the previous literature.

Following Seidl (2007), knowledge is defined as the structures that orient how an organization deals with information. This definition seems like a sleight of hand. In one broad stroke, organizational knowledge is made interchangeable with organizational structure. Knowledge in the organizational sense is not about developing shared mindsets or beliefs or perceptions or strategic information; organizations are not cognitive systems and can never think. Knowledge creation is about changing the decision premises of an organization. It is about adapting organizational structures to select and produce responses that accommodate the uncertainties of the external environment. Ironically, I find myself in familiar territory: the notion that AI summits allow an organization to modify existing organizational structures and construct new ones. We have thus come full circle, but with a richer understanding of how and why this is so relative to other strategizing methods. It directs our attention away from changes in normative behavior (which can only be observed at the individual level), to changes in decision premises. 
A social systems lens suggests that scholars and practitioners may be overlooking an important outcome of an AI summit: the emergence of self-organizing project teams at a summit. These teams are vital for temporally connecting organizational decision communications from the AI summit to the organization's operations, once the strategic episode ends. Under Luhmann, decisions are communication events. They vanish as soon as they are produced. Organizational structure is created when decisions produce other decisions and become premises for future decisions. While the AI summit system is capable of creating and modifying decision premises on the fly, they are quite tentative. Whether those premises gain permanence is contingent upon the premises' ability to continue producing streams of decisions in the future.

A project team is a temporary type of organizational structure. In Luhmann's vocabulary, they constitute a new organizational decision premise comprised of personnel, an emerging initiative or program, and new communication channels. A new project team, therefore, represents new organizational knowledge. The AI summit seeds and incubates such project teams. People self-select themselves for these teams, usually by choosing the specific task or topic they want to work on during the Design and Deploy phases. At TireCo's summit, each participant could choose only one group. People can make their selections based on subject matter expertise, their organizational responsibilities, their interests, or at random.

Participants are encouraged by the organizers to choose what they are most passionate and enthusiastic about. The AI summit provides fertile ground for conceiving what LipmanBlumen and Leavitt (1999) named hot groups. Members of a hot group share a state of mind that is "task-obsessed and full of passion” (p. 3). It implies that its members are experiencing flow (Csikszentmihalyi, 1990); they are absorbed in their task, and their skills are capable of meeting the high challenge level. Lipman-Blumen and Leavitt claimed that organizational teams rarely 
become hot groups because hot groups are mismatched to the nature of traditional organizations. They more often are bred in smaller, “not-yet-well-organized companies” (p. 20). The lack of organizational structure forces members of a hot group to "cling for security to the life raft of common purpose" (p. 20). To grow hot groups in a highly structured organization, "it first needs to relax its old rules and constraints” (p. 177). An AI summit temporarily suspends existing structures, providing that habitat. Not all self-organizing teams become hot groups. Some will run out of steam. Others may provide an organization with an impetus for driving innovation. Intrinsic motivation appears to play a major role in hot groups. Therefore, members of such groups cannot be forced to do one thing or another. Although some leaders may have a knack for seeding multiple hot groups, this is rare.

An AI summit appears to be a systematic method for seeding hot groups. Therefore, the most promising area for future research is to empirically study the formation and impact of selforganizing project teams that emerge from summits. To date, I could not identify any empirical study of an AI summit that tracked the progress of such self-organizing teams. Such teams appear to be taken for granted as a matter of course. It is hard to imagine that the ideas generated at a summit could be implemented without a these teams of people dedicated to delivering results. Practitioners of AI realize the importance of post-summit activities. At TireCo's summit, members of the steering committee called on participants to join their post-summit committee several times during the conference. TireCo's chief sales and marketing officer often remarked about the importance of maintaining post-summit positive energy and momentum. The social systems lens would suggest an emphasis on identifying ways in which the organization can nurture and promote the new project teams into something more substantial. These teams are of crucial importance to continue producing decision communications based on the interactions 
from the strategic episode. A new project team represents a new organizational decision premise. This has implications for existing decision premises and positions. A person can wear only so many hats. If the tentative team structure gains more permanence, the organization will be pressed to produce decisions about what to do with the existing positions that the team members are maintaining while they are working on the new project.

Another contribution of this study is that it offers a starting point for comparative studies of AI methods. I was guided by Mohe and Seidl’s (2011) three step methodology for analyzing "contact systems" in management consulting to develop the conceptual model, and I believe that the method is generic enough to be applied to other forms of strategizing. The steps are to identify the different systems to reconstruct the communication logics, identify the structural coupling mechanisms, and then examine how mutual perturbations are internally (re)constructed (Mohe \& Seidl, 2011, p. 18).

The conceptual model I proposed is specific to AI summits hosted by organizations. It does not address AI summits hosted by communities. AI has a rich history of being used for community development around a common cause. Most recently, Cooperrider and Senge have been promoting a series of AI summits in cities across the United States in the field of sustainability. A social systems model of such summits will be more complex than the one I described. A community is made up of many organizations and institutions. Examining the structural coupling mechanisms may identify characteristics and dynamics that are different from an organizational summit. Such an analysis may yield insights into what key considerations need to be made for a community summit to deliver results.

A qualitative study using the proposed conceptual model and typology of episodes could compare AI summits to other forms of democratic strategizing such as Future Search 
conferences (Weisbord \& Janoff, 2010) and crowdsourcing (Stieger, Matzler, Chatterjee, \& Ladstaetter-Fussenegger, 2012). AI summits evolved from the Future Search format and share many of the same design principles and activities. However, there are notable differences. Future Search conferences are smaller in size and do not emphasize positivity. An empirical study could shed light on how the structural differences between these two formats affect the generation of organizational knowledge and changes in an organization's structure.

Crowdsourcing is another promising candidate for comparison. Crowdsourcing is a method for sourcing ideas and products from crowds of people (Howe, 2006). It is made possible by advances in computer networks. Stieger and his colleagues (2012) developed a framework for company-internal applications of crowdsourcing. They described a project at an Austrian company where a "dialogue platform" for strategizing was deployed to stimulate discussions on issues important to the company. Four conversation topics were chosen by top management: success factors, future customer solutions, process improvement, and innovation (p. 54). All 370 employees were invited to discuss these issues on an online platform for four weeks. Comparing an AI summit with a crowdsourcing platform could show the relative strengths and weaknesses of face-to-face conference compared to a social networking model of communication. Luhmann's concept of episodes might be extended to discussion threads in the dialogue platform, and then compared against the episodes of an AI summit.

A method of applying network analysis to communication episodes can be particularly useful in such a comparison. Blaschke, Schoeneborn and Seidl (2012) demonstrated how network analysis can be used to model communication topics and their transitions over time. Social network analysis typically designates people as nodes. For example, gatekeepers of information can be identified by looking at the flow of information between people. In contrast, 
Blaschke et al. turn this perspective inside out to accommodate a Luhmannian framework. Communication episodes are designated as nodes, while the edges represent people. Communication topics at a startup company initially showed a concentration around research and development, but subsequently shifted to marketing as the company grew. This kind of data visualization can quantify the relative importance of one topic over another.

Finally, this study makes some contributions to organization theory. I extended Luhmann's social systems theory to a new application area in strategizing activities. It complements findings from studies of strategy practices applying a social systems approach in a university setting (Jarzabkowski \& Seidl, 2008), management consulting (Mohe \& Seidl, 2011), and strategic episodes (Hendry \& Seidl, 2003). The typology of episodes I developed could be used to generate research questions related to strategy meetings. For example, the impact of temporary suspension of structures during strategy meetings could be compared in a variety of organizational contexts such as loosely coupled organizations versus tightly coupled ones.

The study complements theories of organizational knowledge creation by describing the knowledge creation process by clearly distinguishing personal and organizational knowledge. Personal knowledge is served by psychological and cognitive structures. Organizational knowledge is served by decision communication structures. This distinction can help unravel the interdependent and complex relationship between individuals and the organization in the creation of organizational knowledge. Nonaka and his colleagues’ (Nonaka \& Konno, 1998; Nonaka et al., 2000) concept of shared contexts or "ba" is rather ambiguous. A "ba" is not necessarily a physical space: it includes virtual space like emails, as well as mental space like shared ideals (Nonaka et al., 2000, p. 14). The authors claimed that " $B a$ sets a boundary for interactions amongst individuals, and yet its boundary is open” (p. 15). It is unclear how those boundaries are 
set, and what a boundary that is simultaneously open and closed looks like. Luhmann's concepts of interaction systems and episodes are much more rigorous in their definitions. A study analyzing concepts like $b a$ and the SECI model through a social systems lens might help clear up some of the ambiguities for better applicability to empirical studies.

\section{Implications for practice}

The findings of this study have immediate implications for managers of organizations, especially executives responsible for developing corporate strategy. One of the greatest strengths of the AI summit format from a strategizing perspective is that it combines strategy development with execution. What managers call “execution” happens when an organization adjusts its organizational knowledge and structures to enable the production of new decisions based on the new strategy the organization has selected. In typical methods of strategy development, there is a lag between the development of corporate strategy and it execution. However, one of the key features of an AI summit is the organization's ability to change its decision premises while the strategic episode is still taking place. The most significant of these structural changes is the emergence of self-organized project teams. At many organizations, it could take weeks, sometimes months to put together a working team or task force to begin implementing a strategic initiative. Furthermore, there is no guarantee that the new team will be functional. Depending on how the members are selected, some employees may resent the extra work the new initiative creates for them.

The teams that form during the AI summit are somewhat different. Participants spontaneously decide for themselves whether they want to be part of an emerging initiative or not. Therefore, the members tend to be highly energized and motivated from the outset. Working groups like project teams and task forces are essential for any new organizational program to be 
executed. The AI summit not only enables such groups to form on the spot without the normal time lag of weeks and months, but does so in a manner that encourages these groups to become hot groups.

The formation of hot groups is one thing. Whether or not they continue to flourish after the summit ends is a completely different matter. Project management after the summit is a critical element of post-summit activities, an element that appears to be seriously neglected. One of the biggest takeaways of this study is for managers to recognize the importance of project management in making an AI summit successful. Organizations that have a specialized, project management office (PMO) might consider having at least one person from that office to be part of the summit steering committee. Once the summit is over, a project manager could be assigned to oversee and monitor the various project teams that emerged during the summit. The selforganizing project team in and of itself is a form of new organizational knowledge because the team represents a new structure that changes how the organization makes subsequent decisions. In order for decision communications to continue to be produced, additional communication channels in the form of email groups and meetings may need to be formed. Such activities require management and coordination. The project manager may also need to initiate negotiations with executives to allocate the funding and resources required by the project teams. Organizations without a dedicated PMO should assign someone with project management expertise to help support the activities of the teams that emerged from the summit.

Lipman-Blumen and Leavitt (1999) gave some general guidelines on how organizations can nurture hot groups. They suggest that a good way to begin is to do the opposite of what organizational manuals prescribe. For example, they suggest that less organization is better than more. Hot groups need room to innovate. Micro-management can stifle their progress. Another 
suggestion is to loosen controls, not tighten them. Existing organizational controls may undermine the very results that the groups are trying to deliver, especially if the group is working on an innovative initiative that may be considered a threat to existing business units. LipmanBlumen and Leavitt also advocated for increasing the span of control of the managers in hot groups rather. Limiting the span of control can diminish the opportunities that the hot group is able to exploit.

An AI summit is indeed resource intensive. That said, in order to gain competitive advantage in a hypercompetitive world (D’Aveni, 1994), experimenting with large group strategizing methods like the AI summit may no longer be a luxury but a necessity. The format can bring payoffs beyond the incubation of hot groups. I argued that including external stakeholders in an organization's strategizing activities boosts an organization's intelligence. Developing strategy together with the customer is unconventional and may initially sound risky to some managers. The AI summit is a strategic episode in which organizational boundaries are temporarily suspended and relaxed. Participants strategize as though they belong to one entity, whether they are internal or external stakeholders. The positive orientation of AI summits creates a safe environment for customers and suppliers to provide feedback which they may not otherwise be willing to share. Taken together, interactions at an AI summit result in a freer flow of information that produces decisions that may not have been possible under normal conditions.

For the summit to achieve its full potential in developing and executing strategy, summit organizers must also be mindful of existing organizational structures and their potential impact. First, the summit must have the buy-in of its executives. Executives must be willing to share decision-making authority with the summit participants. Otherwise, the ideas and new knowledge generated at the summit will not only be buried and converted to nonknowledge, but 
existing structures will be reinforced and made more rigid. If the organizers had positioned the AI summit as a way to transform the organization, then such an outcome would be highly demotivating.

The selection of summit participants is critical. Organizational decisions cannot be produced during the summit unless the positions associated with those decisions are represented at the summit, whether those positions are at the top, middle or bottom of the organizational pyramid. It is unclear how inclusive and diverse a summit has to be for an AI summit to be successful. Wholeness is an important concept in AI, and therefore, the rule of thumb is to be as inclusive as possible. At the very minimum, anybody who plays a key role in executing (or blocking) the task assigned to the summit ought to be selected for participation. The absence (or lukewarm participation) of important decision makers will certainly undermine the knowledgegenerating capacity of a summit. Organizers should be careful not to overlook important opinion and thought leaders, gatekeepers, and subject matter experts.

Sometimes, the true experts may not be the people with the official title. Customer service representatives may have much better information about consumer behavior as it relates to their particular organization than the marketing specialists that rely on aggregated market data, for example. The benefit of having the whole system in the room is that it makes it easy to locate and take advantage of the people with the expertise needed for the task at hand. The spirit of contribution at a summit compels participants to tap into their personal knowledge to contribute useful information. Here again, the organization is able to access what might otherwise have been trapped as nonknowledge. While other large group methods have the potential of surfacing nonknowledge, the AI summit format is particularly strong in this area because of the focus on opportunities and positive aspects of organizing. 
Finally, summit organizers and participants may want to reconsider what activities are necessary after the summit to reconnect the decisions produced during the strategic episode back to the organization's day-to-day operations. Maintaining the positive momentum of the summit is secondary. Most important is how to prevent the fragile and tentative new structures that emerged at the summit from disintegrating. These structures include communication channels, programs, people and their positions. They constitute an organization's knowledge, because the structures orient how an organization deals with information after the summit ends. A social systems perspective suggests that documenting what happened at a summit in the form of reports and videos, then distributing them organization wide (especially to the people who did not participate) has limited impact. First, the act of distributing information does not constitute communication under Luhmann's definition, until somebody understands (or misunderstands) the information that has been transmitted. The notion of a "communication rollout" to the organization is misguided. More importantly, efforts to communicate may enhance the personal knowledge of the people who read or view the reports by evoking thoughts and emotions, but not the organizational knowledge base. Organizational knowledge is produced by changing or creating organizational structures. Post-summit activities should therefore be directed towards monitoring and managing the structural changes initiated at the summit. The project management aspect is crucial for decision communications to continue to produce more decisions in order to contribute to the autopoiesis of the organization.

\section{Experimenting with "experience meetings"}

This study sought to understand how and why an AI summit generates organizational knowledge. Taken together, the findings suggest that the social dynamics found in an AI summit not only enable an organization to create new structures and hence knowledge, but also 
accelerate the process. Using the jargon of the information age, an AI summit can be described as a crowdsourcing platform for developing strategy—with a twist. The twist comes in two forms: positivity and physical, face-to-face interaction. Social networking sites on the Internet arrived with great fanfare in the $21^{\text {st }}$ century, and are undoubtedly revolutionizing how people communicate. Conferences sound anachronistic in contrast. But ignore them at your peril. The potential of innovative conference formats has only just begun to be tapped.

As I went back to early management theories for this research, I discovered that one person had the foresight to anticipate these large group methods nearly one hundred years ago. Her name is Mary Parker Follett, a political scientist who in her later career, became a thought leader in management. Drucker called Parker Follett a prophet of management (Graham, 1995) whose insights on managing organizations were light years ahead of her peers. In the midst of the roaring twenties, she advocated for a democratic form of governance through which people could fulfill their potential and strengthen the groups to which they belong (Graham, 1995, p. vii). It is stunning how she had a keen sense of an embodied mind almost half a century before Maturana and Varela formalized their theory of autopoiesis. Her thoughts foreshadow Luhmann's social systems theory. Consider the following quotes from her 1924 book, Creative experience:

- Democracy...is an assertion that the people who are doing the doing are also thereby doing the thinking. (p. 203)

- Integration, the resolution of conflict...must take place on the motor level, not on the intellectual level. (p. 150)

- Interpretation, like everything else, originates on the motor level. (p. 216)

- We cannot get genuine agreement by mere discussion in conference. As our responses are governed by past habits, by what has been incorporate in the organism, the only way of getting other responses is by getting other things incorporated in the organism. (p. 150)

- There is no use chasing through the universe for a "real" you or a "real" me; it is more useful to study our interactions, these are certainly real. (p. 177) 
- There is no static collective will nor "group mind": we have continuing activity; at any one moment the function which that activity is of the situation is the collective will. Thus its nature is wholly dynamic. We must think no more in terms of social institutions but of social activities. (p. 207)

- The idea of collective will as a unifying of wills must go; there is only a collective will as a unifying of activities - a different matter. (p. 208)

- Psychology now shows us how experience generates its own thought, will, purpose. This means that between expert and people is a chasm which ideas cannot cross. (p. 205)

Nohria, the current dean of Harvard Business School, noted how he was struck by the clarity and comprehensiveness with which Parker Follett articulated the organizational principles that were in vogue in the 90s (Nohria, 1995, p. 156). For example, she wrote that authority must be derived from knowledge and experience, not rank, recognizing that knowledge does not only reside at the top. Nevertheless, Nohria remained highly skeptical and pessimistic about organizations ever achieving Parker Follett's brand of democratic governance, concluding that her principles are more idealistic than pragmatic.

I am inclined to agree with Nohria. The string of corporate scandals in the knowledge society we have experienced in the $21^{\text {st }}$ century only support his claims. I would point out though that at the time of his writing, large group methods of strategizing were only just beginning to come of age. Interestingly, one of the techniques Parker Follett advocated for achieving democratic forms of governance was the experience meeting (1924, pp. 212-216). An experience meeting has three steps: 1) Present the meeting topic in a way that clearly shows its relation to our lives; 2) Find anything in our own experience that throws light on the question; and 3) Unite our various experiences with material provided by the expert. After the meeting, the participants are encouraged to experiment based on what they learned. They would return to another meeting to suggest what new directions experiments can take.

"I am not hereby glorifying 'the people,"” she stressed. She rejected a "mystic faith in a rightness of public opinion” (p. 216). The origin of power, she believed, came from experience. 
Nearly a century has passed since Parker Follett urgently advocated for "experience meetings as an experiment in democracy” (p. 216). Experiments with large group methods such as AI summits are in full swing among giant organizations such as Walmart and the U.S. Navy. Companies like Green Mountain Coffee Roasters, the maker of the ubiquitous K-cup coffee system, have used AI summits to articulate their corporate purpose. The impetus for such experimentation is not democratic ideals, but the economic realities of a knowledge-based society.

Companies require a high spirit of performance (Drucker, 2008) to thrive in times of high uncertainty. An organization "will have the thrill of excitement, the sense of challenge, and the satisfaction of achievement if its energies are put where the results are, and that means on the opportunities” (p. 284). Parker Follett's insights on democratic governance were derived through a synthesis of psychological research and her empirical observations of social work as a political scientist. They deal with dynamics at the individual system level. Luhmann's theory of social systems gives us a different and complementary vantage point-the organizational view. Through experimentation in both theory and practice using multiple approaches, eventually, we may hit upon a method for conducting effective experience meetings. 


\section{References}

Aldred, R. (2009). From community participation to organizational therapy? World Cafe and Appreciative Inquiry as research methods. Community Development Journal, 46, 57-71. doi: 10.1093/cdj/bsp039

Ambrosini, V., \& Bowman, C. (2001). Tacit knowledge: Some suggestions for operationalization. Journal of Management Studies, 38(6), 811-829. doi: 10.1111/14676486.00260

Andersen, N. Å. (2003). The undecidability of decision. In T. Bakken \& T. Hernes (Eds.), Autopoietic organization theory: Drawing on Niklas Luhmann's social systems perspective (pp. 235-258). Herndon, VA: Copenhagen Business School Press.

Andrews, K. R. (1980). The concept of corporate strategy (Rev. ed.). Homewood, Ill.: R.D. Irwin.

Baecker, D. (2006). The form of the firm. Organization, 13(1), 109-142. doi: $10.1177 / 1350508406059644$

Bakken, T., \& Hernes, T. (Eds.). (2003). Autopoietic organization theory: Drawing on Niklas Luhmann's social systems perspective. Herndon, VA: Copenhagen Business School Press.

Bakker, A. B. (2005). Flow among music teachers and their students: The crossover of peak experiences. Journal of Vocational Behavior, 66(1), 26-44. doi:

10.1016/j.jvb.2003.11.001

Barney, J. B. (1996). The resource-based theory of the firm. Organization Science, 7(5), 469. doi: 10.1287/orsc.7.5.469 
Barrett, F. J. (1998). Coda-creativity and improvisation in jazz and organizations: Implications for organizational learning. Organization Science, 9(5), 605-622. doi: 10.1287/orsc.9.5.605

Barrett, F. J., Thomas, G. F., \& Hocevar, S. P. (1995). The central role of discourse in large-scale change: A social construction perspective. The Journal of Applied Behavioral Science, 31(3), 352-372. doi: 10.1177/0021886395313007

Barros, I. O., \& Cooperrider, D. L. (2000). A story of Nutrimental in Brazil: How wholeness, appreciation, and inquiry bring out the best in human organization. Organization Development Journal, 18(2), 22-28.

Bateson, G. (1979). Mind and nature: A necessary unity (1st ed.). New York: Dutton.

Beer, S. (1980). Preface. In H. R. Maturana \& F. J. Varela (Eds.), Autopoiesis and cognition: The realization of the living. Dordrecht: Reidel.

Besanko, D., Dranove, D., \& Shanley, M. (2000). Economics of strategy (2nd ed.). New York: J. Wiley.

Blaschke, S., Schoeneborn, D., \& Seidl, D. (2012). Organizations as networks of communication episodes: Turning the network perspective inside out. Organization Studies, 33(7), 879906. doi: $10.1177 / 0170840612443459$

Bluhm, D. J., Harman, W., Lee, T. W., \& Mitchell, T. R. (2011). Qualitative Research in Management: A Decade of Progress. Journal of Management Studies, 48(8), 1866-1891. doi: 10.1111/j.1467-6486.2010.00972.x

Bohm, D. (1996). On dialogue. London ; New York: Routledge. 
Brown, J., \& Isaacs, D. (2005). The World Cafe: Shaping our futures through conversations that matter Retrieved from http://proquest.safaribooksonline.com/?uiCode=stanford\&xmlId=9781605092515

Brown, T. (2009). Change by design: How design thinking transforms organizations and inspires innovation (1st ed.). New York: Harper Business.

Bunker, B. B., \& Alban, B. T. (1997). Large group interventions: Engaging the whole system for rapid change. San Francisco, CA: Jossey-Bass Publishers.

Bunker, B. B., \& Alban, B. T. (2006). The handbook of large group methods: Creating systemic change in organizations and communities. San Francisco, CA: Jossey-Bass Publishers.

Bunker, B. B., Alban, B. T., \& Lewicki, R. J. (2004). Ideas in currency and OD practice: Has the well gone dry? The Journal of Applied Behavioral Science, 40, 403-422. doi: $10.1177 / 0021886304270372$

Burke, W. W. (2011). A perspective on the field of organization development and change: The Zeigarnik Effect. The Journal of Applied Behavioral Science, 47(2), 143-167. doi: $10.1177 / 0021886310388161$

Bushe, G. R. (2007). Appreciative inquiry is not (just) about the positive. OD practitioner, 39, 30-35.

Bushe, G. R. (2010). A comparative case study of appreciative inquiries in one organization: Implications for practice. Revista de Cercetare si Interventie sociala, 29, 7-24.

Bushe, G. R. (2011). Appreciative inquiry: Theory and critique. In D. M. Boje, B. Burnes \& J. Hassard (Eds.), The Routledge companion to organizational change (pp. 87-103). Oxford: Routledge. 
Bushe, G. R. (2012). Foundations of appreciative inquiry: History, criticism and potential. AI Practitioner, 14(1), 8-20.

Bushe, G. R., \& Coetzer, G. H. (1995). Appreciative inquiry as a team-development intervention: A controlled experiment. The Journal of Applied Behavioral Science, 31, 13-30. doi: 10.1177/0021886395311004

Bushe, G. R., \& Kassam, A. F. (2005). When is appreciative inquiry transformational? The Journal of Applied Behavioral Science, 41(2), 161-181. doi: 10.1177/0021886304270337

Clegg, S. R., Kornberger, M., \& Rhodes, C. (2004). Noise, parasites and translation: Theory and practice in management consulting. Management Learning, 35(1), 31-44. doi: $10.1177 / 1350507604041163$

Cooperrider, D. L. (1986). Appreciative inquiry: Toward a methodology for understanding and enhancing organizational innovation (Doctoral dissertation). Retrieved from ProQuest Dissertations and Theses. (8611485)

Cooperrider, D. L. (1990). Positive image, positive action: The affirmative basis of organizing. In S. Srivastva, D. L. Cooperrider \& Associates (Eds.), Appreciative management and leadership (pp. 91-125). San Francisco, CA: Jossey-Bass Publishers.

Cooperrider, D. L. (2012). The concentration effect of strengths: How the whole system "AI” summit brings out the best in human enterprise. Organizational Dynamics, 41(2), 106117. doi: 10.1016/j.orgdyn.2012.01.004

Cooperrider, D. L., \& Avital, M. (2004). Constructive discourse and human organization (1st ed.). Amsterdam; Boston: Elsevier/JAI. 
Cooperrider, D. L., \& Srivastva, S. (2008). Appreciative inquiry in organizational life. In D. L. Cooperrider, D. Whitney \& J. M. Stavros (Eds.), Appreciative inquiry handbook for leaders of change (2nd ed., pp. 353-376). Brunswick, OH: Crown Custom Publishing.

Cooperrider, D. L., \& Whitney, D. K. (2005). Appreciative inquiry: A positive revolution in change (1st ed.). San Francisco, CA: Berrett-Koehler.

Cooperrider, D. L., Whitney, D. K., \& Stavros, J. M. (2008). Appreciative inquiry handbook for leaders of change (2nd ed.). Brunswick, OH: Crown Custom Publishing.

Cooren, F., Kuhn, T., Cornelissen, J. P., \& Clark, T. (2011). Communication, organizing and organization: An overview and introduction to the special issue. Organization Studies, 32(9), 1149-1170. doi: 10.1177/0170840611410836

Csikszentmihalyi, M. (1990). Flow: The psychology of optimal experience (1st ed.). New York: Harper \& Row.

D’Aveni, R. A. (1994). Hypercompetition: Managing the dynamics of strategic maneuvering. New York: Maxwell Macmillan International.

Dannemiller Tyson Associates. (n.d.). Whole-scale change approach. Retrieved January 19, 2013, from http://dannemillertyson.com/how-we-work/whole-scale-change-approach/

Dierkes, M., Berthoin Antal, A., Child, J., \& Nonaka, I. (Eds.). (2001). Handbook of organizational learning and knowledge Oxford; New York: Oxford University Press.

Drucker, P. F. (1993). Innovation and entrepreneurship: Practice and principles. New York: Harper Business.

Drucker, P. F. (2008). Management (Rev. ed.). New York: Collins.

Easterby-Smith, M., \& Lyles, M. A. (2003a). Introduction: Watersheds of organizational learning and knowledge management. In M. Easterby-Smith \& M. A. Lyles (Eds.), The 
Blackwell handbook of organizational learning and knowledge management (pp. 1-15). Malden, MA: Blackwell Pub.

Easterby-Smith, M., \& Lyles, M. A. (Eds.). (2003b). The Blackwell handbook of organizational learning and knowledge management. Malden, MA: Blackwell Pub.

Edmondson, A. (1999). Psychological safety and learning behavior in work teams. Administrative Science Quarterly, 44(2), 350-383. doi: 10.2307/2666999

Elliott, C. (1999). Locating the energy for change: An introduction to appreciative inquiry. Winnipeg: International Institute for Sustainable Development.

Fey, T. (2011). Bossypants (1st ed.). New York: Little, Brown and Co.

Fry, R. E., Barrett, F. J., Seiling, J., \& Whitney, D. (Eds.). (2002). Appreciative inquiry and organizational transformation: Reports from the field. Westport: Quorum Books.

Garud, R. (2008). Conferences as venues for the configuration of emerging organizational fields: The case of cochlear implants. Journal of Management Studies, 45(6), 1061-1088. doi: 10.1111/j.1467-6486.2008.00783.x

Gergen, K. J. (1978). Toward generative theory. Journal of Personality and Social Psychology, 36(11), 1344-1360.

Gergen, K. J. (1982). Toward transformation in social knowledge. New York: Springer-Verlag. Gergen, K. J. (2009). An invitation to social construction (2nd ed.). Los Angeles; London: Sage.

Gergen, K. J., \& Thatchenkery, T. J. (1996). Organization science as social construction: Postmodern potentials. The Journal of Applied Behavioral Science, 32(4), 356-377.

Glaser, B. G., \& Strauss, A. L. (1967). The discovery of grounded theory: Strategies for qualitative research. Chicago: Aldine Pub. Co.

Gleick, J. (1987). Chaos: The making of a new science. New York: Viking. 
Gleick, J. (2011). The information: A history, a theory, a flood (1st ed.). New York: Pantheon Books.

Golsorkhi, D., Rouleau, L., Seidl, D., \& Vaara, E. (Eds.). (2010). Cambridge handbook of strategy as practice. Cambridge, UK; New York: Cambridge University Press.

Graham, P. (Ed.). (1995). Mary Parker Follett—prophet of management: A celebration of writings from the 1920s. Boston: Harvard Business School Press.

Grand, S., Rüegg-Stürm, J., \& von Arx, W. (2010). Constructivist epistemologies in Strategy as Practice research. In D. Golsorkhi, L. Rouleau \& D. Seidl (Eds.), Cambridge handbook of strategy as practice (pp. 63-78). Cambridge, UK; New York: Cambridge University Press.

Grant, S., \& Humphries, M. (2006). Critical evaluation of appreciative inquiry: Bridging an apparent paradox. Action Research, 4, 401-418. doi: 10.1177/1476750306070103

Gustavsen, B. (1986). The design of conferences and the evolving role of democratic dialogue in changing working life. Human Relations, 39(2), 101-116. doi:

$10.1177 / 001872678603900201$

Hatfield, E., Cacioppo, J. T., \& Rapson, R. L. (1994). Emotional contagion. Cambridge; New York; Paris: Cambridge University Press.

Hektner, J. M., Schmidt, J. A., \& Csikszentmihalyi, M. (2007). Experience sampling method: Measuring the quality of everyday life. Thousand Oaks, CA: Sage Publications.

Hendry, J., \& Seidl, D. (2003). The structure and significance of strategic episodes: Social systems theory and the routine practices of strategic change. Journal of Management Studies, 40(1), 175-196. doi: 10.1111/1467-6486.00008

Howe, J. (2006). The rise of crowdsourcing. WIRED, 14.06. 
Jackson, F. (2009, August 23). It's our turn to dream big: Cleveland will be first city to achieve sustainability. The Plain Dealer, p. G6.

Jantsch, E. (1980). The self-organizing universe: Scientific and human implications of the emerging paradigm of evolution (1st ed.). Oxford; New York: Pergamon Press.

Jarzabkowski, P., Balogun, J., \& Seidl, D. (2007). Strategizing: The challenges of a practice perspective. Human Relations, 60(1), 5-27. doi: 10.1177/0018726707075703

Jarzabkowski, P., \& Paul Spee, A. (2009). Strategy-as-practice: A review and future directions for the field. International Journal of Management Reviews, 11(1), 69-95. doi: 10.1111/j.1468-2370.2008.00250.x

Jarzabkowski, P., \& Seidl, D. (2008). The role of meetings in the social practice of strategy. Organization Studies, 29(11), 1391-1426. doi: 10.1177/0170840608096388

Johnson, K. J., Waugh, C. E., \& Fredrickson, B. L. (2010). Smile to see the forest: Facially expressed positive emotions broaden cognition. Cognition \& Emotion, 24(2), 299-321.

Jones, D. A. (1998). A field experiment in appreciative inquiry. Organization Development Journal, 16, 69-78.

Kiechel, W. (2010). The lords of strategy: The secret intellectual history of the new corporate world. Boston: Harvard Business Press.

Kieser, A. (2007). Niklas Luhmann and organization studies. Academy of Management Review, 32(3), 991-993. doi: 10.5465/amr.2007.25275688

Kim, W. C., \& Mauborgne, R. (1998). Procedural justice, strategic decision making, and the knowledge economy. Strategic Management Journal, 19(4), 323-338. doi: $10.2307 / 3094069$ 
Knodt, E. M. (1995). Foreword. In N. Luhmann, (J. Bednarz Jr \& D. Baecker, Trans.) Social systems (pp. ix-xxxvi). Stanford: Stanford University Press.

Kuhn, T. (2008). A communicative theory of the firm: Developing an alternative perspective on intra-organizational power and stakeholder relationships. Organization Studies, 29(8-9), 1227-1254. doi: 10.1177/0170840608094778

Langley, A. (1999). Strategies for theorizing from process data. The Academy of Management Review, 24(4), 691-710.

Latane, B., \& Darley, J. M. (1968). Group inhibition of bystander interventions in emergencies. Journal of Personality and Social Psychology, 10(3), 215-221.

Le Bon, G. (1930). The crowd: A study of the popular mind London: E. Benn.

Leonard - Barton, D. (2007). Core capabilities and core rigidities: A paradox in managing new product development. Strategic Management Journal, 13(S1), 111-125.

Lewin, K. (1946). Action research and minority problems. Journal of Social Issues, 2(4), 34-46. doi: 10.1111/j.1540-4560.1946.tb02295.x

Lewin, K. (1947a). Frontiers in group dynamics: Concept, method and reality in social science; social equilibria and social change. Human Relations, 1(1), 5-41. doi: $10.1177 / 001872674700100103$

Lewin, K. (1947b). Frontiers in group dynamics: II. Channels of group life; social planning and action research. Human Relations, 1(2), 143-153. doi: 10.1177/001872674700100201

Lipman-Blumen, J., \& Leavitt, H. J. (1999). Hot groups: Seeding them, feeding them, and using them to ignite your organization. New York: Oxford University Press. 
Losada, M., \& Heaphy, E. (2004). The role of positivity and connectivity in the performance of business teams: A nonlinear dynamics model. American Behavioral Scientist, 47(6), 740765. doi: $10.1177 / 0002764203260208$

Ludema, J. D., Whitney, D., Mohr, B. J., \& Griffin, T. J. (2003). The appreciative inquiry summit: A practitioner's guide for leading large-group change. San Francisco, CA: Berrett-Koehler Publishers.

Luhmann, N. (1986). Ecological communication. Chicago: University of Chicago Press.

Luhmann, N. (1988). Law as a social system. Northwestern University Law Review 83, 136-150.

Luhmann, N. (1990). Essays on self-reference. New York: Columbia University Press.

Luhmann, N. (1992). What is Communication? Communication Theory, 2(3), 251-259. doi: 10.1111/j.1468-2885.1992.tb00042.x

Luhmann, N. (1995). Social systems (J. Bednarz Jr \& D. Baecker, Trans.). Stanford, CA: Stanford University Press.

Luhmann, N. (2000a). Art as a social system. Stanford, CA: Stanford University Press.

Luhmann, N. (2000b). The reality of the mass media. Stanford, CA: Stanford University Press.

Luhmann, N. (2003). Organization. In T. Bakken \& T. Hernes (Eds.), Autopoietic organization theory: Drawing on Niklas Luhmann’s social systems perspective (pp. 31-52). Herndon, VA, USA: Copenhagen Business School Press.

Luhmann, N. (2005a). The autopoiesis of social systems. In D. Seidl \& K. H. Becker (Eds.), Niklas Luhmann and organization studies (pp. 64-84). Herndon, VA: Copenhagen Business School Press. 
Luhmann, N. (2005b). Communication barriers in management consulting. In D. Seidl \& K. H. Becker (Eds.), Niklas Luhmann and organization studies (pp. 351-364). Herndon, VA: Copenhagen Business School Press.

Luhmann, N. (2005c). The paradox of decision making. In D. Seidl \& K. H. Becker (Eds.), Niklas Luhmann and organization studies (pp. 85-106). Herndon, VA: Copenhagen Business School Press.

Makino, E. (2011). TireCo 2011 post summit report: A personal recollection by a participantobserver (pp. 1-12).

March, J. G., \& Simon, H. A. (1993). Organizations (2nd ed.). Cambridge, MA: Blackwell.

Maturana, H. R., \& Varela, F. J. (1980). Autopoiesis and cognition: The realization of the living. Dordrecht: Reidel.

Maturana, H. R., \& Varela, F. J. (1987). The tree of knowledge: The biological roots of human understanding. Boston: Shambhala.

Messerschmidt, D. (2008). Evaluating appreciative inquiry as an organizational transformation tool: An assessment from Nepal. Human Organization, 67, 454-468.

Mingers, J. (1995). Self-producing systems: Implications and applications of autopoiesis. New York: Plenum Press.

Mingers, J. (2003). Observing organizations: An evaluation of Luhmann's organization theory. In T. Bakken \& T. Hernes (Eds.), Autopoietic organization theory: Drawing on Niklas Luhmann’s social systems perspective (pp. 103-150). Herndon, VA: Copenhagen Business School Press.

Mohe, M., \& Seidl, D. (2011). Theorizing the client-consultant relationship from the perspective of social-systems theory. Organization, 18(1), 3-22. doi: 10.1177/1350508409353834 
Morgan, G. (1997). Images of organization (2nd ed.). Thousand Oaks, CA: Sage Publications.

Nohria, N. (1995). Mary Parker Follett's view on power, the giving of orders, and authority: An alternative to heirarchy or a utopian ideology? In P. Graham (Ed.), Mary Parker Follettprophet of management: A celebration of writings from the 1920s (pp. 154-162). Boston: Harvard Business School Press.

Nonaka, I. (1994). A dynamic theory of organizational knowledge creation. Organization Science, 5(1), 14-37.

Nonaka, I., \& Konno, N. (1998). The Concept of "Ba": building a foundation for knowledge creation. California Management Review, 40(3), 40-54.

Nonaka, I., \& Takeuchi, H. (1995). The knowledge-creating company: How Japanese companies create the dynamics of innovation. New York: Oxford University Press.

Nonaka, I., Toyama, R., \& Konno, N. (2000). SECI, ba and leadership: A unified model of dynamic knowledge creation. Long Range Planning, 33(1), 5-34. doi: 10.1016/s00246301(99)00115-6

Nonaka, I., \& von Krogh, G. (2009). Perspective: Tacit knowledge and knowledge conversion: Controversy and advancement in organizational knowledge creation theory. Organization Science, 20(3), 635-652. doi: 10.1287/orsc.1080.0412

Owen, H. (1997). Open space technology: A user's guide (2nd ed.). San Francisco: BerrettKoehler Publishers.

Page, S. E. (2010). Diversity and complexity. Princeton, NJ: Princeton University Press.

Pagés, M. (1990). The illusion and disillusion of appreciative management. In S. Srivastva, D. L. Cooperrider \& Associates (Eds.), Appreciative management and leadership (pp. 353-380). San Francisco, CA: Jossey-Bass Publishers. 
Parker Follett, M. (1924). Creative experience. New York: Longmans, Green and Co.

Patton, M. Q. (2002). Qualitative research and evaluation methods (3rd ed.). Thousand Oaks, CA: Sage Publications.

Polanyi, M. (2009). The tacit dimension. Chicago; London: University of Chicago Press.

Porter, M. E. (1996). What is strategy? Harvard Business Review, 61-78.

Powley, E. H., Fry, R. E., Barrett, F. J., \& Bright, D. S. (2011). Dialogic democracy meets command and control : through Transformation the Summit Inquiry Appreciative. The Academy of Management Executive, 18, 67-80.

Richer, M.-C., Ritchie, J., \& Marchionni, C. (2009). ‘If we can’t do more, let’s do it differently!’: Using appreciative inquiry to promote innovative ideas for better health care work environments. Journal of nursing management, 17, 947-955. doi: 10.1111/j.1365-2834.2009.01022.x

Rizzolatti, G., \& Craighero, L. (2004). The mirror-neuron system. Annu. Rev. Neurosci., 27, 169192.

Rogers, E. M. (2003). Diffusion of innovations (5th ed.). New York: Free Press.

Rudel, T. K. (2008). Meta-analyses of case studies: A method for studying regional and global environmental change. Global Environmental Change, 18(1), 18-25. doi: 10.1016/j.gloenvcha.2007.06.001

Schoeneborn, D. (2011). Organization as communication: A Luhmannian perspective. Management Communication Quarterly, 25(4), 663-689.

Seidl, D. (2005a). The basic concepts of Luhmann’s theory of social systems. In D. Seidl \& K. H. Becker (Eds.), Niklas Luhmann and organization studies (pp. 21-53). Herndon, VA: Copenhagen Business School Press. 
Seidl, D. (2005b). Organisational identity and self-transformation: An autopoietic perspective. Aldershot, Hants, England; Burlington, VT: Ashgate.

Seidl, D. (2005c). Organization and interaction. In D. Seidl \& K. H. Becker (Eds.), Niklas Luhmann and organization studies (pp. 145-170). Herndon, VA: Copenhagen Business School Press.

Seidl, D. (2007). The dark side of knowledge. E:CO, 9(3), 14-27.

Seidl, D., \& Becker, K. H. (2005a). Introduction: Luhmann’s organization theory. In D. Seidl \& K. H. Becker (Eds.), Niklas Luhmann and organization studies (pp. 145-170). Herndon, VA: Copenhagen Business School Press.

Seidl, D., \& Becker, K. H. (2006). Organizations as distinction systems: Niklas Luhmann’s contribution to organization studies. Organization, 13(1), 9-35. doi: $10.1177 / 1350508406059635$

Seidl, D., \& Becker, K. H. (Eds.). (2005b). Niklas Luhmann and organization studies. Herndon, VA: Copenhagen Business School Press.

Seligman, M. E. P., \& Csikszentmihalyi, M. (2000). Positive psychology: An introduction. American Psychologist, 55(1), 5-14. doi: 10.1037//0003-066x.55.1.5

Senge, P. (2006). The fifth discipline: The art and practice of the learning organization: Doubleday.

Simpson, E. H. (1949). Measurement of diversity. Nature, 163, 688-688. doi: 10.1038/163688a0

Spender, J. C. (2007). Data, meaning and practice: How the knowledge-based view can clarify technology's relationship with organisations. International Journal of Technology Management, 38(1), 178-196. 
Srivastva, S., \& Cooperrider, D. L. (1986). The emergence of the egalitarian organization. Human Relations, 39, 683-724. doi: 10.1177/001872678603900801

Stager, P. (1967). Conceptual level as a composition variable in small-group decision making. Journal of Personality and Social Psychology, 5(2), 152-161. doi: 10.1037/h0024202

Stieger, D., Matzler, K., Chatterjee, S., \& Ladstaetter-Fussenegger, F. (2012). Democratizing strategy: How crowdsourcing can be used for strategy dialogues. California Management Review, 54(4), 44-68. doi: 10.1525/cmr.2012.54.4.44

Taylor, J. R. (2000). Thinking about organization in a new way: An inquiry into the ontological foundations of organization. Electronic Journal of Communication, 10(1/2).

TireCo. (2011). TireCo Sales Summit Participant Workbook.

Toffler, A. (1981). The third wave. London: Pan.

Tsoukas, H. (2003). Do we really understand tacit knowledge? In M. Easterby-Smith \& M. A. Lyles (Eds.), The Blackwell handbook of organizational learning and knowledge management (pp. 410-427). Malden, MA: Blackwell Pub.

Tulving, E., \& Schacter, D. L. (1990). Priming and human memory systems. Science, 247(4940), 301-306.

Ulrich, D. (2002). The GE work-out: How to implement GE's revolutionary method for busting bureaucracy and attacking organizational problems--fast! New York: McGraw-Hill.

Ulrich, W. (2005). A brief introduction to critical systems heuristics ( CSH ). from http://www.ecosensus.info/about/index.html

van de Ven, A. H. (1992). Suggestions for studying strategy process: A research note. Strategic Management Journal, 13(S1), 169-188. doi: 10.1002/smj.4250131013 
von Bertalanffy, L. (1969). General system theory: Foundations, development, applications. New York: G. Braziller.

von Krogh, G., Roos, J., \& Slocum, K. (1994). An essay on corporate epistemology. Strategic Management Journal, 15, 53-71.

Wegner, D. M. (1987). Transactive memory: A contemporary analysis of the group mind. Theories of group behavior, 185, 208.

Weick, K. E. (1976). Educational organizations as loosely coupled systems. Administrative Science Quarterly, 21, 1-19.

Weick, K. E. (1979). The social psychology of organizing (2d ed.). Reading, MA: AddisonWesley Pub. Co.

Weick, K. E. (1995). Sensemaking in organizations. Thousand Oaks, CA: Sage Publications.

Weick, K. E. (2001). Making sense of the organization. Oxford, UK ; Malden, MA: Blackwell Publishers.

Weisbord, M. R. (1987). Productive workplaces: Organizing and managing for dignity, meaning, and community. San Francisco: Jossey-Bass Publishers.

Weisbord, M. R., \& Janoff, S. (2010). Future search: Getting the whole system in the room for vision, commitment, and action (3rd ed.). San Francisco: Berrett-Koehler Publishers.

Weiss, P. A. (1978). Causality: Linear or systemic? In G. A. Miller \& E. Lenneberg (Eds.), Psychology and biology of language and thought: Essays in honor of Eric Lenneberg (pp. 13-26). New York: Academic Press.

Whitney, D., \& Trosten-Bloom, A. (2003). The power of appreciative inquiry: A practical guide to positive change. San Francisco: Berrett-Koehler Publishers. 
Wilson, T. D. (2002). Strangers to ourselves: Discovering the adaptive unconscious. Cambridge, MA: Belknap Press of Harvard University Press.

Winograd, T., \& Flores, F. (1987). Understanding computers and cognition: A new foundation for design. Reading, MA: Addison-Wesley.

Wooldridge, A. (2010, March 12). Big think in the boardroom, Book review, The Wall Street Journal. Retrieved from http://online.wsj.com/article/SB10001424052748704869304575109591109900792.html

Yin, R. K. (1984). Case study research: Design and methods. Beverly Hills, CA: Sage Publications.

Yin, R. K. (2011). Qualitative research from start to finish. New York: Guilford Press.

Zimbardo, P. G. (1973). On the ethics of intervention in human psychological research: With special reference to the Stanford prison experiment. Cognition, 2(2), 243-256. doi: 10.1016/0010-0277(72)90014-5 